\title{
PINK AND DUDE CHEFS: EFFECTIVENESS OF AN AFTER-SCHOOL NUTRITION KNOWLEDGE AND CULINARY SKILLS PROGRAM FOR MIDDLE SCHOOL STUDENTS TO INCREASE FRUIT AND VEGETABLE CONSUMPTION
}

\author{
A Thesis \\ presented to \\ the Faculty of California Polytechnic State University,
}

San Luis Obispo

In Partial Fulfillment

of the Requirements for the Degree

Master of Science in Nutrition

by

Alyssa Vaziri

May 2018 
(C) 2018

Alyssa Vaziri

ALL RIGHTS RESERVED

ii 
TITLE:

AUTHOR:

DATE SUBMITTED:

COMMITTEE CHAIR:

COMMITTEE MEMBER:

COMMITTEE MEMBER:
Pink and Dude Chefs: Effectiveness of an AfterSchool Nutrition Knowledge and Culinary Skills Program for Middle School Students to Increase Fruit and Vegetable Consumption

Alyssa Vaziri

June 2018

Dr. Aydin Nazmi, Ph.D

Associate Professor of Food Science and Nutrition

Dr. Kari Pilolla, Ph.D., RD

Assistant Professor of Food Science and Nutrition

Dr. Katherine Soule, Ph.D

Director of University of California Cooperative Extension in San Luis Obispo and Santa Barbara Counties; Youth, Families, and Communities Advisor 


\begin{abstract}
Pink and Dude Chefs: Effectiveness of an After-School Nutrition Knowledge and Culinary Skills Program for Middle School Students to Increase

Fruit and Vegetable Consumption

Alyssa Vaziri
\end{abstract}

The rate of overweight and obesity among adolescents aged 12-19 years has more than tripled since 1980, and disproportionately impacts low-income and marginalized populations. Reduction in adolescent obesity rates may result in decreased health risks, decrease healthcare costs, and increased quality of life. Effective intervention methods for adolescent participants have incorporated nutrition knowledge and culinary skill building into afterschool programs. This study examines whether building knowledge, skills, and confidence through a culinary intervention can improve adolescent participants' choices of healthful foods through increased fruit and vegetable intake.

Pink and Dude Chefs (PDC) is an afterschool nutrition education and culinary skills program for middle-school adolescents aged 11-14 years. This project aimed to improve eating behavior in participants by increasing culinary and nutrition selfefficacy. PDC was implemented in Shandon, California from Spring 2014 to Fall 2014, and in Santa Maria, Guadalupe, and New Cuyama, California from Fall 2015 to Summer 2016. Eighty-three middle school students participated and completed surveys in the 12-lesson program that covered food safety, micro- and macronutrients, meal planning, and USDA MyPlate guidelines.

Participant fruit and vegetable consumption improved following participation. Girls' frequency of overall fruit consumption increased from a mean of 1.8 (SD 0.9) to 2.0 (SD 1.0). Girls' vegetable consumption increased from 1.2 (SD 0.8) to 1.5 (SD 0.9). Boys' fruit consumption increased from 1.9 (SD 1.0) to 2.2 (SD 1.0), and boys' vegetable consumption increased from 1.1 (SD 0.9) to 1.3 (SD 0.8).

More research is needed to evaluate the long-term effect of participation in nutrition education and culinary skills programs. If obesity prevention programs that incorporate a skill-based culinary approach continue to show promising outcomes for adolescents, larger scale efforts may contribute to decreasing the public health and economic burdens associated with obesity.

Key words: nutrition education, adolescent obesity, culinary intervention, after-school program, adolescents, obesity prevention, cooking program, culinary nutrition intervention 


\section{ACKNOWLEDGMENTS}

This thesis project is dedicated in the memory of my friend and classmate, Beatrice Lunday. To have known her is to be inspired to work one hundred times harder, especially when it comes to sharing love of all things nutrition. I miss our always interesting talks, elaborate weeknight dinners to help with studying, spontaneous outdoor adventures that often pushed me to my physical limits, and most of all, her kindness and bold spirit. I am forever grateful for our friendship.

Thank you to my parents, Susan and Alex, and brother Connor, for allowing me to so fully immerse myself in pursuit of acceptance into and completion of this program, with unconditional support. I am also grateful to my boyfriend Manuel Herrmann for his unyielding emotional and moral encouragement, and for leading by example with his own determination. It has been a journey, and no obstacle seemed impossible knowing they were behind me.

I am grateful to my graduate advisor, Dr. Aydin Nazmi, for recognizing a spark in me over a phone interview many years ago, and for offering encouragement and advice even before I became his graduate student. I have been privileged to try and rise to the challenge of meeting his expectations over these past three years at Cal Poly.

Thank you also to my former supervisor and thesis committee member Dr. Katherine Soule, for allowing me the chance to put theory into practice, and most of all for being a role model as an intelligent, ambitious, and encouraging leader. Thank you to Dr. Kari Pilolla for providing guidance and for bringing infectious, positive energy to class and work every day.

Many thanks to Stephanie Teaford for enthusiastically lending her expertise and mentorship while getting PDC off the ground and into five new sites. Thank you to Casey Heaney for her unfailing support throughout the project. Thank you also to my research partner Jacqueline Chen, who made long work days and site visits fun.

Special gratitude to all at the Orfalea Foundation, especially Kathleen Dechadenedes, who spearheaded the funding of PDC and challenged me with opportunities to present our work at one local conference, then the national Farm to Cafeteria conference in Madison, Wisconsin, which I will always cherish as one of the most meaningful and exciting experiences of my time as a graduate student.

Finally, thank you to the wonderful and dedicated PDC instructors, and of course all of their emerging student chefs. May you always discover new things to love about cooking and find your dreams! 


\section{TABLE OF CONTENTS}

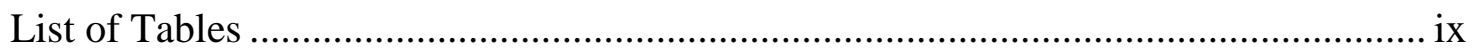

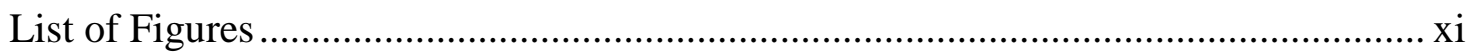

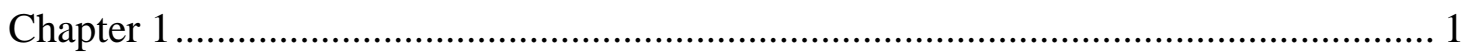

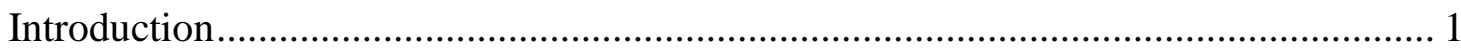

Classification of Childhood and Adolescent Obesity …………................................. 5

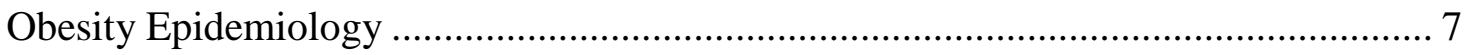

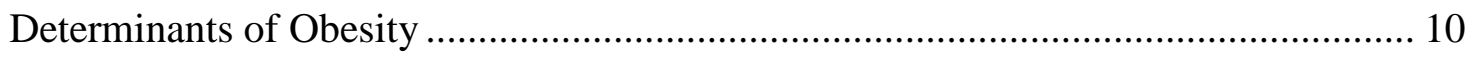

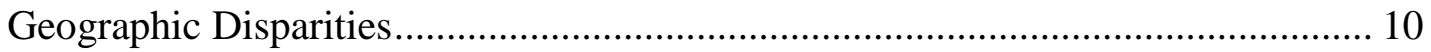

Racial/Ethnic and Socioeconomic Disparities ...................................................... 12

Behavioral and Social Factors............................................................................ 18

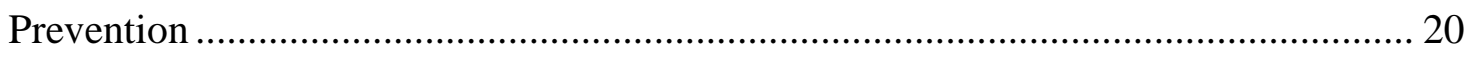

Culinary Skills Intervention Programs.................................................................... 23

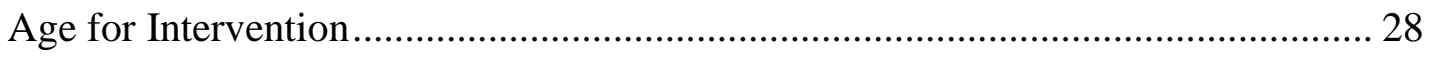

Background: Pink and Dude Chefs ........................................................................ 30

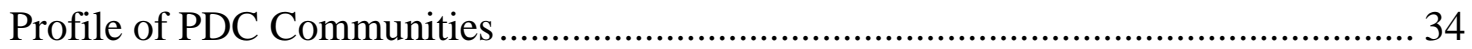

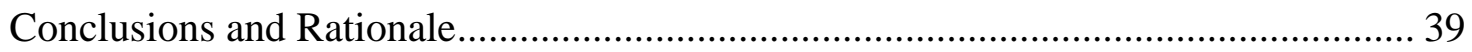

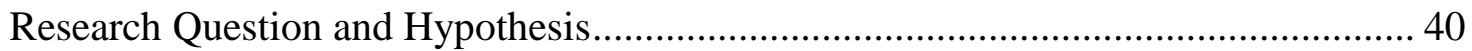

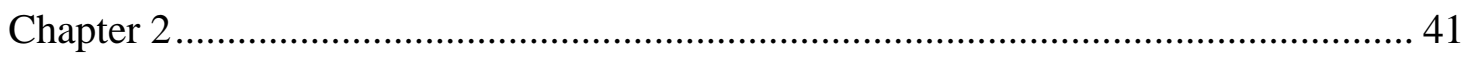

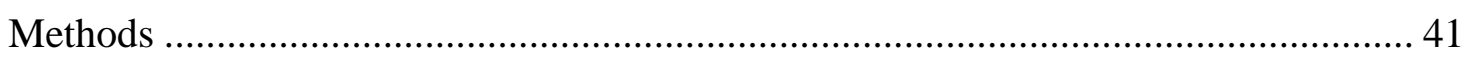

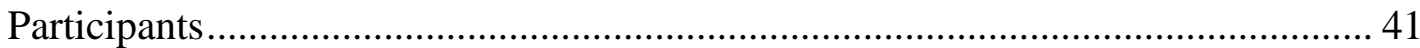

Site Recruitment and Program Implementation ...................................................... 41

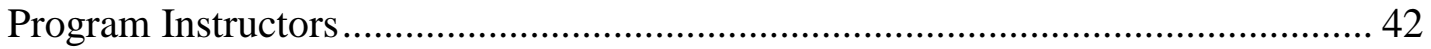




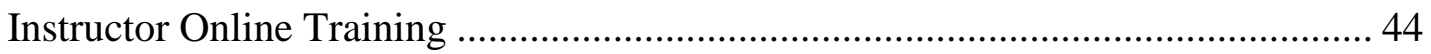

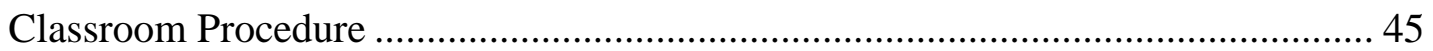

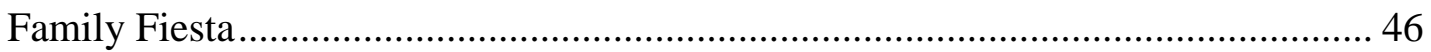

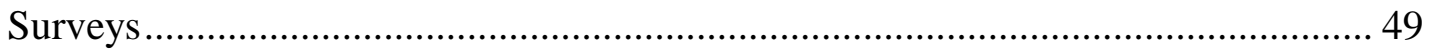

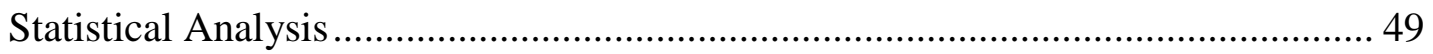

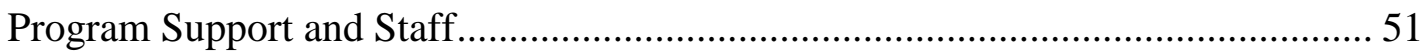

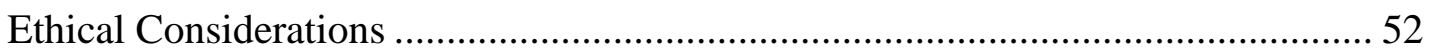

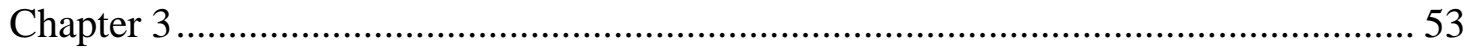

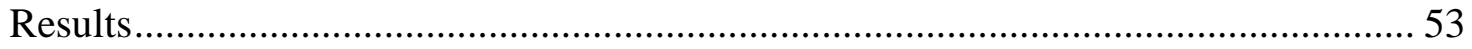

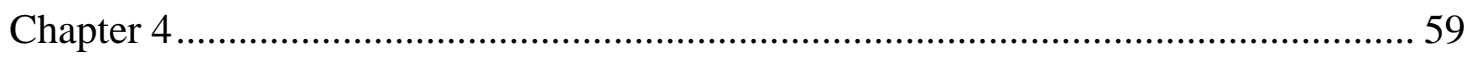

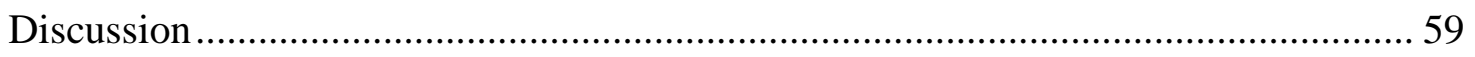

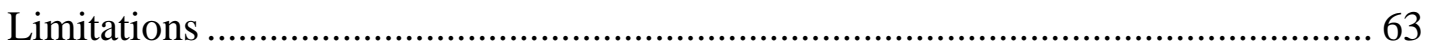

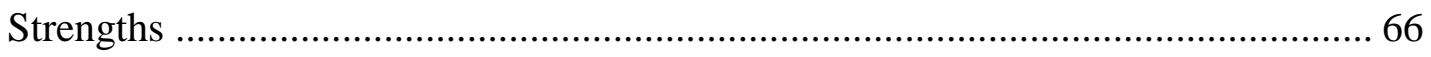

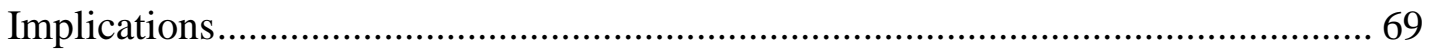

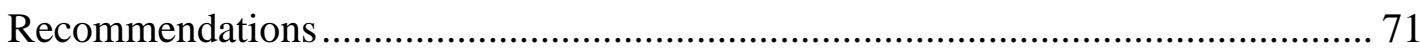

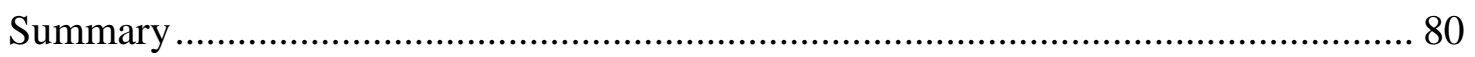

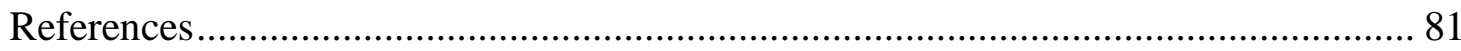

Appendices

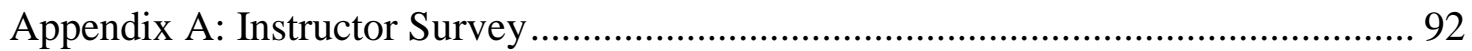

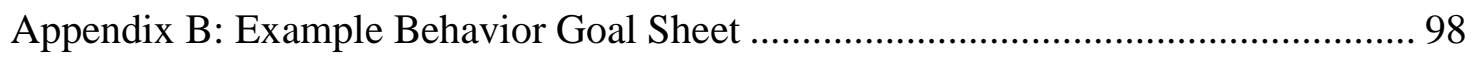

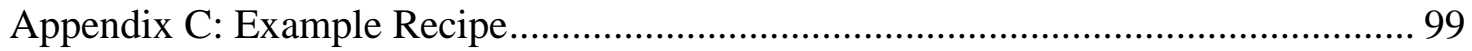

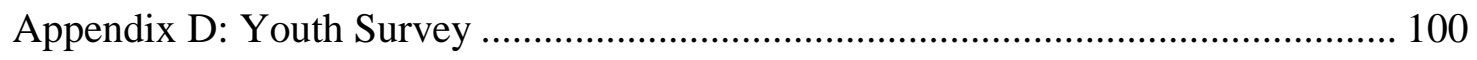

Appendix E: Semi-Structured Interview Script (Youth) ........................................... 107

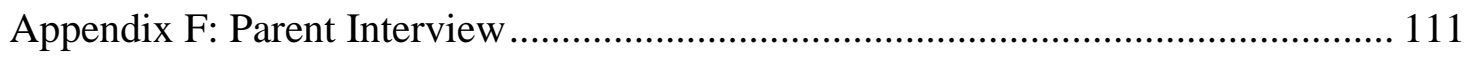

Appendix G: Informed Assent Form for Youth Participants..................................... 114 
Appendix H: Informed Consent Form for Parents/Guardians (English) .................. 116

Appendix I: Informed Consent For Parents/Guardians (Spanish) ........................... 119 


\section{LIST OF TABLES}

Table

Table 1: Weight status category and percentile range for childhood BMI

(CDC, 2016)

Table 2: Session overview of the 12-week LA Sprouts gardening after-school

program for Latino fourth- and fifth-grade students (Davis et al, 2011)

Table 3: Results of the HOME Study, an RCT that focused on promoting the frequency and healthfulness of family meals (2014)

Table 4: Self-efficacy score for cooking for each of the seven items used to calculate

(Chessen, 2008)

Table 5: Mean fruit preference score from pre- and post-survey and change in mean fruit preference (Sheehan, 2013)

Table 6: Comparison of Mean Differences between Male and Female Participants

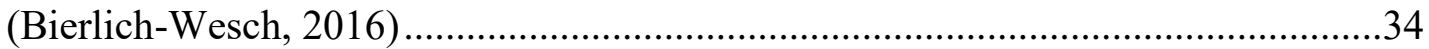

Table 7: Cohort Locations and Program Length.....................................................43

Table 8: Curriculum Layout and Student Goals ...........................................................48

Table 9: Food Frequency Questionnaire Variables .......................................................50

Table 10: Mean weekly fruit intake values from pre- and post- food frequency questionnaire, and change in mean weekly fruit intake for participants in Northern San Luis Obispo County and Northern Santa Barbara County (2014-2016).

Table 11: Mean weekly vegetable intake values from pre- and post- food frequency questionnaire, and change in mean weekly vegetable intake for participants in 
Northern San Luis Obispo County and Northern Santa Barbara County (2014-2016).

Table 12: Mean differences in fruit and vegetable intake and changes in mean fruit and vegetable intake as reported in pre- and post- food frequency questionnaires among male and female participants in Northern Santa Barbara County and Northern San Luis Obispo County (2014-2016). 


\section{LIST OF FIGURES}

Figure Page

Figure 1: Trends in obesity among adolescents aged $12-17$ y by parental education in the NHANES III (1999-2010) (A) and the NSCH (2003, 2007, and 2011). Obesity is defined as being at or above the sex- and age-specific 95th percentile of the $2000 \mathrm{CDC}(95 \% \mathrm{CI})$.

Figure 2: Prevalence of Overweight, Obesity, Class 2 Obesity, and Class 3 Obesity Among US Children by 2-Year Increments (Skinner et al) .8

Figure 3: Trends in the prevalence of overweight (body mass index over the 95th percentile) in US children and adolescents, by gender, age, and ethnicity, National Health and Nutrition Examination Survey, 1971-2004.

(Wang \& Beydoun,, 2007)

Figure 4: Prevalence trends in the disparity of overweight in American adolescents, aged 10-18 years in 1999-2002 (Youfa, Wang, and Zhang 2006).....

Figure 5: Prevalence trends in the disparity of overweight in African-American and White adolescents, aged 10-18 years in 1999-2002 (Youfa, Wang, and Zhang 2006)

Figure 6: Overweight/obesity prevalence among adolescents aged 12-17 years by race/ethnicity, in 2001 and in 2011-12 (Source: 2001 and 2011-12 California

Health Interview Surveys) .35

Figure 7: Dietary behaviors in California adolescents among various age groups

(Source: 2014 California Health Interview Surveys). 
Figure 8: Percent change in mean scores for pre- and post-survey questions on individual question scores for participants in California and Tennessee) stratified by sex (female $n=11-16$, male n=9-14) from Spring 2014 to Fall 2016 $(p=0.6)($ Bierlich-Wesch, 2016)

Figure 9: Comparison of "High Attendance" students who were present for at least $75 \%$ of PDC lessons $(n=16)$, to "Low Attendance" students, who represented the remaining students $(\mathrm{n}=6)$ (Chessen, 2008) .64 


\section{CHAPTER 1}

\section{Introduction}

The prevalence of childhood and adolescent obesity in high-income countries, including the United States, increased for several decades, having only recently stabilized. However, this apparent plateau obscures the underlying socioeconomic gradient: Whereas the proportion of obesity among adolescents of high socioeconomic status has remained the same since 1990, the proportion of obesity among adolescents of low socioeconomic status continues to increase (Frederick, Snellman, \& Putnam, 2014). Dietary patterns are influenced by socioeconomic status due to the high cost of quality foods, such as fresh fruits and vegetables, compared to the low cost of calorically-dense, highly-processed foods (Manyanga et al., 2017). According to the 2013-2014 NHANES survey, 20\% of children and adolescents aged 2-19 years in the United States are obese (Cheryl, Carroll, \& Ogder, 2016; Flegal, Kruszon-Moran, Carroll, Fryar, \& Ogden, 2016; Ogden, Carroll, Fryar, \& Flegal, 2015). 


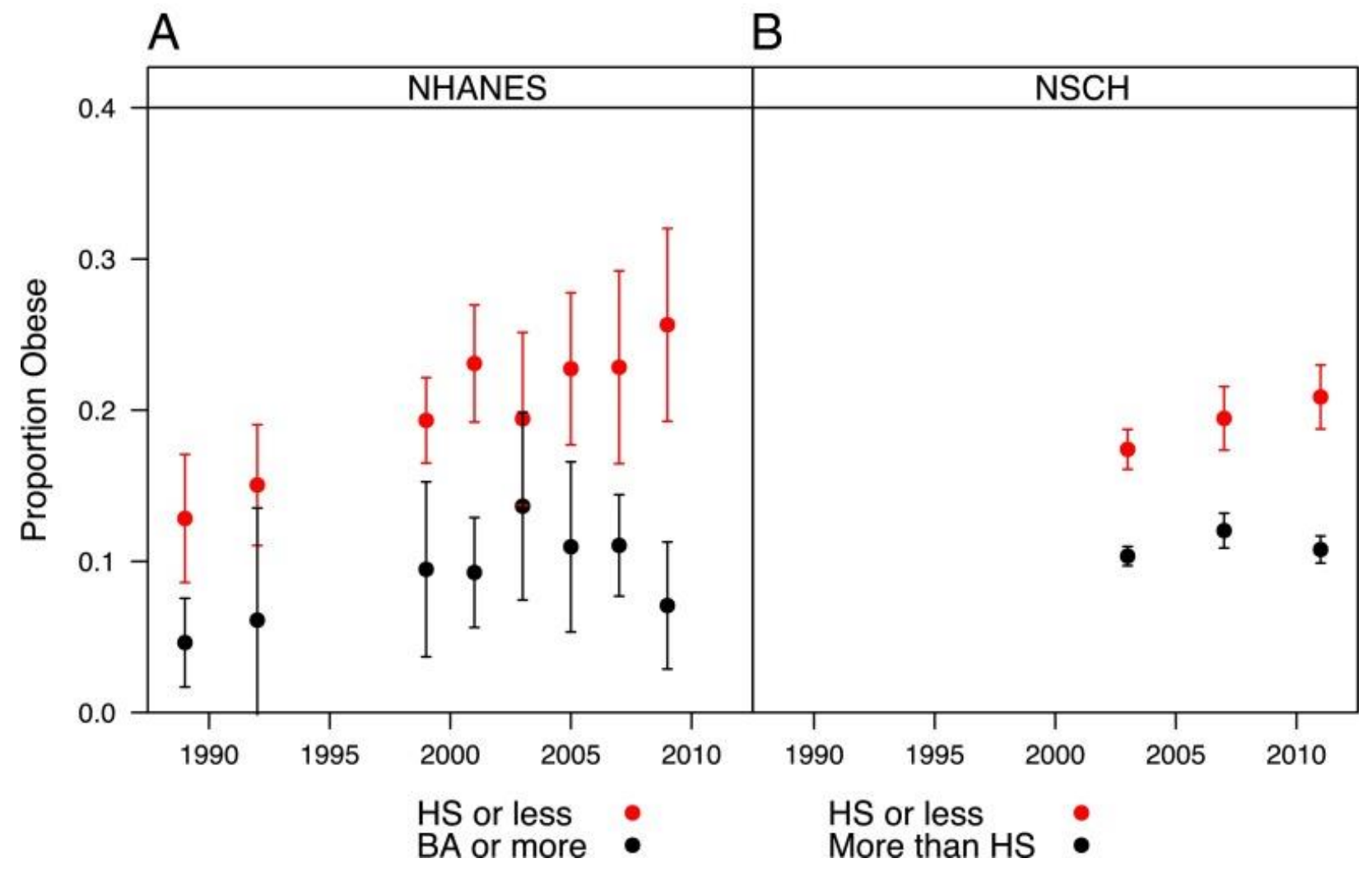

Figure 1: Trends in obesity among adolescents aged 12-17 y by parental education in the NHANES III (19992010) (A) and the NSCH (2003, 2007, and 2011). Obesity is defined as being at or above the sex-and age-specific 95th percentile of the 2000 CDC $(95 \%$ CI).

The states of overweight and obesity are defined as excessive accumulation of fat mass, which may impair health due to its association with co-morbidities (James, Leach, Kalamara, \& Shayeghi, 2001). The overall percentage of children aged 12 to 19 years who were obese increased from $5 \%$ in the years $1976-1980$ to $21 \%$ in the years 2011-2014 (Ogden et al., 2015). In a 2017 study, black and Hispanic children had substantially higher BMI, total fat mass, and prevalence of overweight and obesity at age 7 years compared to their non-Hispanic white peers (Taveras, Gillman, Kleinman, Rich-Edwards, \& Rifas-Shiman, 2013). This trend of increasing rates of obesity, especially among low-income and marginalized populations, indicates a need for obesity prevention efforts that more equitably serve susceptible populations. 
Overweight and obese children experience more stigmatization and social marginalization than their peers of a normal weight (Myers \& Rosen, 1999; Strauss \& Pollack, 2003). Negative emotional well-being has a weak association with childhood overweight and obesity in several epidemiologic studies, suggesting that any potentially adverse effects of overweight and obesity on emotional well-being impact some subgroups of obese individuals over others (Gall et al., 2016; Loth, Mond, Wall, \& Neumark-Sztainer, 2011; Myers \& Rosen, 1999). For example, body dissatisfaction, low self-esteem, and poorer psychological well-being are more common in treatmentseekers in comparison to normal weight controls and population-based obese youth (Jane Wardle \& Cooke, 2005). Additionally, females, adolescents, and Caucasians are at a higher risk of poor emotional well-being due to their negative perceptions of their weight and/or shape, regardless of whether they are clinically overweight or obese (Jansen, van de Looij-Jansen, de Wilde, \& Brug, 2008; Jane Wardle \& Cooke, 2005). Societal expectations of body shape may have variable emotional and psychological impacts on different segments of the population, and because adolescents of any gender and ethnicity are susceptible to negative emotional outcomes, including major depressive disorder, associated with high BMI, they are a critical subpopulation to consider for intervention. (Marmorstein, Iacono, \& Legrand, 2014).

Increases in childhood overweight and obesity rates are widely attributable to a diet high in fat and sugar but low in essential nutrients, coupled with a sedentary lifestyle (WHO, 2017). Other factors are beyond the behavior of children, but have been widely implicated as predictors of obesity: urbanization, social and economic development and policies in the sectors of transportation, agriculture, food processing, 
and urban planning (WHO, 2017). Diets rich in whole foods like fruits and vegetables reduce the risk of death and chronic disease, but fewer than one in three Americans eat the recommended amounts of fruits and vegetables (Ileana Arias, n.d.). Defining the types of lifestyle interventions that address the multifactorial influences on family and consumer behavior is crucial in order for public health professionals to drive change in the direction of increasing intake of nutrient-dense foods in an effort slow the rate of obesity and its associated consequences.

Obesity - related illnesses impart an economic burden on the individual and population levels due to decreased work productivity, missed days of work, permanent disability, and premature death (Tremmel, Gerdtham, Nilsson, \& Saha, 2017). Children and adolescents who are overweight and obese are at increased risk of becoming overweight and obese adults, which is associated with a higher risk of other serious health conditions. A 2017 systematic review that investigated the economic burden of diabetes, cardiovascular disease, hypertension, cancer, respiratory disorders, musculo-skeletal disorders, digestive diseases, and other obesity-related diseases showed that the direct per-capita cost of obesity - related illnesses in the United States increased from \$2741 in 2005 to $\$ 6899$ in 2011 (Tremmel et al., 2017). The median healthcare costs for obese individuals (\$585.54) exceeded those of non-obese individuals (\$333.24), largely due to prescription drugs for Type II diabetes, hypertension, and other co-morbidities associated with elevated BMI (H. Thomas, 2006). The total per-capita costs over a lifetime ( $>65$ years) were estimated to be \$171,482 in the United States in 2010 (Tremmel et al., 2017). Obesity-related medical costs occur not only in the aging adult population, but in children and adolescents as 
well. The annual direct costs of childhood and adolescent obesity in the United States is estimated to be $\$ 14.3$ billion (Hammond \& Levine, 2010). Given that overweight and obese children and adolescents are at an increased risk of becoming obese adults, the direct costs associated with adolescent obesity imply future direct costs in adulthood. The projected cost of direct medical expenses among US adults aged 35-64 years of age between 2020 and 2050, which is based on the current levels of adolescent and childhood obesity, is estimated to be $\$ 45$ billion (Hammond \& Levine, 2010). The success of obesity prevention programs may have notable economic benefits on both the individual and national levels.

\section{Classification of Childhood and Adolescent Obesity}

Body composition, which is the balance of fat and lean mass, can be quantified using both direct and indirect methods. One of the most common diagnostic tools is body mass index (BMI), which provides an interpretation of weight in relation to height $\left(\mathrm{m} / \mathrm{kg}^{2}\right)$. BMI calculation is often preferred among health professionals because it is a fast and non-invasive measurement that does not require expensive equipment. However, at least three potential problems with the use of BMI have been identified. First, studies that assess how reliably BMI predicts adiposity, which is the proportion of fat mass, disproportionately represent Caucasian subjects, so it is not known whether there are differences across ethnic populations (Deurenberg, Yap, \& Van Staveren, n.d.). In addition, children with a history of undernutrition that results in decreased stature have a higher weight-for-height than children of average height, for reasons other than elevated adiposity (Dietz \& Bellizzi, 1999). Finally, the BMI measurement cannot differentiate between fat and lean mass and therefore is not a 
direct measure of obesity, which is defined as having an excess amount of body fat. Despite these limitations, BMI has been found to be strongly associated with total body fat in children, and BMI-for-age is therefore recommended as an estimate of adiposity (David S. Freedman, Khan, Serdula, Ogden, \& Dietz, 2006; Pietrobelli et al., 1998).

The assessment of BMI for children under the age of 19 years differs from the standards of adults, because unlike the evaluation of adults, children's age is a factor of the resulting classification. This corrects for fluctuating relationships between weight and height that are normal during the growth of a child. For children aged 5-19 years, the state of overweight is defined as being weight-for-height greater than 2 standard deviations above WHO Child Growth Standards median; and obesity is weight-forheight greater than 3 standard deviations above the WHO Child Growth Standards median (WHO, 2017).

The most common method of assessment in the United States, however, utilizes a reference population derived from five nationally-representative cross-sectional surveys of youth aged 2-20 years (Kuczmarski et al., 2002). The resulting CDC growth charts, which provide context for BMI-for-age, are the preferred instrument among healthcare providers for growth screening (Kuczmarski et al., 2002). Underweight is classified as a BMI-for-age equal to or under the $5^{\text {th }}$ percentile, a healthy weight is between the $5^{\text {th }}-84^{\text {th }}$ percentile, overweight is between the $85^{\text {th }}-94^{\text {th }}$ percentile, and obese is equal to or over the $95^{\text {th }}$ percentile (Table 1 ). 
Table 1: Weight status category and percentile range for childhood BMI (CDC, 2016)

\begin{tabular}{r|l} 
Weight Status & \multicolumn{1}{c}{ BMI Category } \\
\hline Underweight & $<5^{\text {th }}$ percentile \\
Healthy weight & $5^{\text {th }-84^{\text {th }} \text { percentile }}$ \\
Overweight & $85^{\text {th }}-94^{\text {th }}$ percentiles \\
Obese & $>95^{\text {th }}$ percentile
\end{tabular}

\section{Obesity Epidemiology}

National health examination survey data on BMI is utilized to estimate the prevalence of obesity in the United States. Childhood obesity is defined as a BMI exceeding the $95^{\text {th }}$ percentile for age and sex. The most recent NHANES data (20112014) showed that among children aged 2-19 years, the prevalence of obesity remained stable at $17.3 \%$ (95\% CI 15.3-19.3) and affected 12.7 million children and adolescents (Ogden et al., 2015). Additionally, as depicted in Figure 2, 5.9\% (95\% CI 4.4-7.4) met criteria for class 2 obesity $\left(\mathrm{BMI} \geq 120 \%\right.$ of the $95^{\text {th }}$ percentile for age and sex, or BMI $\geq 35 \mathrm{~kg} / \mathrm{m}^{2}$ ) and $2.1 \%$ (95\% CI 1.6-2.7) met criteria for class 3 obesity (BMI $\geq 140 \%$ of $95^{\text {th }}$ percentile, or BMI $\geq 40 \mathrm{~kg} / \mathrm{m}^{2}$ ) (Skinner, Perrin, \& Skelton, 2016). 


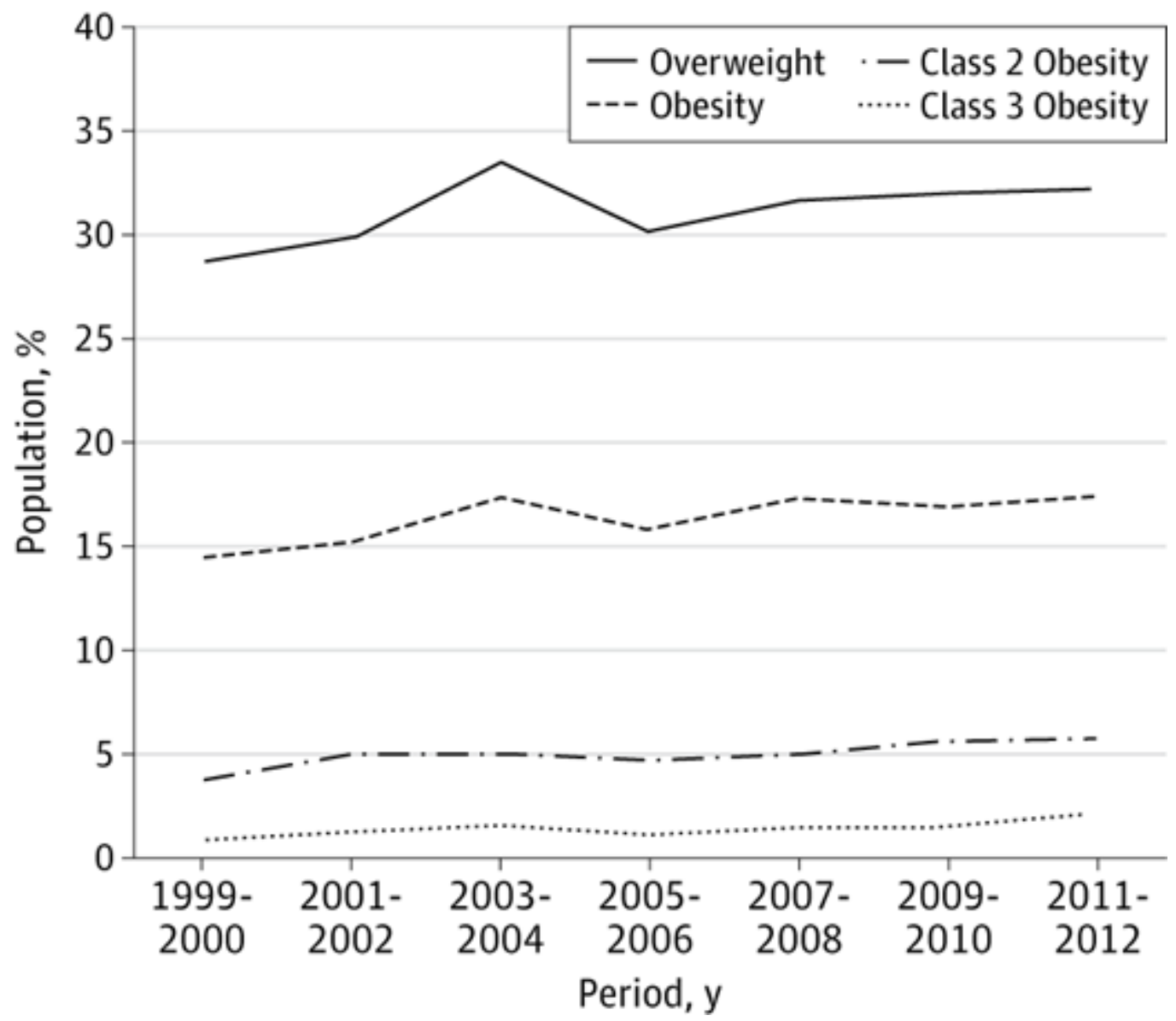

Figure 2: Prevalence of Overweight, Obesity, Class 2 Obesity, and Class 3 Obesity Among US Children by 2-Year Increments (Skinner et al)

The prevalence of obesity among $2-5$ year old children was $8.9 \%$, compared to $17.5 \%$ among 6 - to 11 - year-olds and $20.5 \%$ of $12-19$ year old teenagers, highlighting the enduring nature of obesity (Ogden, Carroll, \& Flegal, 2014). Non-Hispanic Asian youth had the lowest prevalence of obesity (8.6\%), while Hispanic youth had the highest prevalence of obesity (21.9\%), followed by non-Hispanic blacks (19.5\%) and non-Hispanic whites (14.7\%) (Ogden CL, Carroll MD, Fryar CD, 2018).

While this most recent, nationally representative data did not show significant changes in prevalence of childhood and adolescent obesity, an upward trend of more severe forms of obesity was detected (Skinner et al., 2016). Additionally, differences 
in obesity rates were detected between subpopulations; younger children and nonwhite survey participants were found to be at greater risk for obesity and severe obesity (Skinner et al., 2016).

The complexities in studying disparities and the need to consider the health and well-being of children of all levels of socioeconomic status and racial/ethnic groups in the United States should be noted. Research has shown that U.S. children are in overall worse health, by many standard indicators, than children in comparable industrialized countries (Mehta, Lee, \& Ylitalo, 2013). Of the 13 nations categorized as "industrialized," the U.S. ranks $13^{\text {th }}$ in infant mortality, and $24^{\text {th }}$ globally (Duderstadt, 2007). Additionally, of the 26 countries classified as "economically developed," the U.S. ranks twentieth in child mortality among ages 1-14 years (Duderstadt, 2007). The U.S. ranks significantly behind peers - New Zealand, Australia, Canada, and the United Kingdom - in child poverty, classified by household income household and neighborhood conditions, possession of durable goods, and meeting of basic needs (Duderstadt, 2007). Finally, based in international standards for BMI, U.S. youth had the highest rate of childhood obesity at $12.7 \%$, when compared to the twenty most populous countries (Friedrich, 2017). Further research will be necessary to continue to identify, measure, and monitor appropriate indicators of child health for all demographics in the population, improve overall child health across multiple indicators, and reduce social disparities in these health indicators where they exist. 


\section{Determinants of Obesity}

Body weight and body composition are regulated by precise physiological mechanisms that maintain homeostasis between energy expenditure and energy intake (Ebbeling, Pawlak, \& Ludwig, 2002). Although genetic factors have been identified, the rising prevalence of childhood and adolescent obesity in genetically stable populations suggest that environmental and behavioral factors may contribute more directly (Ebbeling et al., 2002). Obesity is a multifactorial condition, and evidence exists for the clustering of behavioral risks among adolescents (Driskell, Dyment, Mauriello, Castle, \& Sherman, 2007; Hartley et al., 2013). Nearly 80\% of adolescents have multiple risk factors related to diet, lack of physical activity, and excessive

physical inactivity (Driskell et al., 2007). However, NHANES data prior to 2007 showed a dramatic increase in the prevalence of obesity across all SES and ethnic/racial subgroups, indicating that individual or genetic characteristics are not the central factor to which the rise of obesity is traditionally ascribed (Y. Wang \& Beydoun, 2007). It is important to understand the determinants of obesity, in order to create interventions that are setting-based, multi-level, and emphasize efficiency and transferability.

\section{Geographic Disparities}

Environmental factors include the availability of calorie-dense and convenience foods in place of home-cooked meals, the cost and availability of fruits and vegetables, and the structure of communities (Meldrum, Morris, \& Gambone, 2017). Both food access and opportunities for physical activity are influenced by neighborhood; lowincome neighborhoods have fewer sidewalks, recreational facilities, and playgrounds 
than affluent neighborhoods (Vaughan et al., 2013). Disparities in the geographic and social distribution of physical activity (PA) facilities were documented in a nationally representative cohort, which found that increased numbers of PA facilities were associated with decreased rates of overweight and obesity in adolescents and increased relative odds of achieving at least 5 hours of moderate-to-vigorous PA, defined as 5-8 metabolic equivalents (METs) (Gordon-Larsen, Nelson, Page, \& Popkin, 2006). Census-block groups with high proportions of college-educated residents had a relative odds of having at least 1 PA facility of 2.18 (95\% CI 1.94-2.44) (Gordon-Larsen et al., 2006). For every $100 \%$ increase in the proportion of individuals with a college education or higher, there was more than a two-fold increase in access to PA facilities (Gordon-Larsen et al., 2006).

Additionally, lack of neighborhood safety can discourage physical activity as leisure and as a form of transportation. The 2011-2012 California Health Interview Survey showed that 10.8 percent of adolescents aged 12-17 in California "never/sometimes feel safe" in their neighborhoods (Wolstein, Babey, \& Diamant, 2015). The rate of respondents who indicated that they "never/sometimes feel safe" nearly quadrupled among obese adolescents (40.6 percent) which was significantly different from obese respondents who reported that they "always feel safe" (29.4 percent, $\mathrm{p}<0.05$ ) (Wolstein et al., 2015).

Furthermore, access to healthy foods, such as fruits and vegetables, may be limited for some, based on geographical location. Spatial access to healthy foods was estimated between 2006-2010 for subpopulations such as households with low income, households without vehicles, and populations that live in low-income areas, compared 
to the overall U.S. population (Ploeg et al., 2012). This data from the 2010 Census, income and vehicle availability data from the 2006-2010 American Community Survey, and a directory of supermarkets showed that 9.7 percent of the population, which equates to 29.7 million people, lived in low-income areas that were more than one mile from a supermarket, which is $8.4 \%$ more than what was observed in 2006 (Ploeg et al., 2012). Of these households in low-income areas that were located more than one mile from the supermarket, 2.1 million did not have a vehicle (Ploeg et al., 2012). Geographical accessibility to healthy foods is just one indicator of the choices available to families. Additional indicators include the level of competition among stores, and the estimated distance from a household to the nearest three supermarkets (Ploeg et al., 2012). Half of the U.S. population was estimated to live within two miles of three supermarkets, while $80 \%$ of the U.S. population was within five miles of three supermarkets, in 2010 (Ploeg et al., 2012). Although defining "healthy food" is not straightforward, and measuring the relative competition between supermarkets may be limited, this study demonstrated potential barriers to adopting desired dietary patterns in low-income households, households in low-income areas, and households without access to a vehicle in the U.S.

\section{$\underline{\text { Racial/Ethnic and Socioeconomic Disparities }}$}

Race and ethnicity are social determinants of health status within the United States because of their persistent and powerful associations with poverty, racism and segregation, and access to healthcare due to both historical and enduring forms of institutionalized discrimination (Mehta et al., 2013). These findings remain consistent even after adjusting for confounding socioeconomic factors such as education and 
income, indicating disparate access to economic and social resources (Hruby \& $\mathrm{Hu}$, 2015; Sanders-Phillips, Settles-Reaves, Walker, \& Brownlow, 2009). As such, simply targeting income inequality is not likely to reduce racial disparities in overall health and obesity.

The limited studies of childhood health disparities examining body mass index (BMI) show that health inequalities exist among racial/ethnic groups of children in the United States (Figure 3). 


\section{ADOLESCENT BOYS (AGE 12-19 YEARS)}
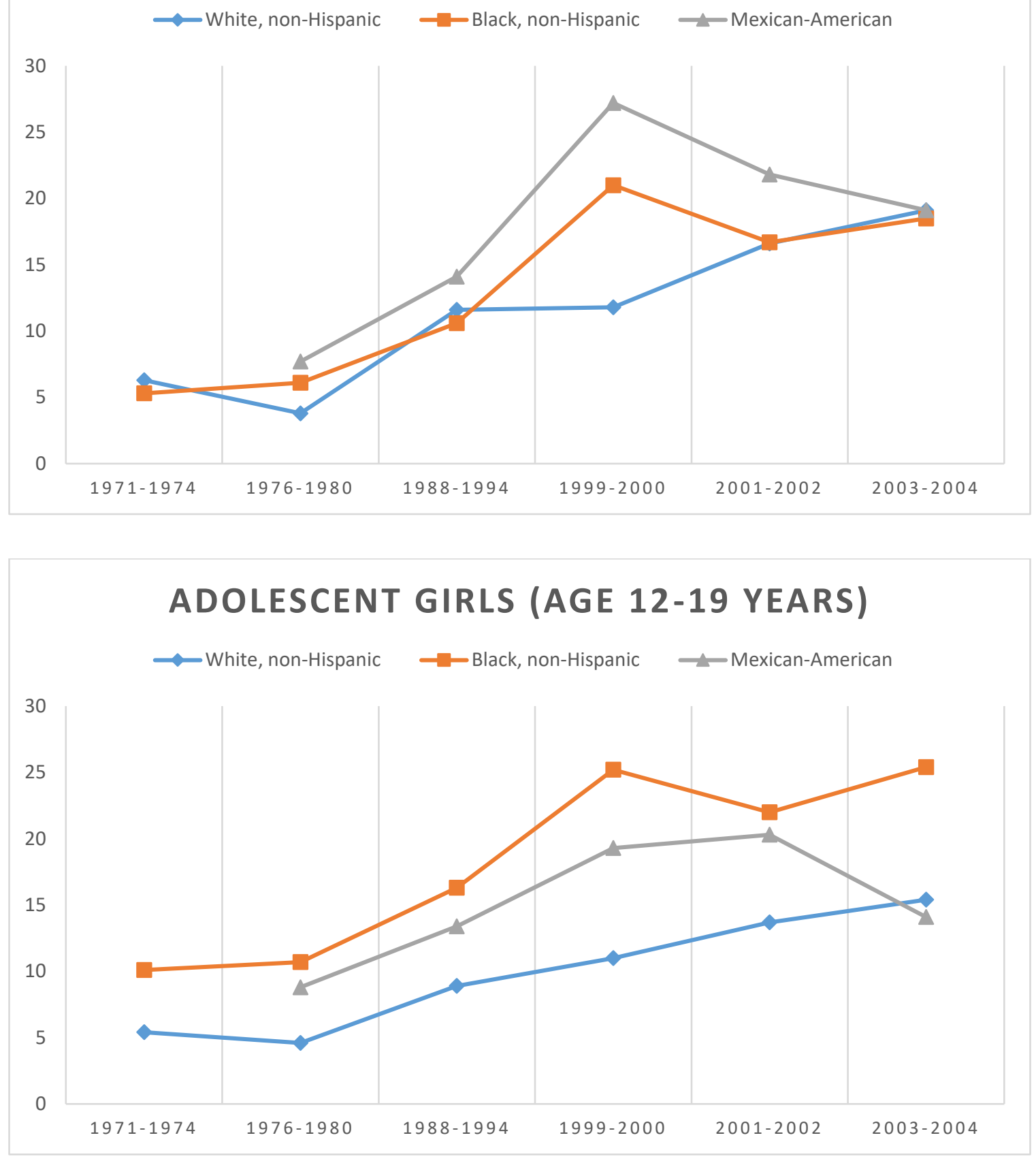

Figure 3: Trends in the prevalence of overweight (body mass index over the 95th percentile) in US children and adolescents, by gender, age, and ethnicity, National Health and Nutrition Examination Survey, 1971-2004. (Wang \& Beydoun, 2007) 
While the incidence of child and adolescent overweight and obesity in the United States has plateaued among non-Hispanic whites and those of high socioeconomic status, low-income populations and ethnic minorities continue to be disproportionately representative of the disease (Taveras et al., 2013). A study examining the association between overweight $\left(\mathrm{BMI}>95^{\text {th }}\right.$ percentile) and SES (categorized as low, middle, and high) in adolescents aged 10-18 years between 19992002 found that, consistently among all three SES categories, the rates of overweight in Mexican-American boys (22.7-35.2\%) and girls (18.3-24.0\%) were higher than white boys (14.2-14.8\%) and girls (10.6-17.9\%), as depicted in Figure 4 (Youfa Wang \& Zhang, 2006).

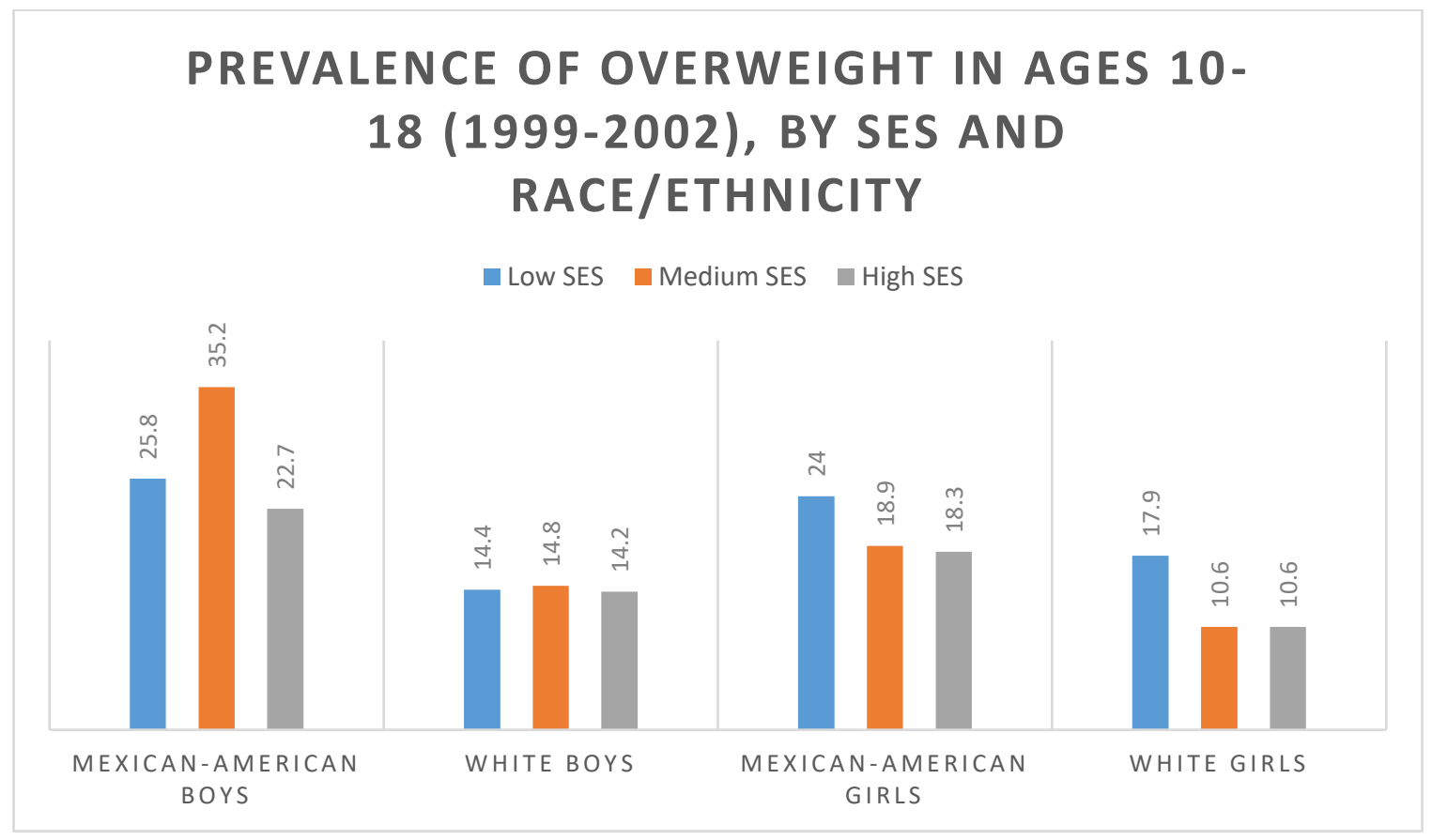

Figure 4: Prevalence trends in the disparity of overweight in American adolescents, aged 10-18 years in 1999-2002 (Youfa, Wang, and Zhang 2006) 
Additionally, the rates of overweight in African-American boys (18.4-22.2\%) and girls (18.7-38.0\%) exceeded the rates of overweight in white boys and girls in every SES category, as depicted in Figure 5 (Youfa Wang \& Zhang, 2006). This unequal health outcome is indicative of opportunities for further public health nutrition interventions to more effectively serve marginalized and low-income youth and their families.

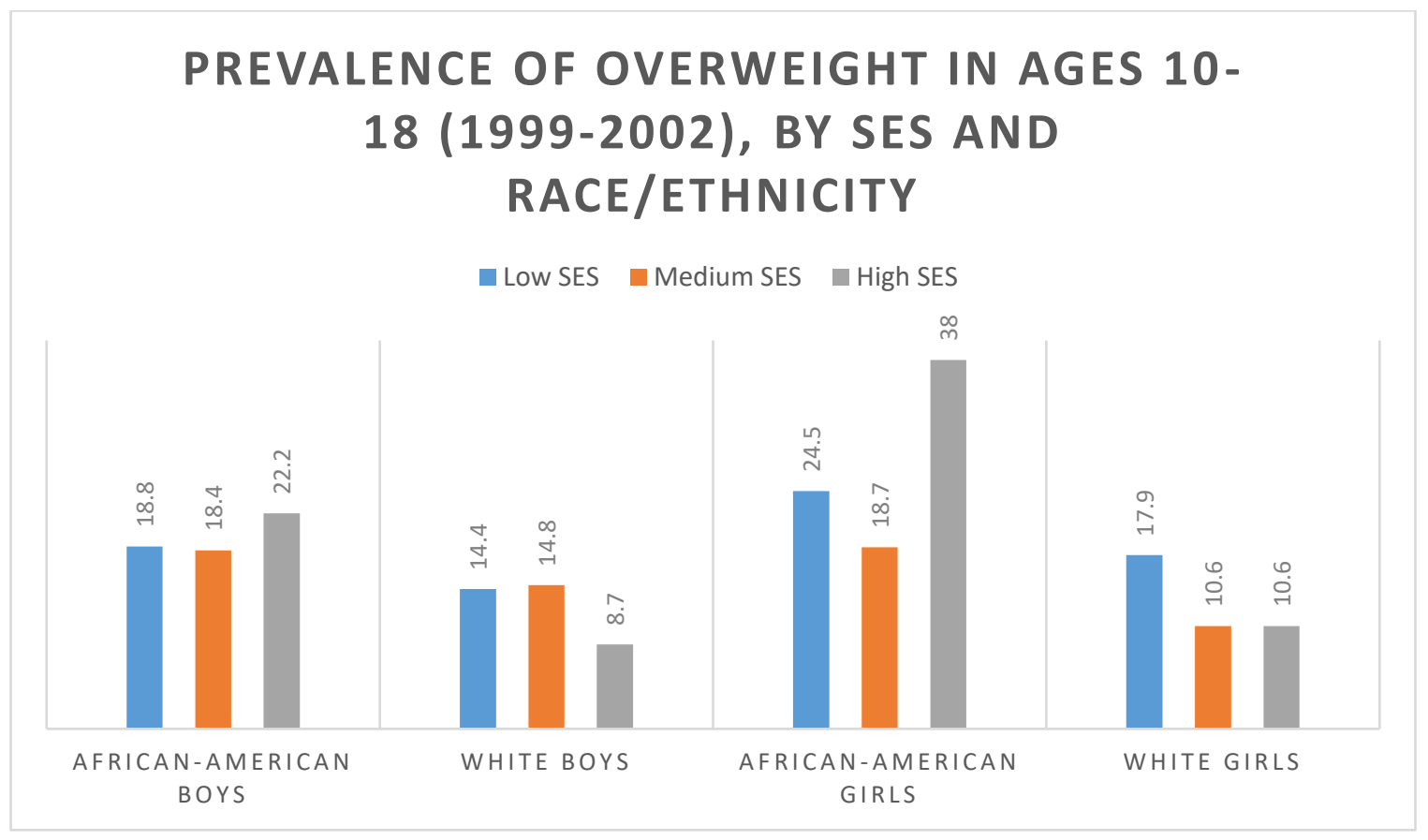

Figure 5: Prevalence trends in the disparity of overweight in African-American and White adolescents, aged 10-18 years in 1999-2002 (Youfa, Wang, and Zhang 2006)

A strong association exists between low socioeconomic position and risks for chronic nutrition-related diseases, such as cardiovascular disease (Zarnowiecki, Dollman, \& Parletta, 2014). A common interpretation of this relationship hypothesizes that poor health is a result of limited access to resources. Another understanding is that the states of poor health, for example, as measured by BMI, compromise social mobility. 
Overweight and obese children are more likely than peers of a leaner body composition to develop noncommunicable diseases, such as cardiovascular diseases, disordered glucose tolerance, metabolic syndrome, and some cancers at a younger age (Cunningham, Kramer, \& Narayan, 2014). Children with chronic health conditions may face lower academic achievement, more missed school days, and therefore the lower educational attainment will likely result in reduced productivity and earning potential, paired with increased out-of-pocket medical costs, in adulthood (Ogden et al., 2015).

Preventing childhood obesity may have positive social outcomes, as children with chronic health conditions may face lower academic achievement, more missed school days, and fewer job opportunities when they enter adulthood (Ogden et al., 2015). It is imperative that risk factors for obesity be mitigated as early in life as possible, because the prevalence of obesity increases with age; children who are obese are more likely than children of a healthy body composition to continue to experience obesity as adults (Cunningham et al., 2014). In fact, the risk for obese children becoming obese adults is $2-6.5$ times higher than for non-obese children (Shonkoff, Boyce, \& McEwen, 2009). Additionally, preventing severe (class 2 and class 3) obesity is a critical public health concern because severe obesity is more strongly associated with cardiometabolic risk factors, pertaining to the primary cause of death in the United States which is cardiovascular disease, than class 1 obesity, and it is predicted to increase significantly through 2030 among adults (Finkelstein et al., 2012; Skinner et al., 2016). Genetic, demographic, and socioeconomic risk factors are non- 
modifiable, so public health interventions may benefit from targeting behavioral risk factors.

$\underline{\text { Behavioral and Social Factors }}$

Impact of Culinary Skill on Dietary Patterns

Americans have reduced the amount of time spent preparing and eating meals at home since the 1980s (Smith \& Smith, 2016; Tiwari, Aggarwal, Tang, \& Drewnowski, 2017). From 1985-2000, the USDA reported that Americans increased their caloric intake by 300 calories each day, amounting to $12 \%$ of their total intake (Condrasky \& Hegler, n.d.). Of a range of socioeconomic groups in the United States, the lowest income group has shown the greatest decline in the time spent cooking at home (Hersch, Perdue, Ambroz, \& Boucher, 2014). Socioeconomically disadvantaged children are more likely to consume a diet low in fruits and vegetables, and high in non-core foods, such as candy, chips, and other foods with added refined sugar and/or high fat content, and sugar-sweetened beverages (SSB) (Zarnowiecki et al., 2014). The consumption of non-core foods, classified as foods that do not fit within nutritional guidelines due to their high energy and low nutritional density, is attributed to the child's positive attitudes regarding the consumption of these foods.

The increase of childhood obesity during a widespread cultural shift away from cooking demonstrates an opportunity to restore culinary knowledge and skills to adolescents, as transference of these skills from parent to child is no longer the norm (Nelson, Corbin, \& Nickols-Richardson, 2013). A systematic review of the impact of cooking classes on the food-related behaviors of school-aged children found that although cooking classes often positively influenced fruit and vegetable intake in 
participants, modes of delivery were varied and there was no singular set of best practices or consistent theme among the most successful interventions (Hersch et al., 2014). These findings are consistent with the results of a longitudinal study showing that adolescents' food preparation is positively correlated with lower intakes of fat, sugar-sweetened beverages, and fried foods; and higher intakes of fruits, vegetables, dietary fiber, folate, and vitamin A (Larson, Perry, Story, \& Neumark-Sztainer, 2006). Culinary skills programs for children shown to be successful on a relatively small scale, but further research is needed to establish standardized programs serving geographically and culturally diverse populations.

Influence of Home Environment on Dietary Patterns

The home environment has been a primary research focus to understand the influences of the food preferences of children (Zarnowiecki et al, 2014). Familiarity and accessibility of foods have been identified as drivers of food preferences in children and adolescents (Rollins, Savage, Fisher, \& Birch, 2016). Parents and other caregivers influence the types of foods favored by their children not only by selecting what foods are eaten at home, but also by transferring eating behaviors (Rollins et al., 2016). These behaviors, such as eating meals in a social group, may predict future eating behaviors in young adulthood. For example, a study investigating the eating habits of university students found that the frequency of childhood family dinners predicted students' current frequency of commensality as independent young adults, presumably living outside of the childhood home (De Backer, 2013). Additionally, parents' health attitudes and nutrition knowledge may positively affect the fruit and vegetable consumption of their children (Zarnowiecki et al 2014). The attitudes of the 
family toward fruit and vegetable consumption, combined with cultural factors, influence dietary behavior during the period of childhood and adolescent continued plasticity (Gluckman, Nishtar, \& Armstrong, 2015). Similar to eating behaviors, cooking behaviors are also passed down from caregivers to children; one study tracked use of family recipes as a means to transfer culinary knowledge from generation to generation, with mothers more likely than fathers to pass down a family recipe (De Backer, 2013). A successful obesity prevention program for adolescent participants may benefit from familial and community involvement as well as culturally appropriate foods and eating practices in order to translate into lasting behavioral changes.

\section{Prevention}

Results-driven youth obesity prevention programs are often grounded by theory- or model-informed approaches to planning. The Cooperative Extension System (CES) recommends both the social ecological model and the social cognitive theory for youth obesity prevention programming (Benke, Bailey, Martz, \& Lynch, 2013). The social ecological model states that there is a reciprocal relationship between environment and individual behavior (Bronfenbrenner, 1979), so a program utilizing this model may contain elements that change both the food environments and various health-related behaviors (Benke et al., 2013). The social cognitive theory states that behavior change is influenced by self-efficacy, which is achieved through techniques such as modeling and goal-setting (Benke et al., 2013). Furthermore, adult learning theories emphasize S.M.A.R.T. (Specific, Measurable, Achievable, Realistic, and Time-bound) goaloriented programming that is relevant to participants and respectful of participants' 
baseline knowledge and experiences (Benke et al., 2013). A comprehensive behavior modification strategy may include all of these elements, resulting in a program that enhances self-efficacy through S.M.A.R.T. goal setting, strengthens social networks through participation in programming, and applies relevant skills that are practiced both in class and at home (Kataura \& Block, 2011).

Childhood and adolescent obesity prevention programs may be relevant to a majority of youth encompassing a wide array of baseline BMI values. A longitudinal study of a 1947 birth cohort $(n=1142)$ found that the only obese adults were all obese at the age of 13 (Wright, Parker, Lamont, \& Craft, 2001). Children above the $90^{\text {th }}$ percentile of BMI at age 13 were twice as likely as the remaining participants to be in the $75^{\text {th }}$ percentile for body fat as adults (Wright et al., 2001). However, children in the bottom quarter of recorded BMI scores were also more likely to have either excessive or insufficient body fat as adults (Wright et al., 2001). Given that adolescents of both high and low BMI values are at increased risk of obesity as adults, obesity prevention strategies may be critical for all children and adolescents, regardless of BMI.

Not only does S.M.A.R.T. goal-setting play a role in participant self-efficacy, it also informs overall program outcome measures. In a 2006 meta-analysis assessing the effectiveness of childhood obesity prevention programs from 1985-2003, Thomas et al (2006) cited the following most frequently reported, reliable and valid outcome measures: 1) self-reported changes in fruit, vegetable, fat, and salt intake based on a 24-hour recall; 2) changes in body mass index; 3) changes in skinfold thickness; 4) self-reported changes in moderate-to-vigorous physical activity (MVPA); 5) selfreported changes in the duration, frequency, and intensity of physical activity $(\mathrm{H}$. 
Thomas, 2006). A successful intervention may benefit from utilizing similar outcome measures.

Fruit and vegetable consumption is associated with reduced energy intake, lower fat and sugar intake, lower BMI, waist circumference, and blood pressure, and increasing fruit and vegetable intake is therefore an attractive intervention strategy (Driskell et al., 2007). The composition of fruits and vegetables, which are rich in water and fiber while low in energy, modulates the glycemic load and postprandial hormonal shifts, causing stabilization and reduction of adiposity in children and adults in both experimental and longitudinal studies (Ledoux, 2011). The consumption of at least five servings of fruits and vegetables per day supports the protective effects of consumption ("Increasing fruit and vegetable consumption to reduce the risk of noncommunicable diseases," 2017). However, dietary interventions that encourage participants to reduce consumption of high-fat, low-nutrient dense foods have been shown to be susceptible to the effects of relapse, potentially due to the increased preference for the foods that are perceived to be restricted (Epstein et al., 2001). The alternative approach, to encourage the desirable behavioral change of increasing nutrient-dense food sources such as fruits and vegetables, reduces the risk of relapse (Epstein et al., 2001).

Participant age is an important factor in the success of obesity prevention programs that aim to provide skills that transfer into adulthood, because the program outcomes may be most relevant to an audience of young adults. Many researchers have hypothesized that middle school and high school students are more effective targets of culinary-focused obesity prevention programs, compared to grade school students, 
because they are more able to grasp the intervention strategies (Baranowski, Cullen, Nicklas, Thompson, \& Baranowski, n.d.). Additionally, research suggests that parents have the most influence over the development of habits during adolescence (Benke et al., 2013).

\section{Culinary Skills Intervention Programs}

A recent systematic review showed that culinary skills programs can improve the preferences, attitudes, and food-related behaviors of children and adolescents (Hersch et al., 2014). For example, the LA Sprouts obesity prevention program for fourth and fifth grade students ( $n=31$ LA Sprouts participants, $n=70$ control participants) combined gardening, nutrition, and cooking classes for 12 weeks, at 90 minutes per session, as depicted in Table 2 (Davis, Ventura, Cook, Gyllenhammer, \& Gatto, 2011). Although participants were not randomly allocated to the control and experimental groups, LA Sprouts is an uncommon example of a community intervention that utilized an experimental study design. The outcome variables tested included anthropometric measurements, biochemical analysis, and dietary recall.

Significant results among all participants of LA Sprouts, compared with the control group, included increased dietary fiber intake $(+22 \%$ vs $-12 \%, \mathrm{p}=0.04)$ and decreased diastolic blood pressure (-5\% vs. $-3 \%, \mathrm{p}=0.04$ ) (Davis et al., 2011). Among the overweight participants (59\%; LA Sprouts $n=18$, control $n=43$ ), LA Sprouts participants reported higher dietary fiber intake ( $0 \%$ vs. $-29 \%, \mathrm{p}=0.01)$, and had less weight gain $(+1 \%$ vs 4\%, $\mathrm{p}=0.04)$ than the control group (Davis et al., 2011). 
Table 2: Session overview of the 12-week LA Sprouts gardening after-school program for Latino fourth-and fifthgrade students (Davis et al, 2011)

\section{Session Nutrition Topics Recipe Gardening Topics}

\begin{tabular}{|c|c|c|c|}
\hline 1 & $\begin{array}{l}\text { Introduction to LA } \\
\text { Sprouts Kitchen and knife } \\
\text { safety }\end{array}$ & Winter garden salad & $\begin{array}{l}\text { Materials needed for } \\
\text { gardening } \\
\text { Sowing seeds }\end{array}$ \\
\hline 2 & $\begin{array}{l}\text { Types of fruits, colors, } \\
\text { seasonality } \\
\text { Fruit health benefits and } \\
\text { serving size } \\
\text { Adding fruit to your diet }\end{array}$ & Fruit rainbows & $\begin{array}{l}\text { Introduction to } \\
\text { documenting garden } \\
\text { progress } \\
\text { Sowing seeds }\end{array}$ \\
\hline 3 & $\begin{array}{l}\text { Types of vegetables, } \\
\text { colors, seasonality } \\
\text { Vegetable health benefits } \\
\text { and serving size } \\
\text { Adding vegetables to your } \\
\text { diet }\end{array}$ & Quinoa Salad & Visit to farmers' market \\
\hline 4 & $\begin{array}{l}\text { Real food vs packaged } \\
\text { food } \\
\text { Reading ingredient lists }\end{array}$ & $\begin{array}{l}\text { Vegetable quesadillas with } \\
\text { salsa }\end{array}$ & Transplanting \\
\hline 5 & $\begin{array}{l}\text { Healthy family dining } \\
\text { habits } \\
\text { Conversation starters }\end{array}$ & Migas with salsa & $\begin{array}{l}\text { Using recycled materials } \\
\text { for gardening }\end{array}$ \\
\hline 6 & $\begin{array}{l}\text { Health benefits of fiber } \\
\text { Sources of fiber and } \\
\text { serving size } \\
\text { Finding fiber on a } \\
\text { nutrition label } \\
\text { High-fiber foods taste test }\end{array}$ & $\begin{array}{l}\text { Whole-grain pasta with } \\
\text { vegetables }\end{array}$ & Composting \\
\hline 7 & $\begin{array}{l}\text { Natural vs added sugar } \\
\text { Finding sugar on a } \\
\text { nutrition label } \\
\text { Low-sugar drinks taste } \\
\text { test }\end{array}$ & $\begin{array}{l}\text { Apples and bananas with } \\
\text { peanut butter } \\
\text { Cucumber lemon water } \\
\text { Agua de Jamaica }\end{array}$ & Visit to farmers' market \\
\hline 8 & $\begin{array}{l}\text { Role of vitamins A and C } \\
\text { in the body } \\
\text { Sources of vitamins A and } \\
\text { C }\end{array}$ & $\begin{array}{l}\text { Beet, carrot, and avocado } \\
\text { salad }\end{array}$ & $\begin{array}{l}\text { Composting } \\
\text { Mulching }\end{array}$ \\
\hline 9 & $\begin{array}{l}\text { Importance of eating } \\
\text { breakfast } \\
\text { Ways to eat a healthier } \\
\text { breakfast } \\
\text { Shortcuts to make time for } \\
\text { breakfast }\end{array}$ & Yogurt parfait & $\begin{array}{l}\text { Identifying fruit and } \\
\text { vegetable plants }\end{array}$ \\
\hline 10 & $\begin{array}{l}\text { Importance of healthy } \\
\text { lunch } \\
\text { Selecting healthy school } \\
\text { lunch }\end{array}$ & Ultimate sandwich & Watering \\
\hline 11 & $\begin{array}{l}\text { Choosing healthy options } \\
\text { at holidays and parties }\end{array}$ & $\begin{array}{l}\text { Corn and bean dip with } \\
\text { pita chips }\end{array}$ & Visit to farmers' market \\
\hline 12 & Review of nutrition topics & Strawberry balsamic salad & $\begin{array}{l}\text { Harvesting fruits and } \\
\text { vegetables }\end{array}$ \\
\hline
\end{tabular}


Bolstering the findings of prior observational studies, the LA Sprouts pilot program showed that participation in the culturally tailored gardening/nutrition/culinary intervention could result in improved nutritional intake (in this study, through increased dietary fiber), reduced blood pressure, improved BMI among overweight participants, and improved rate of weight gain.

Another culinary-based obesity prevention program that utilized an experimental study design, and therefore may provide causative evidence, was the Healthy Home Offerings via the Mealtime Environment (HOME) study. Guided by the Social Cognitive Theory, this study focused on engaging whole families in meal planning, meal preparation, eating together, and increasing the availability of healthful foods at mealtime, such as fruits and vegetables (Friend, Flattum, Fulkerson, NeumarkSztainer, \& Garwick, 2014). HOME consisted of five monthly 90-minute sessions comprised of a cooking practicum with 44 parent-child dyads, parent discussion groups, and nutrition education classes. A study assessing the impact of HOME found that the intervention group $(n=71$ children) stated they were more willing to try new foods $(85 \%)$, eat more fruits and vegetables $(84 \%)$, and that they eat healthier snacks (82\%) (Table 3). Parent participants $(n=68)$ were also surveyed about eating behavior of their children. Consistent with the responses observed in the youth participants, $87 \%$ of parents reported that their children were more willing to try new foods as a result of participation in the HOME intervention (Table 3). Additionally, 92\% of parents stated they were more aware of their portion sizes, while $86 \%$ of parents said their children were more aware of their portion sizes (Table 3). Results indicate that the HOME 
program delivery met its objectives and was well-accepted by participants (Friend et al., 2014).

The program's strengths which may have contributed to its success included the theory-based approach, family involvement, offerings of multiple class times to maximize attendance, duration over ten weeks, and quality assurance focused on making sure programming was delivered as intended (Friend et al., 2014). Limitations included the considerable use of staff time, a wide age range of children, and difficulty recruiting families that were representative of their geographic area, as frequent inperson meetings may not be feasible for socioeconomically disadvantaged individuals (Friend et al., 2014). 
Table 3: Results of the HOME Study, an RCT that focused on promoting the frequency and healthfulness of family meals (2014)

Parent and Child Participant-Reported HOME Plus Satisfaction

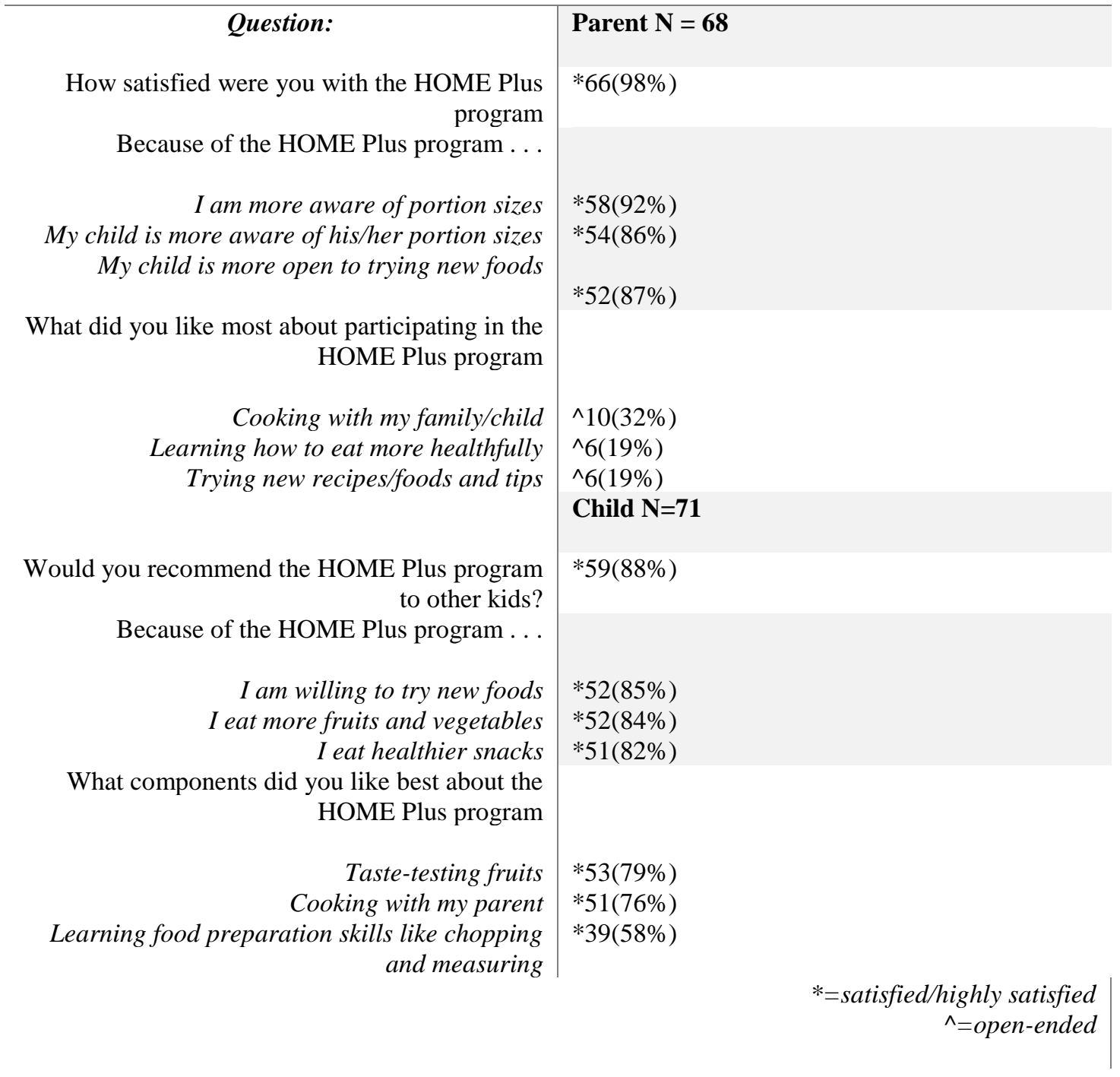

There are substantial challenges in determining the long-term outcomes and cost-effectiveness of large-scale behavioral intervention for adolescents. Foremost, the implementation of an intervention program requires an "up-front" cost that will potentially not result in savings for decades, when obesity-related diseases become more prevalent (Gortmaker et al., 2015). Although there are studies showing cost effectiveness between 5-10 years after the intervention, there are no studies that follow 
up 20-40 years after the intervention (Best, John R. et al, 2012; Epstein, Valoski, Wing, \& McCurley, 1990; Johnson et al., 1997). Therefore, the well-documented association between adolescent overweight and obesity and their persistent state into adulthood are relied upon to demonstrate the importance of adopting lifestyle changes before adulthood (D S Freedman et al., 2004; Whitaker, Wright, Pepe, Seidel, \& Dietz, 1997). According to a 2013 systematic review, the most successful interventions that were published were community-based interventions that involved a school component, and focused on both diet and physical activity (Bleich, Segal, Wu, Wilson, \& Wang, 2013). Because of the limited set of outcomes that are typically examined by an intervention study, the effects may be underestimated (Gortmaker et al., 2015). Adolescence is a critical developmental stage in which it is pertinent to establish favorable eating habits, in order to meet increased nutrient needs to maximize physical growth, as well as an appropriate age to grasp behavioral learning outcomes (Meiklejohn, Ryan, \& Palermo, 2016a).

\section{$\underline{\text { Age for Intervention }}$}

Adolescents are gaining more independence and decision-making power at a time when their dietary behaviors are influenced by social norms, friends, and increased accessibility of food (Contento, Isobel, et al, 1995). Additionally, the largest increases in BMI take place during adolescence, making adolescence an attractive target for intervention (Cunningham et al., 2014). The prevalence of obesity has positive association with age. A 2006 longitudinal study found that increases in health risk and health disparity occur from adolescence to adulthood across all sex, racial, and ethnic groups (Harris, Gordon-Larsen, Chantala, \& Udry, 2006). Noteworthy results included 
the mean decrease in breakfast consumption among white adolescents by $19 \%$, from 4.18 times per week (CI 4.01 to 4.34 ) to 3.38 times per week as young adults (CI 3.25 to 3.52 ), mean weekly increased consumption of fast foods by $20.9 \%$, from 1.72 times per week (CI 1.29 to 2.15 ) to 2.08 times per week (CI 1.55 to 2.61) among Native American adolescents and young adults, rates of no exercise among Native American adolescents increasing by $875 \%$ from 0.04 (0.02 to 0.07$)$ to $0.39(0.23$ to 0.59$)$ in young adulthood, and rates of obesity in Hispanic adolescents by $100 \%$, from 0.13 (CI 0.10 to 0.16 ) to 0.26 (CI 0.22 to 0.31 ) among Hispanic young adults (Harris et al., 2006). These results highlight opportunities for meaningful behavioral interventions for adolescents, with the goal of preventing health declines between adolescence and young adulthood.

The impact of high-risk eating patterns are long-lasting, as suggested by the incidence of obesity between the ages of 5 and 14 years, which is four times as high among children who had been overweight at the age of 5 years compared to those who had a normal weight at that age (Cunningham et al., 2014). There is evidence to suggest the impact of eating patterns on obesity risk is high from a very young age, indicating the opportunity to mitigate the risk through the introduction of behavioral interventions (Cunningham et al., 2014). Due to the influence of adolescents on family consumer behavior, their susceptibility to convenience foods as independence increases, and the ability of this age group to grasp knowledge and skills, adolescents may be appropriate targets for obesity prevention programs. 


\section{Background: Pink and Dude Chefs}

Pink and Dude Chefs (PDC) is an afterschool nutrition education and culinary skills training program for middle school-aged students. Based on the Social Cognitive Theory and Kolb's Model of Experiential Learning, this program expands on a pilot study conducted in 2008 and formative research projects completed in 2013, 2014, and 2015 in San Luis Obispo County of California. PDC has since expanded to other parts of the state and country, including Nashville, TN, and Santa Barbara County, CA.

PDC was developed and piloted in Arroyo Grande and Oceano, CA, in 2008, in response to a local initiative to promote the San Luis Obispo Food Bank Coalition's fresh produce (Chessen, 2008). The overall goal of the curriculum was to increase utilization of produce from the Food Bank and to improve culinary skills among local middle school girls (Chessen, 2008). Through repetition of core culinary skills, participants $(\mathrm{n}=22)$ increased their perceived culinary competence, which is a common barrier to engaging in home-cooking.

Results indicated that after the PDC pilot program, participants' confidence to use culinary skills as a tool to make dietary changes improved (Chessen, 2008). Chessen found that self-reported culinary self-efficacy, in which participants rated their confidence on a scale of 1-5 in a series of questions, improved after participation in the program (Table 4: +3.273 overall, $\mathrm{p}=0.005)$. 
Table 4: Self-efficacy score for cooking for each of the seven items used to calculate (Chessen, 2008)

SELF-EFFICACY ITEMS

\begin{tabular}{|c|c|c|c|c|}
\hline $\begin{array}{l}\text { HOW CONFIDENT DO } \\
\text { YOU FEEL ABOUT ... }\end{array}$ & $\begin{array}{l}\text { Range of } \\
\text { differences }\end{array}$ & $\begin{array}{l}\text { Combined } \\
\qquad(\mathrm{n}=22)\end{array}$ & $\begin{array}{l}\text { Oceano } \\
(n=11)\end{array}$ & $\begin{array}{l}\text { Arroyo } \\
\text { Grande } \\
(n=11)\end{array}$ \\
\hline $\begin{array}{l}\text { BEING ABLE TO COOK } \\
\text { FROM BASIC }\end{array}$ & $(-2,2)$ & $0.182( \pm 0.243)$ & $-0.000( \pm 0.357)$ & $0.364( \pm 0.338)$ \\
\hline INGREDIENTS. & & 1.140 & 1.183 & 1.120 \\
\hline $\begin{array}{l}\text { CREATING MEALS } \\
\text { USING NEW }\end{array}$ & $(-2,3)$ & $0.545( \pm 0.292)$ & $0.818( \pm 0.444)$ & $0.273( \pm 0.384)$ \\
\hline INGREDIENTS. & & 1.371 & 1.471 & 1.272 \\
\hline $\begin{array}{l}\text { FOLLOWING A SIMPLE } \\
\text { RECIPE. }\end{array}$ & $(-1,2)$ & $0.409( \pm 0.170)$ & $0.636( \pm 0.279)$ & $0.182( \pm 0.182)$ \\
\hline $\begin{array}{l}\text { USING A KNIFE SAFELY } \\
\text { WHEN COOKING. }\end{array}$ & $(-1,4)$ & $\begin{array}{c}0.769 \\
0.364( \pm 0.251)\end{array}$ & $\begin{array}{c}0.924 \\
0.727( \pm 0.407)\end{array}$ & $\begin{array}{c}0.603 \\
-0.000( \pm 0.270)\end{array}$ \\
\hline $\begin{array}{l}\text { PLANNING A MEAL AT } \\
\text { LOW COST. }\end{array}$ & $(-2,2)$ & $\begin{array}{c}1.177 \\
0.318( \pm 0.232)\end{array}$ & $\begin{array}{c}1.348 \\
0.545( \pm 0.366)\end{array}$ & $\begin{array}{c}0.894 \\
0.091( \pm 0.285)\end{array}$ \\
\hline $\begin{array}{l}\text { USING LEFTOVERS TO } \\
\text { CREATE A NEW MEAL. }\end{array}$ & $(-2,2)$ & $\begin{array}{c}1.086 \\
0.409( \pm 0.194)\end{array}$ & $\begin{array}{c}1.214 \\
0.727( \pm 0.273)\end{array}$ & $\begin{array}{c}0.944 \\
0.091( \pm 0.251)\end{array}$ \\
\hline $\begin{array}{l}\text { BEING ABLE TO } \\
\text { CHANGE WHAT YOUR }\end{array}$ & $(-2,2)$ & $\begin{array}{c}0.908 \\
-0.273( \pm 0.230)\end{array}$ & $\begin{array}{c}0.905 \\
0.091( \pm 0.343)\end{array}$ & $\begin{array}{c}0.831 \\
-0.636( \pm 0.279)\end{array}$ \\
\hline FAMILY EATS & & 1.077 & 1.136 & 0.924 \\
\hline $\begin{array}{l}\text { TOTAL SELF-EFFICACY } \\
\text { SCORE }\end{array}$ & $(-6,6)$ & $1.955( \pm 0.698)$ & $3.535( \pm 0.731)$ & $0.360( \pm 1.000)$ \\
\hline & & 3.273 & 2.423 & 3.320 \\
\hline
\end{tabular}

Knowledge of the Food Guide Pyramid was assessed through five survey questions. Although an overall 15\% improvement was observed in the knowledgebased section, there was insufficient evidence to conclude that participants correctly answered more of the five questions about the Food Guide Pyramid improved due to participation in PDC, because the resulting p-value that was greater than the designated $\alpha$ level of $0.01(+1.058, p=0.025)($ Chessen, 2008). However, the scores of students with "high attendance," defined as attendance in over $75 \%$ of classes $(n=16)$, were compared to "low attendance" students $(n=6)$. "High attendance" students demonstrated a greater number of correct answers: 0.69 to 0 (Chessen, 2008). 
Although this observation is limited by a small sample of "low attendance" students, it is consistent with the expectation that attendance should explain some variation in nutrition knowledge at the end of the program.

Chessen also assessed whether the participants' perceptions of barriers to cooking were decreased after PDC, in response to the question, "Why do you eat out?" Participants could select from responses such as, "Too much time and effort [to cook]," "Busy," and "To have fun." Results showed that the proportion of students who perceived that cooking a meal took excessive time and effort did not significantly change after the intervention.

After Chessen's research, PDC continued to expand from a pilot program to an established curriculum in after school programs implemented in Arroyo Grande (n=13) and Carpinteria, California $(\mathrm{n}=10)$ (Sheehan, 2013). A majority of participants were female (60.9\%) and Hispanic/Latino (60.9\%). (Sheehan, 2013). Sheehan assessed the PDC curriculum's effectiveness related to culinary skills, willingness to try new foods, culinary confidence, nutrition knowledge, preferences, and intake (Sheehan, 2013). Mean culinary confidence, nutrition knowledge, fruit intake, and fruit and vegetable preferences all increased $(n=23)$ (Sheehan, 2013). Among the most significant results were each of the variables in fruit intake (Table 5). The largest mean increases in intake were for cherries $(+0.68)$, plums $(+0.55)$, and dried plums $(+0.55)$ (Table 5). 
Table 5: Mean fruit preference score from pre-and post-survey and change in mean fruit preference (Sheehan, 2013)

\begin{tabular}{lcccc}
\hline Variable & $\begin{array}{c}\text { Mean Pre- } \\
\text { Score }\end{array}$ & $\begin{array}{c}\text { Mean Post- } \\
\text { Score }\end{array}$ & $\begin{array}{c}\text { Change in } \\
\text { Mean }\end{array}$ & P-value \\
\hline Cherry & 0.91 & 1.59 & 0.68 & 0.03 \\
\hline Dried Plum & -0.50 & 0.05 & 0.55 & 0.20 \\
\hline Grapefruit & 0.50 & 0.86 & 0.36 & 0.30 \\
\hline Tangerines & 1.09 & 1.59 & 0.50 & 0.02 \\
\hline Melons & 1.00 & 1.23 & 0.23 & 0.20 \\
\hline Persimmons & -0.55 & -0.41 & 0.14 & 0.50 \\
\hline Plums & 0.36 & 0.91 & 0.55 & 0.10 \\
\hline Overall & 2.82 & 5.82 & 3.00 & 0.01 \\
\hline
\end{tabular}

In 2014, PDC was implemented in four cohorts in Nashville, $\mathrm{TN}(\mathrm{n}=17)$ and Shandon, CA and Arroyo Grande, CA (n=15) (Bierlich-Wesch, 2016). Bierlich-Wesch focused on participants' preferences for fruits and vegetables, fruit and vegetable intake, and nutrition knowledge, and then stratified the results by gender and race/ethnicity. In assessment of fruit and vegetable preferences, participants were provided a list of fruits and vegetables and rated them using a scale that was later coded 0-5 (Bierlich-Wesch, 2016). A mean increase in preference was observed for each fruit, except for melons, but the findings did not achieve statistical significance $(n=29 ; p=0.6)($ Bierlich-Wesch, 2016). Fifteen participants $(56 \%)$ had an overall increased preference for vegetables, while $9(32 \%)$ reported decreased preferences for vegetables overall, and 3 (11\%) showed no change in score (Bierlich-Wesch, 2016). Potential reasons for the mixed findings related to intake and preferences may be related to geographical differences between California and Tennessee; the food frequency questionnaire items available to California participants from September to November may have differed from items available in Nashville, TN from April to June and from September to November, thus resulting in different levels of familiarity, availability, and intake. Additionally, cultural differences between the cohorts may 
have led to varying outcomes, as participants in California identified themselves as $38.5 \%$ Hispanic/Latino, $46.2 \%$ white, and $15.3 \%$ other, while Tennessee participants identified themselves as $6 \%$ white, $88.2 \%$ black, and $5.8 \%$ other (Bierlich-Wesch, 2016). The results do not indicate that the program impacted boys differently than it impacted girls (Table 6). When differences between racial/ethnic subgroups were examined for fruit and vegetable preferences, fruit intake, and vegetable intake, no differences were found ( $p>0.9$ ) (Bierlich-Wesch, 2016). The most noteworthy differences between Black, White, and Hispanic/Latino participants were in the survey questions regarding vegetable preference $(\mathrm{p}=0.2)$ and nutrition knowledge $(\mathrm{p}=0.1)$ (Bierlich-Wesch, 2016).

Table 6: Comparison of Mean Differences between Male and Female Participants (Bierlich-Wesch, 2016)

\begin{tabular}{|c|c|c|c|}
\hline Gender $^{2}$ & Boys & Girls & $\begin{array}{l}\text { Between } \\
\text { Groups }\end{array}$ \\
\hline Pre vs. Post Measure Item & $\begin{array}{l}\text { Change in } \\
\text { Mean (SD) }\end{array}$ & $\begin{array}{l}\text { Change in } \\
\text { Mean (SD) }\end{array}$ & p-value ${ }^{1}$ \\
\hline Fruit Preference & $0.7(2.8)$ & $1.5(4.5)$ & 0.6 \\
\hline Vegetable Preference & $2.3(16.4)$ & $4.9(9.6)$ & 0.6 \\
\hline Nutrition Knowledge & $1.4(1.4)$ & $1.1(1.4)$ & 0.6 \\
\hline Fruit Intake & $2.0(5.3)$ & $1.0(6.1)$ & 0.6 \\
\hline Vegetable Intake & $0.8(15.5)$ & $0.6(11.1)$ & $>0.9$ \\
\hline $\begin{array}{r}{ }^{1} p \text {-value by one-way ANOVA } \\
{ }^{2} n=9-14 \text { for boys, } n=11-16 \text { for girls }\end{array}$ & & & \\
\hline
\end{tabular}

\section{Profile of PDC Communities}

The prevalence of overweight and obesity among adolescents in California increased over from 30.5\% to 32.4\% between 2001 and 2012, as shown in Figure 6 (Wolstein et al., 2015). Over 1 million adolescents in California were overweight, representing $16 \%$ of the adolescent population, or obese, representing adolescent $17 \%$ of the population, in 2012 (Wolstein et al., 2015). However, racial/ethnic disparities 
exist, with marginalized subpopulations disproportionately representing the increased rate of obesity in California. White adolescent overweight and obesity in California decreased from $26 \%$ to $21 \%$ between 2001 and 2012, while all other racial groups had similar or higher rates over time (Figure 6).

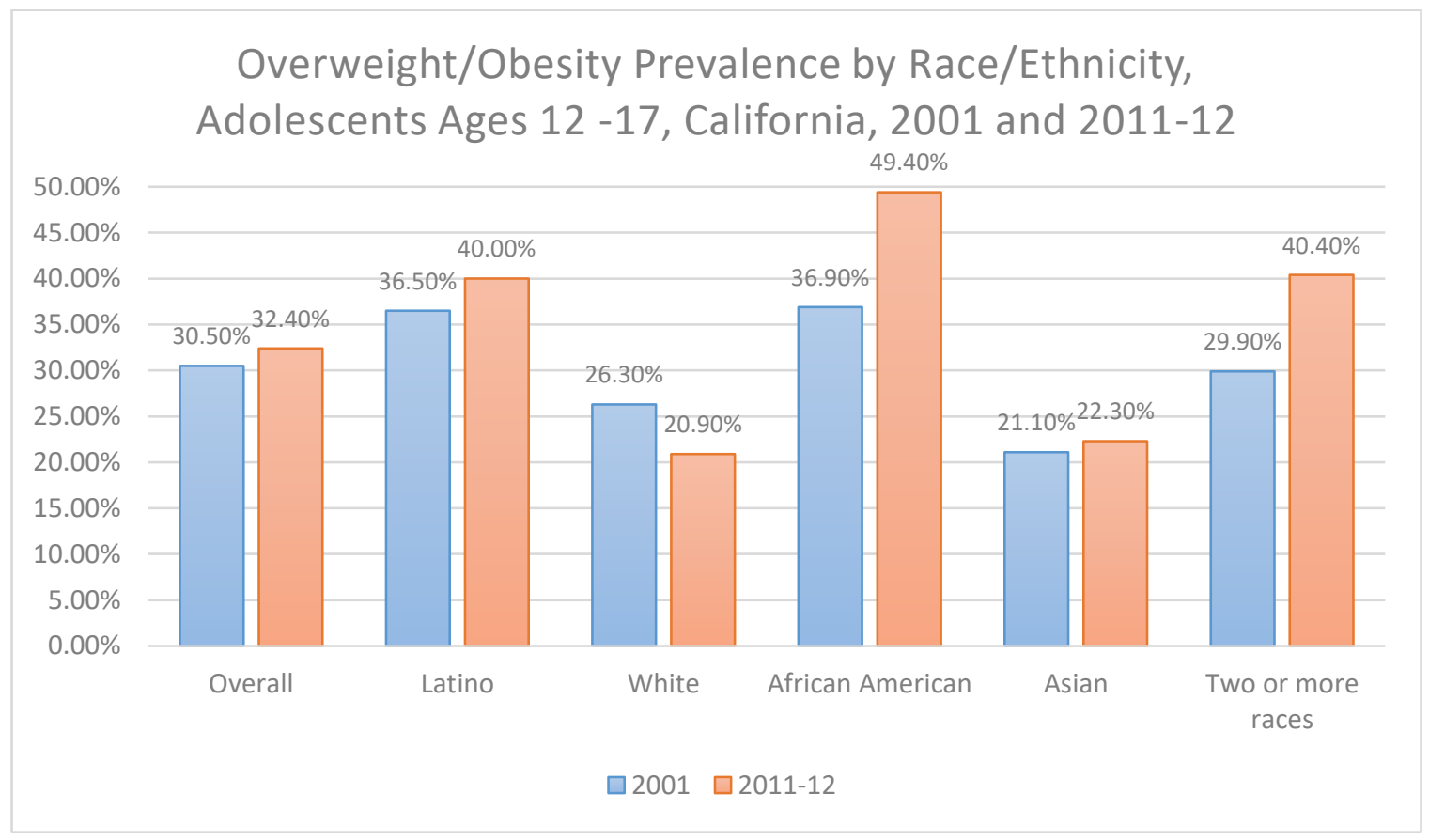

Figure 6: Overweight/obesity prevalence among adolescents aged 12-17 years by racelethnicity, in 2001 and in 2011-12 (Source: 2001 and 2011-12 California Health Interview Surveys)

The higher rates of overweight and obesity observed among people living in lowincome environments are attributed to disparities in diet and physical activity behaviors, which are driven by inequities in access to healthy foods, parks, and other safe environments (Wolstein et al., 2015). Data from CHIS 2011-2012 suggests that low-income adults, Latinos, and African-Americans are more likely to report that fresh fruits and vegetables are not affordable, and that their neighborhoods are not safe. More than one-quarter (28 percent) of Latinos surveyed indicated that fresh produce 
was not available in their neighborhood, while 14 percent of white respondents said fresh fruits and vegetables were not available (Wolstein et al., 2015).

The 2014 report The Weight of the State showed a trend of worsening dietary behaviors over time among children and adolescents (Figure 7). While 10.8 percent of children aged 2-5 years were reported to consume one or more sugar-sweetened sodas in the past day (95\% CI: 4.6, 17.0), 30.5\% of adolescents aged 12-17 years reported consuming at least one sugar-sweetened soda in the last day (Figure 7) ("Obesity in California: The Weight of the State, 2000-2014,” 2016). Similarly, frequency of consumption of other sugar-sweetened beverages and fast food were found to increase among advancing age groups (Figure 7) (“Obesity in California: The Weight of the State, 2000-2014,” 2016). In contrast, intake of at least two fruits per day among children aged 2-5 was reported among $76.10 \%$ of respondents (95\% CI: 69.6, 82.7), compared to only $54.30 \%$ of adolescents (95\% CI: 49.4, 59.3) ("Obesity in California: The Weight of the State, 2000-2014," 2016). 


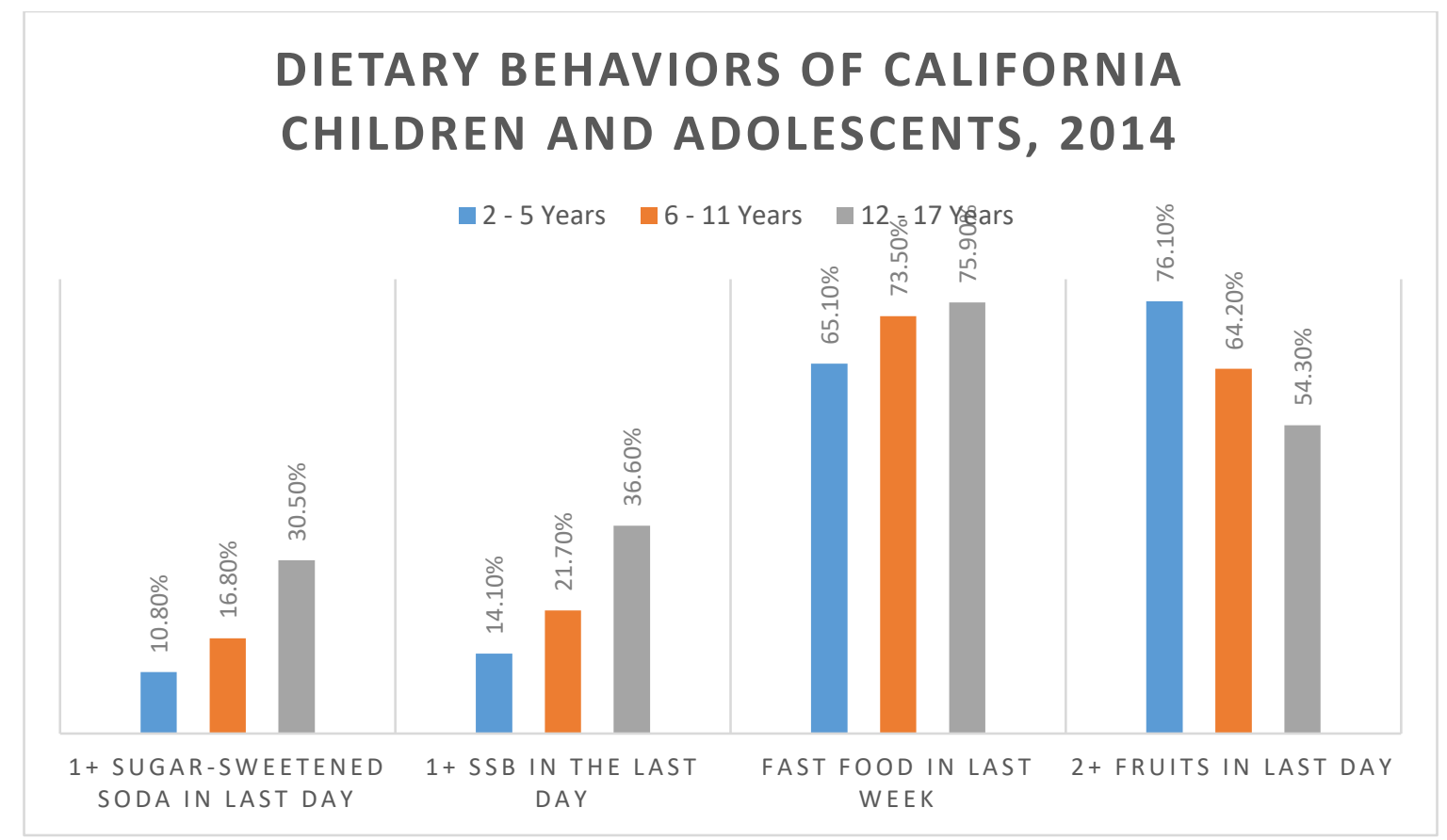

Figure 7: Dietary behaviors in California adolescents among various age groups (Source: 2014 California Health Interview Surveys) 
Reducing childhood and adolescent obesity may be of economic benefit in the state of California, where the estimated costs of obesity and inactivity were $\$ 28.7$ billion in healthcare expenses, injuries, and lost productivity in 2005, representing a $32 \%$ increase from 2000 (G. Thomas, 2005).

Childhood and adolescent obesity is of major concern in the Santa Barbara and San Luis Obispo Counties, especially among the Hispanic community and those with lower income (G. Thomas, 2005). Latino $5^{\text {th }}$ graders in San Luis Obispo County are twice as likely to be overweight $(41.2 \%)$, compared to white $5^{\text {th }}$ graders $(23.5 \%)(\mathrm{G}$. Thomas, 2005). The prevalence of overweight and obesity among adolescents aged 12-17 years in San Luis Obispo County increased from 23.6\% in 2001 (95\% CI: 12.334.9) to $26.0 \%$ in 2012 (95\% CI: 12.2-39.8) (Wolstein et al., 2015). The prevalence of adolescent overweight and obesity also increased in Santa Barbara County, from $27.1 \%$ (95\% CI: 15.538 .7 ) in 2001, to $36.1 \%$ in 2012 (95\% CI: $20.5-51.7)$ (Wolstein et al., 2015).

The Santa Barbara Public Health Department identified several barriers to effectively addressing obesity prevention and treatment. Limitations of funding and geographic barriers cause existing obesity prevention programs to serve narrow fragments of society for a limited amount of time, leaving many areas underserved (Santa Barbara County Public Health, 2017). Furthermore, many programs focus solely on individual behavioral change, rather than addressing corresponding issues of policy and access (Santa Barbara County Public Health, 2017). 


\section{Conclusions and Rationale}

Overweight and obesity are associated with a number of co-morbidities, including heart disease, certain cancers, and metabolic syndrome (Gluckman et al., 2015). Providing high-quality nutrition education and culinary skills training for adolescents may help mitigate obesity risk as participants enter adulthood.

Adolescence is a transitional time in which new responsibilities are acquired, including decision-making around food and eating. National nutrition data consistently shows that diet patterns of adolescents and teenagers are high in sugar-sweetened beverages, convenience foods that are high in fat and salt, while fruit, vegetable, and whole grain consumption are inadequate. Common barriers to meeting the recommendations for fruits, vegetables, and whole grains include negative attitudes toward cooking, often due to a lack of cooking confidence (Larson et al., 2006). However, there is a positive association between cooking and diet quality (Johnson et al., 1997; Larson et al., 2006) such that cooking skill is associated with increased fruit and vegetable consumption.

Due to low statistical power, it had not been possible to conclude whether students' intake of fruits and vegetables increased during their participation in the Pink and Dude Chefs curriculum. Prior Pink and Dude Chefs research has focused on student outcomes of culinary confidence and skill, nutrition knowledge, and improved preferences for fruits and vegetables (Bierlich-Wesch, 2016; Chessen, 2008; Sheehan, 2013). The aim of this project was to address the gap in PDC research by combining survey data to the greatest extent possible, in order to bolster the sample size and assess effectiveness in facilitating behavioral change in its participants. By comparing 
pre- and post- food frequency questionnaires, fruit and vegetable intake will be measured to determine the effectiveness of the program to meet its primary goal of facilitating increased intake of fruits and vegetables among participants.

\section{Research Question and Hypothesis}

The research question is: Does participation in the Pink and Dude Chefs afterschool nutrition education and culinary skills program improve intake of fruits and vegetables among middle school students, across diverse communities in Shandon (CA), and Northern Santa Barbara County (CA)?

It is hypothesized that participation in the Pink and Dude Chefs program will result in increased frequency of fruit and vegetable consumption by participants. 


\section{CHAPTER 2}

\section{Methods}

\section{$\underline{\text { Participants }}$}

The Pink and Dude Chefs curriculum was designed for middle school students aged 11-14 years, which comprised the eligibility criteria for participation in this study. The content is appropriate for adolescents at this age because they are prepared to handle scientific content and culinary skills, and moreover, they may be influential in family decision-making with regards to food choices. The after-school mode of delivery was chosen to ease implementation in organizations, without the constraints of adapting Pink and Dude Chefs curriculum to meet state standards for academic credit.

$\underline{\text { Site Recruitment and Program Implementation }}$

Pink and Dude Chefs was implemented from September 2014 to December 2014 in Shandon, CA, and from September 2015 to August 2016 at five locations in Northern Santa Barbara County (Table 7). Recruitment of the five Santa Barbara County cohorts was conducted during August 2015, while the Shandon cohort was established through an existing partnership between the Cal Poly Solutions Through Research in Diet and Exercise (STRIDE) Center and the Shandon YMCA.

Site requirements included access to a kitchen, a place for students to sit and take notes during the lecture component of the course, a staff instructor to undergo PDC online training, volunteers to maintain a 4:1 youth-to-adult ratio, eight children 
aged 11-14 years, and for the 2015-2016 project, for the site to be located within northern Santa Barbara County, as stipulated by the funding organization. The five Santa Barbara County partner agencies were: Marian Medical Center, People's Self Help Housing, ASES in Guadalupe, the Cuyama Valley Resource Center, and the Boys and Girls Club of Santa Maria Valley.

Program coordinators completed the Pink and Dude Chefs online training in order to provide instructors with training, program implementation, and technical support. They provided instructors with access to the online training, and monitored their progress while offering their support as needed.

\section{$\underline{\text { Program Instructors }}$}

All twelve PDC instructors were paid staff of partner organizations, which reduced the staff time required of Cal Poly's STRIDE Center. While STRIDE also authorized the use of volunteers as instructors, the organizations that partnered with this current project all chose to dedicate paid staff to PDC. Reasons for using paid staff included eliminating need for volunteer recruitment, the ease of managing paid staff compared to volunteers, and the perception that paid staff may be more likely to complete the entire twelve lesson curriculum than a volunteer would.

An additional advantage that the staff of partner agencies provided was their community presence and established credibility; introducing PDC to rural communities seemed to be benefitted by the recognition of instructors who had already worked with PDC youth participants in other community programs. 
Table 7 Cohort Locations and Program Length

\begin{tabular}{|c|c|c|c|}
\hline $\begin{array}{l}\text { Partner } \\
\text { Organization }\end{array}$ & Cohort & Start Date & End Date \\
\hline Shandon YMCA & $\begin{array}{l}\text { Shandon } \\
\text { Elementary } \\
\text { School } \\
\text { Shandon, CA }\end{array}$ & $09 / 2014$ & $12 / 2014$ \\
\hline $\begin{array}{l}\text { Marian Medical } \\
\text { Center }\end{array}$ & $\begin{array}{l}\text { Mariposa } \\
\text { Townhomes, } \\
\text { Orcutt, CA }\end{array}$ & $8 / 22 / 2015$ & $12 / 17 / 2015$ \\
\hline $\begin{array}{l}\text { Kermit } \\
\text { McKenzie Junior } \\
\text { High School }\end{array}$ & $\begin{array}{l}\text { Kermit McKenzie } \\
\text { ASES Club, } \\
\text { Guadalupe, CA }\end{array}$ & $8 / 29 / 2015$ & $12 / 4 / 2015$ \\
\hline $\begin{array}{l}\text { Marian Medical } \\
\text { Center }\end{array}$ & $\begin{array}{l}\text { Los Adobes de } \\
\text { Maria Apartment } \\
\text { Community, } \\
\text { Santa Maria, CA }\end{array}$ & $1 / 4 / 2016$ & $3 / 7 / 2016$ \\
\hline $\begin{array}{l}\text { Cuyama Boys } \\
\text { and Girls Club }\end{array}$ & Cuyama, CA & $3 / 1 / 2016$ & $5 / 2 / 2016$ \\
\hline $\begin{array}{l}\text { Santa Maria } \\
\text { Boys and Girls } \\
\text { Club }\end{array}$ & Santa Maria, CA & $6 / 1 / 2016$ & $8 / 15 / 2016$ \\
\hline
\end{tabular}

Program coordinators compiled and ordered materials, including workbooks, cookware, kitchen kits, with multiple vendors to ensure timely arrival and price points. All materials were delivered in person before the programs started.

Program coordinators attended each site's first lesson and helped instructors facilitate the first class. They also scheduled weekly or biweekly conference calls with each instructor for updates, along with multiple on-site visits throughout the program. 


\section{$\underline{\text { Instructor Online Training }}$}

Each of the twelve instructors were provided with a comprehensive PDC online train-the-trainer course that covered the following topics: Background of PDC, Kitchen Safety, Lesson Planning and Preparation, and Classroom Control. Before the instructors were given access to the online training, they were surveyed by program coordinators over the telephone to chronicle their level of education, relevant work experience in the food and beverage industry, and food safety and nutrition knowledge prior to the training (Appendix A). The instructor objectives were: To obtain proficiency in the basic principles of food safety, nutrition knowledge, program knowledge, and classroom control after online training, across all educational and experiential backgrounds and geographic locations.

Each section was followed by a five-question quiz that required $100 \%$ accuracy in order to advance to the next section. If a passing grade of $100 \%$ was not obtained, the trainee was prompted to revisit section content before having access to the next section. The training concluded with a fifty-question, comprehensive final exam that required a $100 \%$ passing grade. The final exam reviewed the topics covered in the training: the program overview of Pink and Dude Chefs, classroom management, how to prepare for the lesson, food safety, and nutrition knowledge. When the passing final exam score was earned, the new PDC instructor was administered a post-survey identical to the one given before the training (Appendix A). Additionally, the new instructor was provided two kits with all of the kitchen supplies, workbooks, instructor manuals, and aprons needed to teach the course to eight middle school students. 


\section{$\underline{\text { Classroom Procedure }}$}

The curriculum consisted of twelve two-hour lessons that were taught in a lecture setting, followed by a hands-on cooking practicum. The lecture portion, which was outlined in detail in the instructor manuals, was designed to be 45 minutes in duration. Each lesson was themed and the nutrition and culinary concepts progressively built on the previous lesson's foundational knowledge. Therefore, attendance at each lesson was expected of the participants. The lecture content and corresponding culinary activity prepared the participants for a take-home goal sheet, which encouraged a single behavioral change to work on with their families before the next lesson (Appendix B). Parents signed the goal sheet when the goal was accomplished, and students were allotted one raffle ticket per goal sheet to potentially win a prize at the Family Fiesta, PDC's culminating lesson and celebration.

The hands-on cooking practicum lasted the remaining 1 hour and 15 minutes. The cooking portion began with a demonstration of a core cooking skill by the instructor. After the demonstration, the students practiced the cooking skill individually or in groups, under the close supervision of the instructors and adult volunteers. After this core competency was achieved by the students, the class read the recipe (Appendix C) and the instructions aloud as a group, and delegated responsibilities as a team. The instructors and volunteers supervised the student-led creation of the recipe. The completed meal was portioned and packaged in to-go containers to be eaten with the participants' families, and the instructors encouraged the participants to make the recipe again with their guardians. 
The remaining time was dedicated to clean-up and group reflection of the day's lesson to reinforce the upcoming week's behavioral goals. The behavioral goals associated with each lesson are listed in detail in Table 8.

The completion of the behavioral goals, which were confirmed by a parent or guardian, combined with the recipe-sharing, fulfilled the program objective to facilitate improved fruit and vegetable intake at home. It was expected that the adolescent participants would influence the grocery purchases of the parent/guardian by demonstrating proficiency in meal preparation, as well as favoring the recipes created in class.

\section{Family Fiesta}

The twelfth and final lesson of PDC was the Family Fiesta, a showcase of new skills and favorite recipes of the student participants for their families, school administrators, and community leaders. Participants selected the multi-course menu for their invited guests, prepared the meal, and served all guests in their class attire of chefs' hats and aprons. Meanwhile, the program instructors scaled the recipes to accommodate the increased headcount and set up stations to prepare at least three recipes. Participants assisted with cleanup and were privately interviewed on their experience before the families arrived. A mealtime recognition ceremony was held for the participants, who were presented with a Culinary Certificate of Completion that was included in each student workbook, but had been removed by instructors before the first class. Instructors were also encouraged to reward attendance and completion 
of behavioral goal "sheets" with raffle tickets to win a non-food-related prize at the Family Fiesta.

The intent of the Family Fiesta was two-fold. First, participants were challenged to work efficiently as teams to prepare a three-course meal, and cater the meal to their families, friends, and communities using culinary skills, time management, and creativity. Secondly, the Family Fiesta served as a demonstration of participants' culinary skills to their parents/guardians, as a way to encourage confidence in the skills of the students so that they may continue to be tasked with meal preparation at home, while fostering a sense of pride in their students' accomplishments. 
Table 8 Curriculum Layout and Student Goals

\begin{tabular}{|c|c|}
\hline Lesson & Goals \\
\hline 1: Personality Pie & $\begin{array}{l}\text { 1. I will replace a dessert with unsweetened yogurt and fruit } \\
\text { 2. I will teach someone the proper handwashing technique by singing } \\
\text { "Happy Birthday" twice }\end{array}$ \\
\hline $\begin{array}{l}\text { 2: How to Read a } \\
\text { Recipe }\end{array}$ & $\begin{array}{l}\text { 1. I will practice a recipe and bring the recipe to class. } \\
\text { 2. I will help at meal time by measuring out some of the ingredients using } \\
\text { the correct utensils } \\
\text { 3. I will teach my family what to do if there is a grease fire in the kitchen. }\end{array}$ \\
\hline 3: Cutting Edge & $\begin{array}{l}\text { 1. I will help prepare a meal by slicing, chopping, and dicing while } \\
\text { demonstrating safe knife handling. } \\
\text { 2. I will help prepare a recipe/meal by selecting the proper knife to use for } \\
\text { the task. }\end{array}$ \\
\hline $\begin{array}{l}\text { 4: Create Your } \\
\text { Plate }\end{array}$ & $\begin{array}{l}\text { 1. I will have a meal based on the MyPlate recommendations we discussed in } \\
\text { class. } \\
\text { 2. I will show a family member the "portion size wallet card" and explain to } \\
\text { them the importance of understanding serving sizes. }\end{array}$ \\
\hline 5: Get the Facts & $\begin{array}{l}\text { 1. I will read a nutrition facts label. } \\
\text { 2. I will walk around the grocery store to see where the foods are placed. } \\
\text { 3. I will find an example of another name for sugar on a product's ingredient } \\
\text { list. }\end{array}$ \\
\hline 6: Carbohydrates & $\begin{array}{l}\text { 1. I will replace a processed, simple carbohydrate with a whole grain version. } \\
\text { 2. I will eat a piece of fruit in the morning instead of drinking fruit juice. } \\
\text { 3. I will drink water instead of a sugary drink. }\end{array}$ \\
\hline 7: Protein & 1. I will replace an animal protein with a vegetable protein in a meal. \\
\hline 8: Fats & $\begin{array}{l}\text { 1. I will replace a saturated fat with an unsaturated fat. } \\
\text { 2. I will choose a baked option instead of a fried food. } \\
\text { 3. I will check a food item's nutrition facts for trans fat and ingredient list for } \\
\text { words like "shortening," "partially hydrogenated oil" or "hydrogenated } \\
\text { oil". }\end{array}$ \\
\hline 9: Calcium & $\begin{array}{l}\text { 1. I will try a dairy source of calcium and a non-dairy source of calcium to } \\
\text { make sure I am getting } 1300 \mathrm{mg} \text { of calcium every day. }\end{array}$ \\
\hline 10: Breakfast & $\begin{array}{l}\text { 1. I will eat a breakfast with one of the following: whole grain and vegetable, } \\
\text { or cheese, or meat. }\end{array}$ \\
\hline 11. Trivia & No goal sheets \\
\hline 12. Family Fiesta & No goal sheets \\
\hline
\end{tabular}




\section{$\underline{\text { Surveys }}$}

During the first lesson, students were administered a multiple-choice survey (Appendix D) to understand their existing knowledge of nutrition, food safety, fruit and vegetable preferences, willingness to try new foods, and weekly intake of a variety of fruits and vegetables. This research will focus on the program's impact on fruit and vegetable consumption, as evidenced by food frequency surveys. Each student was given a unique code to protect their identity, while their sex and location were recorded. Finally, they were surveyed at the twelfth meeting (Family Fiesta) in the exact manner they were surveyed in the first lesson. The students, instructors, and their families were additionally interviewed on their opinion of the program, and whether they have changed their dietary behavior as a result of the experience (Appendices E and F).

\section{$\underline{\text { Statistical Analysis }}$}

Survey answers were coded and each individual student and instructor were assigned a unique code to ensure confidentiality. Students from Northern Santa Barbara County were assigned a code from 1-84; while students from Northern San Luis Obispo County were assigned a code from 101-117. The data from the student and instructor pre- and post- surveys were entered by two graduate students, utilizing the Microsoft Access data management system (Microsoft Access, 2013). Double data entry optimized accuracy of data entry, and the two systems were then downloaded into Microsoft Excel for comparison and addressing any discrepancies. The resulting database had information on each the participants' unique numerical code, sex, 
geographical location, nutrition knowledge, culinary knowledge, culinary confidence, willingness to try new foods, and food frequency surveys.

Student responses in the food frequency questionnaires elucidated on the frequency of the weekly intake of a list of fruits and vegetables, before and after the course (Table 9).

Table 9: Food Frequency Questionnaire Variables utilized for Northern Santa Barbara County participants (20152016). Northern San Luis Obispo County participants were not asked to provide information on mushrooms, onions, or potatoes.

\section{VARIABLES (24 TOTAL)}

\section{FRUITS (7)}

\begin{tabular}{l|l}
$\mathbf{1 .}$ & Apple \\
$\mathbf{2 .}$ & Banana \\
$\mathbf{3 .}$ & Berries (blueberries, strawberries, raspberries) \\
$\mathbf{4 .}$ & Cherries \\
$\mathbf{5 .}$ & Grapefruit \\
$\mathbf{6 .}$ & Melons (honeydew, cantaloupe, watermelon) \\
$\mathbf{7 .}$ & Orange
\end{tabular}

\section{VEGETABLES (17)}

1. $\quad$ Asparagus

2. Avocados

3. Bell Peppers

4. Broccoli

5. Cabbage

6. Carrots

7. Cauliflower

8. Corn

9. Green Beans

10. Greens (spinach, kale, lettuce)

11. Mushrooms

12. Onions

13. Peas

14. Potatoes (do NOT count fries or chips)

15. Sweet potatoes (do NOT count fries or chips)

16. Tomatoes

17. Squash (examples: acorn, yellow, butternut, zucchini) 
As the facilitation of PDC in Shandon was performed by a different researcher, a different survey instrument that fit the needs of that project was utilized and the coding differed from that of the Northern Santa Barbara County survey instrument.

Participants in Northern Santa Barbara County were asked how many times, in the past 7 days, they ate a specific fruit or vegetable, and they were prompted to choose one of the following frequencies: "Not at all; once; twice; three times; four times; five or more times." Participants in Northern San Luis Obispo County could choose among, "Don't know what this is; not at all; once; twice; three times; four or more times."

Scores were assigned to each response. The selection of "Not at all" was designated with the score of 0 . The selection of "once" was designated with the score of 1 . The selection of "twice" was designated with a score of 2 . The selection of "three times" was designated with a score of 3 . The selection of "four or more times" was designated with a score of 4 .

The mean reported intake frequency of each specific fruit or vegetable in both the pre- and post- surveys were calculated for each participant with complete (pre- and post-) data. Paired t-tests were utilized to compare means of each variable. STATA 15 was used for statistical analysis.

\section{Program Support and Staff}

The implementation of the Pink and Dude Chefs program required the purchase of instructor manuals, student workbooks, first aid kits, kitchen supplies, hats, and aprons. These items, as well as program coordinator salaries, were purchased through funding by the Orfalea Foundation. 
Additionally, PDC programming required the purchase of food items for each of the twelve lessons. Instructor salaries and lesson food costs were provided by the partner organizations that facilitated the programs.

For the 2015-2016 project in Santa Barbara County, program coordinators initiated technical assistance calls with instructors on a bi-weekly basis at minimum, depending on the pace of the program. Program coordinators communicated special instructions and documented summaries of the previous lesson shared by instructors. Although subjective information with regard to adherence to the lessons was recorded from these meetings, instructor fidelity was not formally measured in this current project.

\section{$\underline{\text { Ethical Considerations }}$}

Prior to recruitment and implementation, the consent forms, curriculum, and survey materials were approved by the Institutional Review Board of California Polytechnic State University, San Luis Obispo (IRB). All youth participants provided their informed assent (Appendix G) prior to their participation. Parents/guardians signed informed consent forms in either English or Spanish allowing their children to participate in the study, after the first lesson (Appendices $\mathrm{H}$ and I). Instructors also signed informed consent forms prior to participating in the study. 


\section{CHAPTER 3}

\section{Results}

From Fall 2015 to Summer 2016, 68 middle school students aged 11-14 years in Northern Santa Barbara County were invited to complete the pre- and post-food frequency questionnaires as part of their participation in PDC. This research also analyzed data from PDC programming that took place from Spring 2014 to December 2015 in Shandon, CA $(n=15)$ (Bierlich-Wesch, 2016). Overall, 93 pre-questionnaires were returned, while 83 post-questionnaires were returned. Of the 83 paired pre- and post- food frequency questionnaires returned by students, 42 were from girls and 41 were from boys. Due to incomplete data, 29 girls' and 29 boys' average fruit intake, and 31 girls' and 23 boys' average vegetable intake could be evaluated. A total of 58 pairs of pre- and post-surveys contained complete data on fruit intake, and 54 pairs contained complete date on vegetable intake.

Food frequency questionnaires were utilized to obtain information about the frequency of participants' weekly fruit and vegetable intake before and after the nutrition and culinary skills intervention. The lowest possible score for each variable was 0 , indicating that a fruit or vegetable was not consumed at all during the past week, or the fruit or vegetable was not known to the participant, to 4 , indicating that a fruit or vegetable was eaten 4 or more times during the past week.

Table 10 shows mean weekly frequency of fruit intake of seven fruits before and after the PDC program among boys and girls combined. Although 70 paired surveys were returned, there were some instances of unselected items on the food frequency questionnaires, resulting in different sample sizes ranging from $58-70$, 
depending on the "fruit" variable. The overall sample size was 58 students, accounting for missing or incomplete data. The first line in Table 10 shows that, on average, apples were consumed 0.2 additional times per week after PDC $(\mathrm{p}=0.06)$. This equates to one out of every five participants eating apples one more time per week more than they did before the PDC program. There was a mean increase in frequency of intake for each fruit, with some analyses reaching statistical significance; the mean intake of grapefruit among boys and girls increased by 0.5 (SD 1.6, $\mathrm{p}=0.01$ ) and mean melon intake increased by 0.3 (SD 1.3, p=0.03) (Table 10). Findings were statistically weaker for the other fruits (apples, bananas, berries, cherries, and oranges). The overall findings were statistically significant. Fruit intake increased by $0.3(\operatorname{SD} 0.9, \mathrm{p}=0.01)$ (Table 10). 
Table 10: Mean weekly fruit intake values from pre-and post-food frequency questionnaire, and change in mean weekly fruit intake for participants in Northern San Luis Obispo County and Northern Santa Barbara County (2014-2016).

\begin{tabular}{|c|c|c|c|c|}
\hline \multirow{2}{*}{ Variable } & Mean Pre. & Mean Post- & Chanoes in & \multirow{2}{*}{$\begin{array}{l}\text { P- } \\
\text { Value }\end{array}$} \\
\hline & Score (SD) & Score (SD) & Mean (SD) & \\
\hline Apple & $2.3(1.3)$ & $2.5(1.2)$ & $+0.2(1.1)$ & 0.06 \\
\hline Banana & $2.3(1.4)$ & $2.5(1.2)$ & $+0.2(1.4)$ & 0.26 \\
\hline Berries & $2.1(1.5)$ & $2.4(1.5)$ & $+0.3(1.7)$ & 0.25 \\
\hline Cherries & $1.2(1.3)$ & $1.3(1.4)$ & $+0.1(1.4)$ & 0.43 \\
\hline Grapefruit & $1.0(1.4)$ & $1.5(1.6)$ & $+0.5(1.6)$ & 0.01 \\
\hline Melons & $1.8(1.5)$ & $2.1(1.4)$ & $+0.3(1.3)$ & 0.03 \\
\hline Orange & $2.5(1.4)$ & $2.7(1.3)$ & $+0.2(1.2)$ & 0.15 \\
\hline $\begin{array}{r}\text { Overall } \\
(n=58-70)\end{array}$ & $1.8(0.9)$ & $2.1(1.0)$ & $+0.3(0.9)$ & 0.01 \\
\hline
\end{tabular}

Similarly, Table 11 shows that most of the 14 vegetables examined were, on average, eaten more frequently after PDC, with six analyses reaching statistical significance. The sample sizes ranged from 54 to 73 paired surveys, depending on the "vegetable" variable. The only vegetable that decreased in frequency of consumption was peas, which decreased from 0.9 (SD 1.2) to 0.8 (SD 1.1, $\mathrm{p}=0.77$ ). The greatest increase in intake was observed with bell peppers, which increased from an average of 0.9 (SD 1.2) to 1.5 (SD 1.3, $\mathrm{p}<0.01$ ). Consumption of bell peppers, broccoli, cabbage, carrots, cauliflower, and sweet potatoes increased (all $\mathrm{p}<=0.04)$, whereas differences were weaker for the other vegetables. Overall, consumption of vegetables increased by $0.3(\mathrm{SD} 0.8, \mathrm{p}=0.01)$. 
Table 11: Mean weekly vegetable intake values from pre- and post-food frequency questionnaire, and change in mean weekly vegetable intake for participants in Northern San Luis Obispo County and Northern Santa Barbara County (2014-2016).

Variable Mean Pre- Mean Post- Changes in $\quad$ P-

\begin{tabular}{|c|c|c|c|c|}
\hline Asparagus & $0.6(1.0)$ & $0.7(1.0)$ & $+0.1(1.1)$ & 0.47 \\
\hline Avocado & $1.6(1.5)$ & $1.7(1.4)$ & $+0.1(1.0)$ & 0.65 \\
\hline Bell Pepper & $0.9(1.2)$ & $1.5(1.3)$ & $+0.6(1.4)$ & $<0.01$ \\
\hline Broccoli & $1.5(1.5)$ & $1.8(1.5)$ & $+0.3(1.2)$ & 0.04 \\
\hline Cabbage & $1.1(1.4)$ & $1.5(1.5)$ & $+0.4(1.3)$ & 0.01 \\
\hline Carrots & $1.9(1.4)$ & $2.3(1.4)$ & $+0.4(1.3)$ & 0.01 \\
\hline Cauliflower & $1.1(1.3)$ & $1.4(1.5)$ & $+0.3(1.1)$ & 0.04 \\
\hline Corn & $1.9(1.4)$ & $2.1(1.5)$ & $+0.2(1.5)$ & 0.26 \\
\hline Green Beans & $1.0(1.3)$ & $1.2(1.5)$ & $+0.2(1.4)$ & 0.32 \\
\hline Greens & $1.7(1.5)$ & $1.9(1.5)$ & $+0.2(1.5)$ & 0.22 \\
\hline Peas & $0.9(1.2)$ & $0.8(1.1)$ & $-0.1(1.2)$ & 0.77 \\
\hline $\begin{array}{r}\text { Sweet } \\
\text { Potatoes }\end{array}$ & $0.7(1.0)$ & $1.0(1.3)$ & $+0.3(1.2)$ & 0.02 \\
\hline Tomatoes & $1.5(1.5)$ & $1.7(1.4)$ & $+0.2(1.4)$ & 0.30 \\
\hline Squash & $0.7(1.0)$ & $0.8(1.1)$ & $+0.1(0.9)$ & 0.36 \\
\hline $\begin{array}{r}\text { Overall } \\
(n=54-73)\end{array}$ & $1.1(0.8)$ & $1.4(0.1)$ & $+0.3(0.8)$ & 0.01 \\
\hline
\end{tabular}


Nearly equal numbers of girls and boys participated in the PDC program; 42 girls and 41 boys were enrolled. Overall, both boys and girls demonstrated an increased frequency of consumption of fruits and vegetables after the PDC program, with some statistically significant findings. The changes documented by the pre- and post food frequency questionnaires are detailed in Table 12; the frequency of consumption of all fruits and vegetables, respectively, presented on the food frequency questionnaire, are represented as a single average. Girls' frequency of overall fruit consumption increased from a mean of 1.8 (SD 0.9) to 2.0 (SD 1.0, p=0.06). Girls' vegetable consumption increased from 1.2 (SD 0.8) to 1.5 ( $\mathrm{SD} 0.9, \mathrm{p}=0.01$ ). Boys' fruit consumption increased from 1.9 (SD 1.0) to 2.2 (SD 1.0, $\mathrm{p}=0.10$ ), and boys' vegetable consumption increased from 1.1 (SD 0.9) to 1.3 ( $\mathrm{SD} 0.8, \mathrm{p}=0.21$ ). 
Table 12: Mean differences in fruit and vegetable intake and changes in mean fruit and vegetable intake as reported in pre-and post-food frequency questionnaires among male and female participants in Northern Santa Barbara County and Northern San Luis Obispo County (2014-2016).

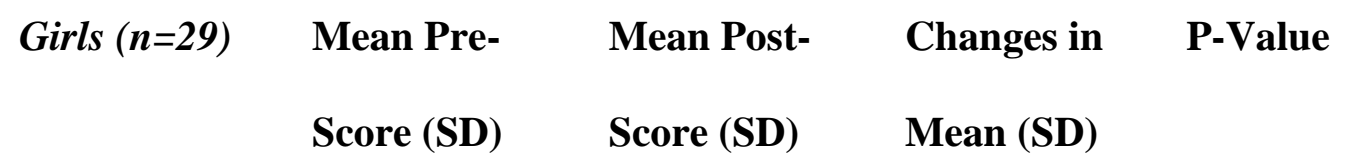

\begin{tabular}{|r|c|c|c|c|}
\hline Fruit $(n=29)$ & $1.8(0.9)$ & $2.0(1.0)$ & $+0.2(0.7)$ & 0.06 \\
\cline { 2 - 4 } Vegetable $(n=31)$ & $1.2(0.8)$ & $1.5(0.9)$ & $+0.3(0.8)$ & 0.01 \\
\cline { 2 - 5 } Overall $(\boldsymbol{n}=27)$ & $\mathbf{1 . 5 ( 1 . 8 )}$ & $\mathbf{1 . 8 ( 0 . 9 )}$ & $+\mathbf{+ 0 . 3 ( 0 . 7 )}$ & $\mathbf{0 . 0 5}$ \\
\cline { 2 - 5 } & & &
\end{tabular}

\begin{tabular}{|c|c|c|c|c|}
\hline Boys $(n=29)$ & $\begin{array}{l}\text { Mean Pre- } \\
\text { Score (SD) }\end{array}$ & $\begin{array}{l}\text { Mean Post- } \\
\text { Score (SD) }\end{array}$ & $\begin{array}{l}\text { Changes in } \\
\text { Mean }\end{array}$ & P-Value \\
\hline Fruit $(n=29)$ & $1.9(1.0)$ & $2.2(1.0)$ & $+0.3(1.0)$ & 0.10 \\
\hline Vegetable $(n=23)$ & $1.1(0.9)$ & $1.3(0.8)$ & $+0.2(0.8)$ & 0.21 \\
\hline Overall $(n=21)$ & $1.5(0.8)$ & $1.7(0.8)$ & $+0.2(0.6)$ & 0.20 \\
\hline
\end{tabular}




\section{CHAPTER 4}

\section{Discussion}

The purpose of this study was to investigate frequency of fruit and vegetable consumption among middle school participants of PDC, an after-school nutrition education and culinary skills program. Prior research on the impact of PDC has examined participants' culinary skill, culinary confidence, food preferences, and frequency of intake of fruits and vegetables. Results from those studies were limited by low participation $(\mathrm{n}<30)$ and low statistical power. This study hoped to fill this gap in knowledge through a multi-site intervention, which would enroll a greater number of participants. In this sample of adolescent participants in this multi-site program $(n=54-$ 73), results indicated increased intake of fruits and vegetables after participation, with overall fruit intake increasing by $0.3(\mathrm{p}=0.01)$ and overall vegetable intake increasing by $0.3(\mathrm{p}=0.01)$ in boys and girls combined.

There was a mean increase in frequency of consumption in every fruit and vegetable on the questionnaire except for peas, even though not all fruits and vegetables in the food frequency questionnaire were introduced as part of the PDC curriculum. Increases in avocado, asparagus, grapefruit, cherries, and melon were observed independent of the foods eaten in class following the cooking practicum, indicating that PDC may have generally improved participants' intake of fruits and vegetables beyond their incorporation in the recipes that the students prepared. Prior PDC research similarly demonstrated general improved preference for fruits and vegetables, regardless of their inclusion in the cooking practicum (Bierlich-Wesch, 2016; Sheehan, 2013). The 2013 evaluation of PDC in Arroyo Grande, CA and 
Carpinteria, CA ( $\mathrm{n}=22)$, showed higher preference for all fruits and most $70 \%$ of vegetables, including cherries ( 0.91 to $1.59, \mathrm{p}=0.03)$ and tangerines, (1.09 to 1.59 , $\mathrm{p}=0.02$ ), which were not included in the cooking practicum (Sheehan, 2013).

Consistent with these findings, 2016 evaluation of PDC in Shandon, CA and Nashville, TN $(\mathrm{n}=29)$ showed a $9.8 \%$ mean increased preference for vegetables $(\mathrm{p}=0.1)$, and a 4.2\% mean increased preference for fruits $(\mathrm{p}=0.1)$, including cherries, which were not included in the cooking practicum (3.5 to 3.5, $\mathrm{p}=0.1$ ) (Bierlich-Wesch, 2016).

This current study showed that the mean increases in fruit intake exceeded increases in vegetable intake. This finding is consistent with the recent CDC report, showing that US children ate $67 \%$ more fruit in 2010 compared to baseline data from 2003, but the vegetable consumption remained unchanged during this period with white potatoes comprising $30 \%$ of total vegetable intake ("Morbidity and Mortality Weekly Report," 2014). While whole fruit intake increased 12\% per year among all socio-demographic groups, total vegetable intake did not change over time, except for a slight but significant decrease among Mexican-Americans and non-Hispanic black children ("Morbidity and Mortality Weekly Report," 2014). This behavior may be influenced by flavor preferences, repeated exposures of fruits over vegetables, availability, and social experiences. The preference for sweet-tasting foods, such as fruits, is a genetic predisposition that also causes children to favor salty foods, while rejecting bitter tastes, which may be found in a variety of vegetables (Birch, 1998).

Although both girls and boys were found to increase frequency of intake of all seven fruits and all but one of the 14 vegetables on the food frequency questionnaire, girls reported a larger mean increase with stronger p-values of fruits and vegetables 
combined $(+0.3, \mathrm{SD} 0.7, \mathrm{p}=0.05)$, compared to their male peers $(+0.2, \mathrm{SD} 0.6, \mathrm{p}=0.20)$. While this difference in overall fruit and vegetable consumption by gender has not been shown in previous PDC studies, it has been demonstrated in other literature (M. Rasmussen et al., 2006; Vereecken et al., 2015). The only other PDC evaluation to assess results based on participant gender resulted in p-values that were greater than 0.6, which suggested no difference between the dietary behaviors of girls and boys after the program (Figure 8) (Bierlich-Wesch, 2016).

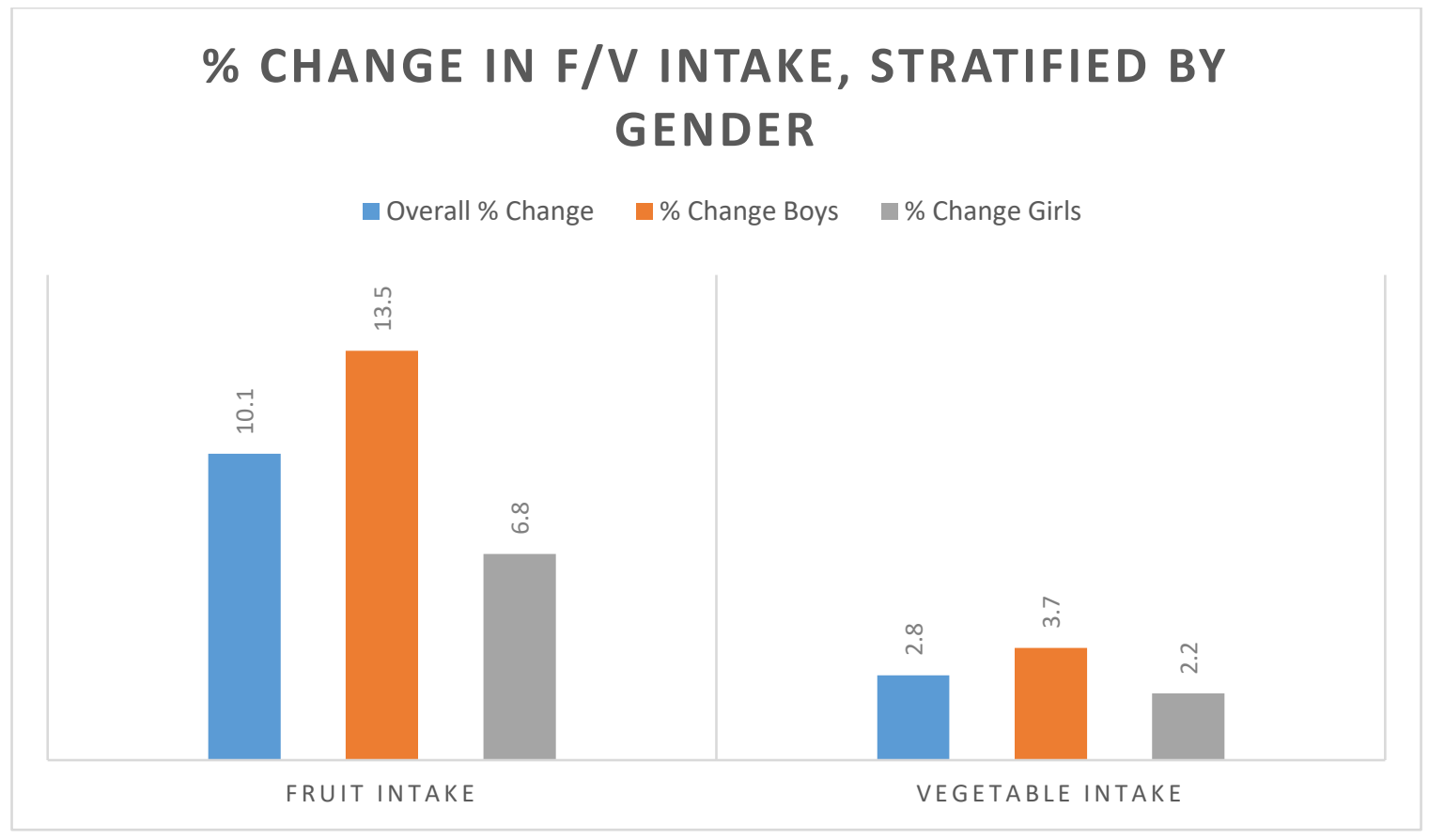

Figure 8: Percent change in mean scores for pre-and post-survey questions on individual question scores for participants in California and Tennessee) stratified by sex (female n=11-16, male n=9-14) from Spring 2014 to Fall 2016 ( $p=0.6)($ Bierlich-Wesch, 2016)

However, consistent with the results of this study, a meta-analysis on nutrition education interventions with outcome measures of fruit and vegetable consumption found that girls report higher or more frequent intake of fruits and/or vegetables than boys in 27 of the 49 studies on gender differences in fruit and vegetable consumption (M. Rasmussen et al., 2006). Eighteen of these studies reported no differences between 
boys and girls, while four papers found higher or more frequent consumption of fruits and vegetables in boys (M. Rasmussen et al., 2006). Additionally, data obtained from the Health Behaviour in School-Aged Children (HBSC) study of 488,591 adolescents from 33 countries showed that across all countries, girls were more likely to consume fruit and vegetables than boys $\left(\mathrm{OR}^{\text {fruit }}=1.39,99 \% \mathrm{CI}: 1.37-1.41 ; \mathrm{OR}^{\text {vegetables }}=1.38,99 \%\right.$ CI: 1.36-1.41) (Vereecken et al., 2015). These results that showed that females may report more frequent consumption of fruits and vegetables than males was in agreement with previous studies in which females were observed to over-document consumption of fruits and vegetables, while under-documenting meat, dairy, and energy intake (Feskanich et al., 1993). This study showed that girls reported less frequent consumption of fruits than boys overall, in both the pre- and post- surveys, but girls also reported a larger mean increase with stronger p-values than boys.

Results from other obesity prevention programs also show that the promotion of "healthy," low-calorie diets, and those that attempted to decrease sedentary behavior and/or increase physical activity were more impactful for female participants compared to male participants (French, Story, \& Perry, 1995). While it is possible these conclusions may represent chance findings, the observation that many obesity prevention programs are more effective for female participants is in accordance with the evidence that females are subjected to greater sociocultural pressures to achieve thinness (Thompson, Heinberg, Altabe, \& Tantleff-Dunn, 1999). Therefore, program outcomes may be amplified in female participants, who are already highly motivated to engage in the desired behavioral changes. Female body dissatisfaction results from concerns of being overweight, while male body image concerns are largely related to a 
desire to gain weight, which may be at odds with the desired outcomes of obesity prevention programs (Perry et al., 1998; Thompson et al., 1999).

The improved dietary patterns that resulted from this nutrition knowledge and culinary skills program may reduce the participants' risk of obesity-related diseases as adults. The results indicated that fruit and vegetable consumption among participants did increase over the duration of the program. Future research should illustrate the longer-term effects of this and similar programming.

\section{$\underline{\text { Limitations }}$}

Incomplete data due to participant attrition was a limitation of this study, which aimed to provide more conclusive data with its larger sample size than previous iterations. Some participants joined PDC after the first lesson, so baseline food frequency information was not collected. Other participants stopped attending PDC before the final lesson, so they did not complete a post- questionnaire. Incomplete paired surveys were not included in the analysis, which also occurred in previous PDC evaluations. Ten unpaired surveys were not evaluated in this current study, while fourteen participants were lost to attrition in the 2008 evaluation (Chessen, 2008) and while attrition was discussed in the 2013 and 2016 evaluations, the exact numbers of unpaired surveys were not made available. The PDC curriculum was designed to cover core skills sequentially, so if a student missed one class, it may have been difficult for that student to attain the same competence as their peers who were present. Prior PDC research showed that a high attendance rate $(>75 \%)$ may have explained increased correct answers in the knowledge portion of the survey (Figure 9) (Chessen, 2008). 


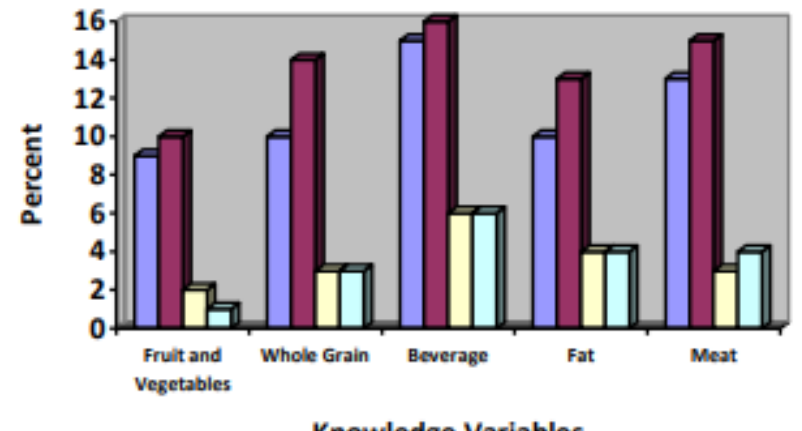

\begin{tabular}{|l|}
\hline$\square$ Pre-"High Attendance" \\
$\square$ Post-"High Attendance" \\
$\square$ Pre-"Low Attendance" \\
$\square$ Post-"Low Attendance" \\
\hline
\end{tabular}

Figure 9: Comparison of "High Attendance" students who were present for at least $75 \%$ of PDC lessons (n=16), to "Low Attendance" students, who represented the remaining students (n=6) (Chessen, 2008)

Although instructors were recommended to keep attendance and encourage participation through all of the twelve lessons, this was difficult to implement and subsequently difficult to assess. Some students inevitably left the program due to conflicting afterschool activities, commonly citing baseball, theater, and study groups as alternative after-school options, which was also documented in prior research of the PDC program (Bierlich-Wesch, 2016; Chessen, 2008). Therefore, post-survey data may have been impacted by irregular attendance by some students.

Another limitation in the analysis of combined data sets were the inconsistent survey instruments between different studies. Each researcher modified the survey instruments in response to the evolving needs for data, which served to diversify the body of knowledge available for PDC, but it also prevented a cohesive program analysis. For example, the food frequency questionnaire that was the focus of the current project was not implemented until 2013. Additionally, the food frequency questionnaires in 2013, 2014, and 2015 differed slightly from one another, both in the specific variables chosen and the corresponding response variables that could be selected by participants. When the data were combined, the "five or more times" 
responses were categorized with "four or more times," and the "don't know what this is" responses were combined with "not at all". This may have led to residual error, but would be difficult to quantify.

Recruiting unique students to participate each cohort was a challenge in Cuyama, CA, and Guadalupe, CA, which are rural regions with small population sizes. Instructors reported difficulty in identifying and recruiting new students to participate in their second and third cohorts. Many students were welcomed to participate in more than one PDC cohort, due to the limited number of middle school students in these areas. However, the utilization of survey information from returning students was a potential source of error, because repeated exposure to new foods is associated with increased preferences and intake of those foods (Caton et al., 2014; Holley, Farrow, \& Haycraft, 2017). To ensure analyses reflected one exposure to PDC curriculum, only data from the students' initial pre- and post-surveys were included in the final analysis. Instructors reported that allowing students to return to the program was a positive experience for new students, who benefitted from peer-to-peer leadership.

The post-survey was administered on the final PDC lesson, so results reflect students' knowledge, confidence, and eating patterns while they were still immersed in the course. While the long-term impact of PDC has been assessed qualitatively through a structured interview, it not yet been assessed quantitatively.

The feasibility of obtaining the ingredients at home, particularly due to geographical limitations and cultural acceptance, is unknown. Parent interviews often revealed positive attitudes regarding reducing salt in cooking, replacing cooking oils high in saturated fat (lard) with cooking spray and plant-based oils, and the inclusion 
of their children's assistance in the home-cooking process. However, among Hispanic parents, there were frequent comments revealing that the inclusion of the fruits and vegetables from the PDC class were limited to iterations of PDC recipes, and not their personal cooking. This may mean that the ingredients used in class were not easily transferred to home cooking.

\section{$\underline{\text { Strengths }}$}

Strengths of PDC include its theory-grounded approach, focus on developing core competency culinary skills, and emphasis on reducing barriers to the consumption of fruits and vegetables. Culinary skills programs have been shown to be key components of nutrition education programs, but perhaps due to the additional resources, facilities, and skills required to facilitate a cooking practicum, they are often under-emphasized in the literature, and most, like the current study, are evaluation studies while fewer controlled trials exist. This study also utilized an online training platform for instructors, which supports efforts to scale the program beyond its primary locations in California and Tennessee (Chen, 2017). Finally, the PDC curriculum facilitates the reinforcement of the educational and skill-based content at home by providing interactive companion workbooks for the students. Participants could take their workbooks home to share the class recipes and content with their families, as well as work on related behavioral goals that were provided for each lesson.

This project supports the existing body of research on PDC outcomes by providing a larger sample size of participants $(n=58$, accounting for incomplete data sets), amounting to nearly double the number of participants in prior research (2008 $\mathrm{n}=22 ; 2013 \mathrm{n}=23 ; 2014 \mathrm{n}=32$ ). This was achieved through strong community-based 
partnerships that enabled implementation at five sites on the Central Coast of California. The student participants were equally distributed among girls and boys. Previous research focused on dietary preferences, culinary confidence, instructor outcomes, and food safety knowledge, establishing that adolescents' motivation and competence to increase their fruit and vegetable intake were improved, yet due to small sample sizes, it has not been determined whether this intervention improves dietary intake of fruits and vegetables. This research focuses on improved dietary patterns as the primary outcome of interest, and bolsters the sample size by including prior data to the fullest extent possible, which added 15 participants' survey data.

Previous evaluations of PDC have demonstrated positive student outcomes, and results from this current project may provide additional theoretical basis to make improvements in future iterations. PDC has consistently demonstrated improved attitudes toward fruits, vegetables, and trying new foods among its middle school participants. The 2008 evaluation $(\mathrm{n}=22)$ showed that PDC resulted in improved culinary confidence to make healthy dietary changes, with a +3.273 self-rating on a scale of 0 to 5 ( $\mathrm{p}=0.005)$ (Chessen, 2008). The 2013 program evaluation $(\mathrm{n}=23)$ showed increases in mean culinary confidence, nutrition knowledge, fruit intake, and fruit and vegetable preferences, with the most significant findings among preferences for the seven fruit variables (overall change in mean $+3.00, p=0.01$ ) (Sheehan, 2013). The 2016 evaluation $(n=23)$ showed an increased overall mean nutrition knowledge score from 3.8 (SD 0.9) to 5.1 (SD 1.1), with a significant p-value of 0.0002, representing a 34.2\% change in mean score (Bierlich-Wesch, 2016). 
Additionally, longer-term study assessing the program's impact three months after the final lesson indicates that positive student outcomes persist beyond the classroom, with all surveyed participants $(\mathrm{n}=8)$ reporting culinary confidence and skills, assisting with home cooking, and making healthy food substitutions (Gentry, 2017).

A strength of culinary-focused nutrition programs like PDC is that impacts may go beyond the improved knowledge, attitudes, and skills that often comprise the general outcomes of interest. A 2016 systematic review that investigated the effects of youth culinary programs $(\mathrm{n}=20)$ also showed many positive social, emotional, and cultural outcomes in qualitative program evaluations. Noteworthy findings included the enjoyment of cooking and tasting new foods $(n=4)$ and the enhancement of peer relationships and team building skills found in most studies (J. Utter, A. Fay, 2016). The study also highlighted the Cooking Communities program, which showed increased awareness of cultural events and cultural foods after participation, while the Cook. Eat. Together program showed that participants were able to recognize their own culture as a resource for their health after participation (J. Utter, A. Fay, 2016). It was an important finding that culinary-focused nutrition interventions could strengthen social and cultural ties while presenting cooking as an enjoyable activity, because the child and adolescent participants of the program, regardless of clinical categorization of BMI, may be susceptible to negative emotional outcomes related to body image (Gall et al., 2016; Myers \& Rosen, 1999). Valuing mental and social outcomes in addition to the physical condition is consistent with the World Health Organization's definition of health, which is "a state of complete physical, mental, and social wellbeing and not merely the absence of disease or infirmity," (2003). 


\section{$\underline{\text { Implications }}$}

Because dietary patterns established during adolescence often transfer into adulthood, adolescence is an important age period to facilitate behavioral changes related to diet (He et al, 2006). Diets that are high in fruits and vegetables are associated with lower risks of cancer, stroke, obesity, coronary heart disease, as well as other chronic diseases (Lien, Lytle, \& Klepp, 2001). However, the majority of US adolescents fail to meet the recommendations for daily intake of fruits and vegetables (CDC). National nutrition surveys indicate that the diets of many young adults are excessively high in high-fat and high-salt foods, sugar-sweetened beverages, while low in fruits, vegetables, and whole grains (Larson et al., 2006). Convenience foods and other foods prepared outside of the home are often higher in energy, added sugar, and fat, than homemade meals. Learning how to prepare foods from scratch, as well as repeating exposures to fruits and vegetables, can change dietary habits and decrease the risk of chronic disease.

Emerging research suggests that culinary self-efficacy during young adulthood may be associated with indicators of nutritious dietary habits in adulthood. Data collected from the Project Eating and Activity in Teens and Young Adults (EAT) longitudinal study associated self-perceived cooking skills in emerging adulthood (1823 years) with diet quality in later adulthood (30-35 years) (Utter, Larson, Laska, Winkler, \& Neumark-Sztainer, 2018). Study participants $(n=211)$ could rate their cooking skills as "very inadequate, inadequate," "adequate," or "very adequate" (Utter et al., 2018). Rating "very adequate" cooking skills in emerging adulthood was associated with greater odds of preparing a meal with vegetables most days during 
adulthood, compared to the "very inadequate, inadequate" reference population (OR 3.5, 95\% CI 2.1-5.9, p<0.001). Similarly, rating "adequate" cooking skills in emerging adulthood was associated with less frequent consumption of fast food per week (OR $0.6,95 \%$ CI 0.4-0.9, p<0.001) (Utter et al., 2018). The enduring association between culinary self-efficacy and positive dietary behaviors later in life provides promising theoretical basis for culinary-focused intervention studies, which are often limited in their ability to provide longer-term impact analyses due to small sample sizes.

The long-term impact of PDC was qualitatively assessed among participants of a cohort in Nashville, TN, through interviews 12 weeks post-intervention (Gentry, 2017). The purpose of this assessment was to determine the extent to which participants continued to cook at home, maintained healthy dietary patterns, and sustained culinary skills from the program (Gentry, 2017). All participants $(\mathrm{n}=8)$ reported that they continued to assist with home cooking, thought about PDC when they cooked at home, and maintained confidence in their cooking abilities (Gentry, 2017). All participants reported making healthy substitutions in their recipes, while 5 out of the 8 participants reported thinking about PDC while they made these substitutions (Gentry, 2017). These findings suggest that PDC may have long-term impacts on dietary patterns of its adolescent participants, and a longer-term follow-up study is needed to elucidate any impact of PDC on dietary patterns as participants reach young adulthood. 


\section{$\underline{\text { Recommendations }}$}

Research

Evidence of PDC's effectiveness, as well as similar community nutrition efforts, could benefit from the implementation of experimental design. Few community nutrition interventions utilize rigorous study designs that use randomization or have control groups, and this is a problem faced by community health educators who wish to improve their practice based on evidence (Garcia, Reardon, McDonald, \& Vargas-Garcia, 2016).

Due to the challenge of implementing an experimental design in afterschool programs, which are limited in the designation of control groups due to small sample sizes, all PDC studies to date have been 'program evaluations.' These studies are beneficial because they provide an indication of what is likely to be achieved in daily practice of the curriculum. For example, the current study extracted qualitative data from student, parent, and instructor interviews that provided insight into the opinions of participants about the program. However, an experimental design utilizing random allocation could have more precisely corrected for confounding variables that are common in community nutrition intervention settings. The experimental study design could also support a cause-and-effect relationship related to the outcomes of improved dietary behavior. An example of a youth nutrition and culinary intervention that utilized an experimental study design is LA Sprouts, although participants were not randomly assigned to their respective groups (Nelson et al., 2013). All youth who were enrolled in the same school as those in the after-school program, but who were not participants of LA Sprouts, were treated as a control group and administered a pre- and 
post- survey at the same interval as the participants (Davis et al., 2011). Finally, because this study was based on self-reported data through food frequency questionnaires, future research utilizing an experimental study design may improve the accuracy of reported data by obtaining information on observed behaviors.

Additionally, a longitudinal study assessing the effectiveness of the nutrition education and culinary skills program on diet quality, utilizing both quantitative and qualitative survey methods, would provide an ideal program evaluation, but this would be more difficult to implement. Qualitative approaches can include food diaries, focus groups, and interviews focused on cooking-related beliefs among parents and middle school participants. Quantitative approaches can include the food frequency questionnaire with portion sizes as well as anthropometric measurements and BMI. However, in the adolescent age range, weight and BMI are not typically useful or recommended (D S Freedman et al., 2005).

Because dietary behavior is influenced by social and cultural factors, it is plausible that differences exist between various geographical and ethnic subpopulations among different socioecomonic statuses. Future research could benefit from increasing representation of more middle school students by recruiting participants in other regions of the United States. This methodology may align with current efforts to scale up the PDC program, and would show whether the results found in this study can be demonstrated in other populations. A study on demographic differences in individual, social, and environmental factors possibly related to fruit and vegetable intake in middle school students $(\mathrm{n}=736)$ indicated that African-American students reported more social influences than their white peers (Granner et al, 2004). 
Additionally, white adolescents reported more family environmental influences on fruit and vegetable intake than their African-American peers (Granner \& Sharpe, 2004). Females and white participants reported higher preference for vegetables than African-American and male participants (Granner \& Sharpe, 2004). Decreases in influence of family, concurrent with increases in social influences that may discourage fruit and vegetable intake during this age range (11-15 years), underscores the importance of intervention for this age group, across a variety of demographics.

The program's design could furthermore be improved by implementing a process evaluation, to ensure that PDC has been administered as planned and to quantify differential impacts on diverse populations. This is especially pertinent if the program continues to expand to diverse geographical areas, and more supervisory duties are delegated to a greater number of facilitators.

Programs

Food education has demonstrable utility in the educational system, yet it has not been emphasized as an essential component of international educational systems for the past four decades (Worsley, Wang, Yeatman, Byrne, \& Wijayaratne, 2015). Research has repeatedly shown that individuals with basic culinary skills training are more likely to consume healthy foods (Davis et al., 2011; Meiklejohn, Ryan, \& Palermo, 2016). Individuals who have attained competency in nutrition knowledge are 23 times more likely to consume the daily recommendations of fruits and vegetables than their counterparts who do not have this nutrition knowledge (J. Wardle, Parmenter, \& Waller, 2000). The "obesity-hunger paradox" that arises from geographical and socioeconomic disparities in which affordable, nutritious alternatives 
to fast and convenience foods are not available, is compounded by a lack of culinary knowledge in preparing inexpensive meals (Lichtenstein \& Ludwig, 2010). Nevertheless, modern educational curricula reflect the replacement of home economics with more scientific subjects, such as food technology and sometimes nutrition (Worsley et al., 2015). The inclusion of culinary education in the form of cooking demonstrations as well as hands-on cooking has shown positive changes in dietary behavior in adults and children alike (Eisenberg, Myrdal Miller, McManus, Burgess, \& Bernstein, 2013). However, students are not obligated to engage in coursework focused on skills to facilitate healthy lifestyle choices.

A modern home economics curriculum devoid of gender-specific stereotypes may include basic cooking techniques, food safety, nutrition, and budgeting (Lichtenstein \& Ludwig, 2010). These multidisciplinary topics do not necessarily need to be taught in one home economics course, rather, they can reach a wider audience when incorporated into core biology, chemistry, economics, math, social studies, and physical activity coursework (Lichtenstein \& Ludwig, 2010). In cooperation with required coursework, the nutrition and culinary skills training would therefore become mandatory without competing with other curricular obligations.

Several challenges are faced by educators who plan and implement health programming for youth and their families in rural, agricultural areas, in which children are $25 \%$ more likely to be overweight or obese than their suburban and urban counterparts (Peters et al., 2016; Smathers, C., Lobb, 2017). For example, families who earn their primary income from the agricultural industry are often bound to their farms and ranches during certain times of the year, which prevents them from traveling 
to program sites (Benke et al., 2013). Additionally, the infrastructure and geography of rural areas contribute to poor nutrition and physical inactivity (Peters et al., 2016).

The Cooperative Extension System (CES) provides protocol in designing researchbased programming that is accessible to rural families. CES, which was established following the 1914 Smith-Lever Act, aims to provide the benefits of research-based knowledge disseminated within land-grant universities to community members who do not attend those institutions, including youth, and continue to provide that information over the lifetime in order to create positive changes (W. D. Rasmussen, 1989). As part of its overall goals, CES provides nutrition education, food safety training, and youth leadership development (W. D. Rasmussen, 1989).

CES has implemented and researched in-school nutrition outreach programs, which may serve as evidence-based resources in the planning of similar programming. The Shaping Healthy Choices Program (SHCP), which aimed to, among other objectives, increase nutrition knowledge, promote the availability, consumption, and enjoyment of fruits and vegetables, and improve dietary patterns showed promise as a model for school-based obesity prevention (Bergman et al., 2018). Over four months, the following strategies were utilized to help students identify regional fruits and vegetables: classroom nutrition education, cooking demonstrations, family newsletters, facilitation of a lunchtime salad bar as well as other lunchroom enhancements, procurement of local produce, formation of a school-site wellness committee, and a community health fair (Bergman et al., 2018). Students in $4^{\text {th }}-6^{\text {th }}$ grade from four elementary schools $(\mathrm{n}=242)$ showed significant increases in nutrition knowledge and after participation in SHCP (Bergman et al., 2018). Additionally, the percentage of 
students able to identify the target vegetables significantly increased for five of the 10 local produce items (Bergman et al., 2018).

Another CES program, “Just Be It!” for fifth graders (n=2079) brought twelve to fourteen health lessons to the classroom between 2006-2009 (DelCampo, D. Baca, J., Jimenez, D., Sánchez, P. DelCampo, 2011). The content included nutrition information, how to make a healthy snack, and how to make time for physical activity. Researchers created a developmentally appropriate survey instrument, which resulted in more accurate estimates of fruit and vegetable intake and physical activity time from students in the 2009 iteration, compared to 2006-2008 (DelCampo, D. Baca, J., Jimenez, D., Sánchez, P. DelCampo, 2011). Students' nutrition knowledge significantly increased by $6.05(\mathrm{p}=0.0001)$ in 2007 and by $5.36(\mathrm{p}=0.0001)$ in 2008 (DelCampo, D. Baca, J., Jimenez, D., Sánchez, P. DelCampo, 2011). Additionally, fruit intake increased by $0.40(\mathrm{p}=0.0016)$, vegetable intake increased by 0.49 ( $\mathrm{p}=0.0001)$, and physical activity increased by 0.32 ( $\mathrm{p}=0.101)$ (DelCampo, D. Baca, J., Jimenez, D., Sánchez, P. DelCampo, 2011). Parents received health information corresponding to the lessons through newsletters, handouts, brochures, and parent night. Parents also showed increased nutrition knowledge as a result of this outreach: in 2007 , the increase was $27 \%$ (26\% return rate), and in 2008 the increase was $22 \%$ ( $56 \%$ return rate), and finally in 2009 , the increase was $24 \%$ (47\% return rate) (DelCampo, D. Baca, J., Jimenez, D., Sánchez, P. DelCampo, 2011). Strengths of the study included the in-school lessons, which enabled the program to be accessible to all students, the age-appropriate Likert scale that was used on the 2009 survey instrument, and the parent involvement through newsletters, meetings, and evaluations 
(DelCampo, D. Baca, J., Jimenez, D., Sánchez, P. DelCampo, 2011). “Just Be It!” and SHCP may provide useful models for implementing core nutrition concepts in a variety of in-school settings, without the requirement of a dedicated course such as home economics.

After-school culinary arts and nutrition education programs like PDC may benefit from advancing their action-competence approaches by formalizing student leadership roles for returning participants. Several students were observed to participate in PDC's full twelve lesson curriculum more than one time, and instructors reported that these students enjoyed guiding their peers, who were learning basic culinary skills for the first time. In addition to instructors' positive regard for peer-to-peer learning, increasing returning participants' responsibilities may have positive effects on both personal and program outcomes. Although there are few studies that measure the effectiveness of youth involvement in school- and community-based preventative health programs, benefits of defining higher levels of youth engagement and participation have been documented.

A 2016 systematic review of empirical studies $(n=12)$ that focused on school- and community-based nutrition and physical activity interventions showed positive effects ranging from school and community policy changes related to environmental modifications, to individual behavioral changes in students (Jourdan et al., 2016). Children's involvement was categorized in a manner consistent with Carmel, Whitaker, and George's user-involvement spectrum, and with Hart's 'Ladder of Children's Participation" (Jourdan et al., 2016). The resulting levels of participation were "consultative," "representative," and "participatory consensus" (Jourdan et al., 
2016). However, the "consultative" level, which is characterized by youth participants providing and receiving information about the program's intervention design, planning, and implementation, was not considered for inclusion in the review because the act of informing participants does not represent genuine youth involvement (Jourdan et al., 2016). The "representative" participation level was defined as informing youth participants, who then provided suggestions to the adult stakeholders, but the youth themselves did not directly engage in program decision-making (Jourdan et al., 2016). The "participatory consensus" level, which was the highest level of engagement, was defined as youth participants having an active role in the development process of an intervention (Jourdan et al., 2016). Examples of youth involvement at the "participatory consensus" level included the students conducting a needs assessment through surveys of their peers, defining problems to prioritize, making decisions about health strategies, and "power-sharing" activities (Jourdan et al., 2016).

Additionally, a 2017 systematic review $(n=26)$ showed that student participation in health promotion at school resulted in improved cognitive outcomes, self-efficacy, and sense of ownership, suggesting that a high level of decision-making about the design and implementation of the program contributed to its effectiveness (Griebler, Rojatz, Simovska, \& Forster, 2017). Outcomes of interest included personal effects on students ( $\mathrm{n}=18)$, effects on the school as an organization ( $\mathrm{n}=11)$, effects on interactions and relationships, including peer-to-peer relationships and student-adult relationships $(n=9)$, and effects on other stakeholders $(n=6)$, while no negative effects were identified in any article (Griebler et al., 2017). Expanding program expectations for 
"participation," which is often limited to the act of taking part in the nutrition lecture and activities, to being recognized as influential collaborators with other students and instructors, may result in personal benefits in children from improved skills, competence, knowledge, motivation, satisfaction, and influence on student perspectives towards health (Griebler et al., 2017).

Policy

Programs that promote increased consumption of fruits and vegetables currently emphasize individually-oriented behavioral and educational approaches. The successes of individual- and focus group- level nutrition education interventions have been widely studied and well-documented; well-designed programs that focus on improved fruit and vegetable intake have been shown to significantly increase fruit and vegetable intake among participants (Garcia et al., 2016). However, there is a discernable gap in the literature describing studies addressing the impact of policy, environmental, and food pricing interventions in grocery stores and restaurants on dietary patterns. Participatory targets for cooking skill interventions often reside in areas of social disadvantage, and skill development alone cannot reverse affordability constraints or directly achieve behavioral change. Research is needed to develop and identify community- and country- level programs to achieve results similar to the successful, yet disconnected, multitude of community interventions. 


\section{Summary}

Increasing intake of fruits and vegetables is a key strategy to improve health, yet intake of fruits and vegetables remains below the recommended levels, especially among socioeconomically disadvantaged groups who are often the target participants for culinary skills programs. The purpose of nutrition education and culinary skills programs is to expose participants to core cooking techniques and new foods, which may facilitate adherence to national guidelines for fruit and vegetable consumption. Pink and Dude Chefs, an afterschool nutrition education and culinary skills program for middle school students, has demonstrated improved fruit and vegetable intake among its participants in a variety of geographical locations in California and Tennessee. Adolescent obesity prevention programs promoting nutrition theory combined with a cooking practicum may be found to cause a decreased risk for obesity and related co-morbidities in adulthood, and if the results found in this current study continue to be repeatable, they should be a key strategy in the design of future, culturally-relevant interventions and programs. 


\section{REFERENCES}

Baranowski, T., Cullen, K. W., Nicklas, T., Thompson, D., \& Baranowski, J. (n.d.). School-based obesity prevention: a blueprint for taming the epidemic. American Journal of Health Behavior, 26(6), 486-93. Retrieved from http://www.ncbi.nlm.nih.gov/pubmed/12437023

Benke, C. J., Bailey, S. J., Martz, J., \& Lynch, W. (2013). Developing a parent-centered obesity prevention program for 4- $H$ families: Implications for extension family programming (51.3, Vol. 51). Journal of Extension. Retrieved from http://www.joe.org/joe/2013june/a8.php

Bergman, J. J., Scholar, P., Linnell, J. D., Scherr, R. E., Ginsburg, D. C., Brian, K. M., ... Soule Advisor, K. (2018). Feasibility of Implementing a School Nutrition Intervention That Addresses Policies, Systems, and Environment. Retrieved from https://www.joe.org/joe/2018february/pdf/JOE_v56_1a6.pdf

Best, John R., Theim, Kelly R., Gredysa, Dana M., Stein, Richard I., Welch, R. Robinson, Saelens, Brian E., Perri, Michael G., Schechtman, Kenneth B., Epstein, Leonard H., Wilfley, D. E. (2012). Behavioral economic predictors of overweight children's weight loss. Journal of Consulting and Clinical Psychology, 60(6), 10861096. Retrieved from http://psycnet.apa.org/doiLanding?doi=10.1037\%2Fa0029827

Bierlich-Wesch, J. (2016). PINK AND DUDE CHEFS: IMPACT OF A NUTRITION AND CULINARY EDUCATION PROGRAM WITH MIDDLE SCHOOL STUDENTS IN AN AFTERSCHOOL SETTING in Agriculture with Specialization in Food Science and Nutrition. Retrieved from http://digitalcommons.calpoly.edu/cgi/viewcontent.cgi?article=2696\&context=these s

Birch, L. L. (1998). Psychological Influences on the Childhood Diet. The Journal of Nutrition, 128(2), 407S-410S. https://doi.org/10.1093/jn/128.2.407S

Bleich, S. N., Segal, J., Wu, Y., Wilson, R., \& Wang, Y. (2013). Systematic Review of Community-Based Childhood Obesity Prevention Studies. Pediatrics, 132(1), e201e210. https://doi.org/10.1542/peds.2013-0886

Bronfenbrenner, U. (1979). The Ecology of Human Development. Harvard University Press1, 15-23. Retrieved from https://khoerulanwarbk.files.wordpress.com/2015/08/urie_bronfenbrenner_the_ecol ogy_of_human_developbokos-z1.pdf

Caton, S. J., Blundell, P., Ahern, S. M., Nekitsing, C., Olsen, A., Møller, P., ... Hetherington, M. M. (2014). Learning to Eat Vegetables in Early Life: The Role of Timing, Age and Individual Eating Traits. PLoS ONE, 9(5), e97609. https://doi.org/10.1371/journal.pone.0097609

Chen, J. (2017). PINK AND DUDE CHEFS: EFFICACY OF AN ONLINE TRAINTHE-TRAINER MECHANISM AND STUDENT PROGRAM OUTCOMES, 
(June).

Cheryl, F., Carroll, M., \& Ogder, C. (2016). Prevalence or Overweight and Obesity Among Children and Adolescents Aged 2-19 Years: United States, 1963-1965 Through 2013-2014. Health E-Stats.

Chessen, J. A. (2008). THE DEVELOPMENT AND PILOT OF A CULINARY INTERVENTION DESIGNED Specialization in Food Science and Nutrition. Retrieved from http://digitalcommons.calpoly.edu/cgi/viewcontent.cgi?article $=1078 \&$ context $=$ these $\mathrm{s}$

Condrasky, M. D., \& Hegler, M. (n.d.). April 2010 Volume 48 Number 2 Article Number 2COM1 How Culinary Nutrition Can Save the Health of a Nation What Culinary Nutrition Means. Retrieved from https://www.joe.org/joe/2010april/pdf/JOE_v48_2comm1.pdf

Cunningham, S. A., Kramer, M. R., \& Narayan, K. M. V. (2014). Incidence of Childhood Obesity in the United States. New England Journal of Medicine, 370(5), 403-411. https://doi.org/10.1056/NEJMoa1309753

Davis, J. N., Ventura, E. E., Cook, L. T., Gyllenhammer, L. E., \& Gatto, N. M. (2011). LA Sprouts: A Gardening, Nutrition, and Cooking Intervention for Latino Youth Improves Diet and Reduces Obesity. Journal of the American Dietetic Association, 111(8), 1224-1230. https://doi.org/10.1016/j.jada.2011.05.009

De Backer, C. J. S. (2013). Family meal traditions. Comparing reported childhood food habits to current food habits among university students. Appetite, 69, 64-70. https://doi.org/10.1016/J.APPET.2013.05.013

DelCampo, D. Baca, J., Jimenez, D., Sánchez, P. DelCampo, R. (2011). Just Be It! Healthy and Fit Increases Fifth Graders' Fruit and Vegetable Intake, Physical Activity, and Nutrition Knowledge. Journal of Extension, 49(1). Retrieved from https://www.joe.org/joe/2011february/rb5.php

Deurenberg, P., Yap, M., \& Van Staveren, W. (n.d.). Body mass index and percent body fat: a meta analysis among different ethnic groups. Retrieved from https://www.nature.com/ijo/journal/v22/n12/pdf/0800741a.pdf

Dietz, W. H., \& Bellizzi, M. C. (1999). Introduction: the use of body mass index to assess obesity in children. The American Journal of Clinical Nutrition, 70(1), 123S-5S. Retrieved from http://ajcn.nutrition.org/content/70/1/123s.full

Driskell, M.-M., Dyment, S., Mauriello, L., Castle, P., \& Sherman, K. (2007). Relationships among multiple behaviors for childhood and adolescent obesity prevention. https://doi.org/10.1016/j.ypmed.2007.07.028

Duderstadt, K. G. (2007). Health of U.S. Children from the Global View. Journal of Pediatric Health Care, 21(6), 403-406. https://doi.org/10.1016/J.PEDHC.2007.08.012

Ebbeling, C. B., Pawlak, D. B., \& Ludwig, D. S. (2002). Childhood obesity: publichealth crisis, common sense cure. The Lancet, 360(9331), 473-482. https://doi.org/10.1016/S0140-6736(02)09678-2 
Eisenberg, D. M., Myrdal Miller, A., McManus, K., Burgess, J., \& Bernstein, A. M. (2013). Enhancing Medical Education to Address Obesity: "See One. Taste One. Cook One. Teach One.” JAMA Internal Medicine, 173(6), 470. https://doi.org/10.1001/jamainternmed.2013.2517

Epstein, L. H., Gordy, C. C., Raynor, H. A., Beddome, M., Kilanowski, C. K., \& Paluch, R. (2001). Increasing Fruit and Vegetable Intake and Decreasing Fat and Sugar Intake in Families at Risk for Childhood Obesity. Obesity Research, 9(3), 171-178. https://doi.org/10.1038/oby.2001.18

Epstein, L. H., Valoski, A., Wing, R. R., \& McCurley, J. (1990). Ten-Year Follow-up of Behavioral, Family-Based Treatment for Obese Children. JAMA: The Journal of the American Medical Association, 264(19), 2519.

https://doi.org/10.1001/jama.1990.03450190051027

Feskanich, D., Rimm, E. B., Giovannucci, E. L., Colditz, G. A., Stampfer, M. J., Litin, L. B., \& Willett, W. C. (1993). Reproducibility and validity of food intake measurements from a semiquantitative food frequency questionnaire. Journal of the American Dietetic Association, 93(7), 790-6. Retrieved from http://www.ncbi.nlm.nih.gov/pubmed/8320406

Finkelstein, E. A., Khavjou, O. A., Thompson, H., Trogdon, J. G., Pan, L., Sherry, B., \& Dietz, W. (2012). Obesity and Severe Obesity Forecasts Through 2030. American Journal of Preventive Medicine, 42(6), 563-570. https://doi.org/10.1016/j.amepre.2011.10.026

Flegal, K. M., Kruszon-Moran, D., Carroll, M. D., Fryar, C. D., \& Ogden, C. L. (2016). Trends in Obesity Among Adults in the United States, 2005 to 2014. Jama, 315(21), 2284. https://doi.org/10.1001/jama.2016.6458

Frederick, C. B., Snellman, K., \& Putnam, R. D. (2014). Increasing socioeconomic disparities in adolescent obesity. Proceedings of the National Academy of Sciences, 111(4). https://doi.org/10.1073/pnas.1321355110

Freedman, D. S., Khan, L. K., Serdula, M. K., Dietz, W. H., Srinivasan, S. R., \& Berenson, G. S. (2004). Inter-relationships among childhood BMI, childhood height, and adult obesity: the Bogalusa Heart Study. International Journal of Obesity, 28(1), 10-16. https://doi.org/10.1038/sj.ijo.0802544

Freedman, D. S., Khan, L. K., Serdula, M. K., Ogden, C. L., \& Dietz, W. H. (2006). Racial and Ethnic Differences in Secular Trends for Childhood BMI, Weight, and Height*. Obesity, 14(2), 301-308. https://doi.org/10.1038/oby.2006.39

Freedman, D. S., Wang, J., Maynard, L. M., Thornton, J. C., Mei, Z., Pierson, R. N., ... Horlick, M. (2005). Relation of BMI to fat and fat-free mass among children and adolescents. International Journal of Obesity, 29(1), 1-8. https://doi.org/10.1038/sj.ijo.0802735

French, S. A., Story, M., \& Perry, C. L. (1995). Self-Esteem and Obesity in Children and Adolescents: A Literature Review. Obesity Research, 3(5), 479-490. https://doi.org/10.1002/j.1550-8528.1995.tb00179.x

Friedrich, M. J. (2017). Global Obesity Epidemic Worsening. JAMA, 318(7), 603. 
https://doi.org/10.1001/jama.2017.10693

Friend, S., Flattum, C., Fulkerson, J. A., Neumark-Sztainer, D., \& Garwick, A. (2014). How Does Eating Family Meals During Childhood Influence Parents. Journal of Nutrition Education and Behavior, 46(4), S179. https://doi.org/10.1016/J.JNEB.2014.04.266

Gall, K., van Zutven, K., Lindstrom, J., Bentley, C., Gratwick-Sarll, K., Harrison, C., ... Mond, J. (2016). Obesity and emotional well-being in adolescents: Roles of body dissatisfaction, loss of control eating, and self-rated health. Obesity, 24(4), 837-842. https://doi.org/10.1002/oby.21428

Garcia, A. L., Reardon, R., McDonald, M., \& Vargas-Garcia, E. J. (2016). Community Interventions to Improve Cooking Skills and Their Effects on Confidence and Eating Behaviour. Current Nutrition Reports, 5(4), 315-322. https://doi.org/10.1007/s13668-016-0185-3

Gentry, V. (2017). Cooking for Life: The Effectiveness of the Pink and Dude Chefs Program Twelve Weeks Post Intervention.

Gluckman, P., Nishtar, S., \& Armstrong, T. (2015). Ending childhood obesity: a multidimensional challenge. The Lancet, 385(21), 1048-1050. https://doi.org/10.1016/S0140-6736(15)60509-8

Gordon-Larsen, P., Nelson, M. C., Page, P., \& Popkin, B. M. (2006). Inequality in the built environment underlies key health disparities in physical activity and obesity. Pediatrics, 117(2), 417-24. https://doi.org/10.1542/peds.2005-0058

Gortmaker, S. L., Long, M. W., Resch, S. C., Ward, Z. J., Cradock, A. L., Barrett, J. L., ... Wang, Y. C. (2015). Cost Effectiveness of Childhood Obesity Interventions: Evidence and Methods for CHOICES. American Journal of Preventive Medicine. https://doi.org/10.1016/j.amepre.2015.03.032

Granner, M. L., \& Sharpe, P. A. (2004). Evaluating community coalition characteristics and functioning: a summary of measurement tools. Health Education Research, 19(5), 514-532. https://doi.org/10.1093/her/cyg056

Griebler, U., Rojatz, D., Simovska, V., \& Forster, R. (2017). Effects of student participation in school health promotion: a systematic review. Health Promotion International, 32(2), 195-206. https://doi.org/10.1093/heapro/dat090

Hammond, R. A., \& Levine, R. (2010). The economic impact of obesity in the United States. Diabetes, Metabolic Syndrome and Obesity: Targets and Therapy, 3, 28595. https://doi.org/10.2147/DMSOTT.S7384

Harris, K. M., Gordon-Larsen, P., Chantala, K., \& Udry, J. R. (2006). Longitudinal Trends in Race/Ethnic Disparities in Leading Health Indicators From Adolescence to Young Adulthood. Archives of Pediatrics \& Adolescent Medicine, 160(1), 74. https://doi.org/10.1001/archpedi.160.1.74

Hartley, L., Igbinedion, E., Holmes, J., Flowers, N., Thorogood, M., Clarke, A., ... Rees, K. (2013). Increased consumption of fruit and vegetables for the primary prevention of cardiovascular diseases. In K. Rees (Ed.), Cochrane Database of Systematic Reviews. Chichester, UK: John Wiley \& Sons, Ltd. 
https://doi.org/10.1002/14651858.CD009874.pub2

Hersch, D., Perdue, L., Ambroz, T., \& Boucher, J. L. (2014). The impact of cooking classes on food-related preferences, attitudes, and behaviors of school-aged children: a systematic review of the evidence, 2003-2014. Preventing Chronic Disease, 11, E193. https://doi.org/10.5888/pcd11.140267

Holley, C. E., Farrow, C., \& Haycraft, E. (2017). A Systematic Review of Methods for Increasing Vegetable Consumption in Early Childhood. Current Nutrition Reports, 6(2), 157-170. https://doi.org/10.1007/s13668-017-0202-1

Hruby, A., \& Hu, F. B. (2015). The Epidemiology of Obesity: A Big Picture. PharmacoEconomics. https://doi.org/10.1007/s40273-014-0243-X

Ileana Arias, P. (n.d.). Children Eating More Fruit, but Fruit and Vegetable Intake Still Too Low. Retrieved January 14, 2018, from https://www.cdc.gov/nccdphp/dnpao/division-information/media-tools/dpk/vs-fruitsvegetables/index.html

J. Utter, A. Fay, S. D. (2016). Child and Youth Cooking Programs: More Than Good Nutrition? Journal of Hunger and Environmental Nutrition, 12(554-580).

James, P. T., Leach, R., Kalamara, E., \& Shayeghi, M. (2001). The Worldwide Obesity Epidemic. Obesity Research, 9(S11), 228S-233S. https://doi.org/10.1038/oby.2001.123

Jansen, W., van de Looij-Jansen, P. M., de Wilde, E. J., \& Brug, J. (2008). Feeling Fat Rather than Being Fat May Be Associated with Psychological Well-Being in Young Dutch Adolescents. Journal of Adolescent Health, 42(2), 128-136. https://doi.org/10.1016/J.JADOHEALTH.2007.07.015

Johnson, W. G., Hinkle, L. K., Carr, R. E., Anderson, D. A., Lemmon, C. R., Engler, L. B., \& Bergeron, K. C. (1997). Dietary and Exercise Interventions for Juvenile Obesity: Long-Term Effect of Behavioral and Public Health Models. Obesity Research, 5(3), 257-261. https://doi.org/10.1002/j.1550-8528.1997.tb00300.x

Jourdan, D., Christensen, J. H., Darlington, E., Bonde, A. H., Bloch, P., Jensen, B. B., \& Bentsen, P. (2016). The involvement of young people in school- and communitybased noncommunicable disease prevention interventions: a scoping review of designs and outcomes. BMC Public Health, 16(1), 1123. https://doi.org/10.1186/s12889-016-3779-1

Kataura, M. P., \& Block, L. M. (2011). Behavior Change Strategies for Successful LongTerm Weight Loss: Focusing on Dietary and Physical Activity Adherence, Not Weight Loss, 49(1), 1-5. Retrieved from https://joe.org/joe/2011february/pdf/JOE_v49_1tt5.pdf

Kuczmarski, R. J., Ogden, C. L., Guo, S. S., Grummer-Strawn, L. M., Flegal, K. M., Mei, Z., ... Johnson, C. L. (2002). 2000 CDC Growth Charts for the United States: methods and development. Vital and Health Statistics. Series 11, Data from the National Health Survey, (246), 1-190. Retrieved from http://www.ncbi.nlm.nih.gov/pubmed/12043359

Larson, N. I., Perry, C. L., Story, M., \& Neumark-Sztainer, D. (2006). Food Preparation 
by Young Adults Is Associated with Better Diet Quality. Journal of the American Dietetic Association, 106(12), 2001-2007.

https://doi.org/10.1016/j.jada.2006.09.008

Lichtenstein, A. H., \& Ludwig, D. S. (2010). Bring Back Home Economics Education. JAMA, 303(18), 1857. https://doi.org/10.1001/jama.2010.592

Lien, N., Lytle, L. A., \& Klepp, K.-I. (2001). Stability in Consumption of Fruit, Vegetables, and Sugary Foods in a Cohort from Age 14 to Age 21. Preventive Medicine, 33(3), 217-226. https://doi.org/10.1006/pmed.2001.0874

Loth, K. A., Mond, J., Wall, M., \& Neumark-Sztainer, D. (2011). Weight Status and Emotional Well-Being: Longitudinal Findings from Project EAT. Journal of Pediatric Psychology, 36(2), 216-225. https://doi.org/10.1093/jpepsy/jsq026

Manyanga, T., Tremblay, M. S., Chaput, J.-P., Katzmarzyk, P. T., Fogelholm, M., Hu, G., ... ISCOLE Research Group, for the I. R. (2017). Socioeconomic status and dietary patterns in children from around the world: different associations by levels of country human development? BMC Public Health, 17(1), 457. https://doi.org/10.1186/s12889-017-4383-8

Marmorstein, N. R., Iacono, W. G., \& Legrand, L. (2014). Obesity and depression in adolescence and beyond: reciprocal risks. International Journal of Obesity, 38(7), 906-911. https://doi.org/10.1038/ijo.2014.19

Mehta, N. K., Lee, H., \& Ylitalo, K. R. (2013). Child health in the United States: Recent trends in racial/ethnic disparities. Social Science and Medicine. https://doi.org/10.1016/j.socscimed.2012.09.011

Meiklejohn, S., Ryan, L., \& Palermo, C. (2016a). A Systematic Review of the Impact of Multi-Strategy Nutrition Education Programs on Health and Nutrition of Adolescents. Journal of Nutrition Education and Behavior. https://doi.org/10.1016/j.jneb.2016.07.015

Meiklejohn, S., Ryan, L., \& Palermo, C. (2016b). A Systematic Review of the Impact of Multi-Strategy Nutrition Education Programs on Health and Nutrition of Adolescents. Journal of Nutrition Education and Behavior, 48(9), 631-646.e1. https://doi.org/10.1016/j.jneb.2016.07.015

Meldrum, D. R., Morris, M. A., \& Gambone, J. C. (2017). Obesity pandemic: causes, consequences, and solutions - but do we have the will? Fertility and Sterility, 107(4), 833-839. https://doi.org/10.1016/j.fertnstert.2017.02.104

Morbidity and Mortality Weekly Report. (2014). Early Release, 63. Retrieved from https://www.cdc.gov/mmwr/pdf/wk/mm63e0805.pdf

Myers, A., \& Rosen, J. (1999). Obesity stigmatization and coping: Relation to mental health symptoms, body image and self-esteem. International Journal of Obesity, 23(3), 221-230. https://doi.org/10.1038/sj.ijo.0800765

Nelson, S. A., Corbin, M. A., \& Nickols-Richardson, S. M. (2013). A Call for Culinary Skills Education in Childhood Obesity-Prevention Interventions: Current Status and Peer Influences. Journal of the Academy of Nutrition and Dietetics, 113(8), 10311036. https://doi.org/10.1016/j.jand.2013.05.002 
Obesity in California: The Weight of the State, 2000-2014. (2016). Retrieved from https://www.cdph.ca.gov/Programs/CCDPHP/DCDIC/NEOPB/CDPH Document Library/RES_ObesityReport20002014.pdf

Ogden, C. L., Carroll, M. D., \& Flegal, K. M. (2014). Prevalence of Obesity in the United States. JAMA, 312(2), 189. https://doi.org/10.1001/jama.2014.6228

Ogden, C. L., Carroll, M. D., Fryar, C. D., \& Flegal, K. M. (2015). Prevalence of Obesity Among Adults and Youth: United States, 2011-2014. NCHS Data Brief, (219), 1-8. https://doi.org/10.1017/S1368980017000088

Ogden CL, Carroll MD, Fryar CD, F. K. (2018). Childhood Obesity Facts | Overweight \&amp; Obesity | CDC. Retrieved April 16, 2018, from https://www.cdc.gov/obesity/data/childhood.html

Perry, C. L., Bishop, D. B., Taylor, G., Murray, D. M., Mays, R. W., Dudovitz, B. S., ... Story, M. (1998). Changing fruit and vegetable consumption among children: the 5a-Day Power Plus program in St. Paul, Minnesota. American Journal of Public Health, 88(4), 603-9. Retrieved from http://www.ncbi.nlm.nih.gov/pubmed/9551002

Peters, P., Gold, A., Abbott, A., Contreras, D., Keim, A., Oscarson, R., ... Mobley, A. R. (2016). A quasi-experimental study to mobilize rural low-income communities to assess and improve the ecological environment to prevent childhood obesity. BMC Public Health, 16(1), 376. https://doi.org/10.1186/s12889-016-3047-4

Pietrobelli, A., Faith, M. S., Allison, D. B., Gallagher, D., Chiumello, G., \& Heymsfield, S. B. (1998). Body mass index as a measure of adiposity among children and adolescents: a validation study. The Journal of Pediatrics, 132(2), 204-10. https://doi.org/10.1016/S0022-3476(98)70433-0

Ploeg, M. Ver, Breneman, V., Dutko, P., Williams, R., Snyder, S., Dicken, C., \& Kaufman, P. (2012). Access to Affordable and Nutritious Food: Updated Estimates of Distance to Supermarkets Using 2010 Data. U.S. Department of Agriculture, Economic Research Service, (November), 15. Retrieved from http://www.ers.usda.gov/publications/err-economic-researchreport/err143.aspx\#.Ut7xXZGtu-k

Rasmussen, M., Krølner, R., Klepp, K.-I., Lytle, L., Brug, J., Bere, E., \& Due, P. (2006). Determinants of fruit and vegetable consumption among children and adolescents: a review of the literature. Part I: quantitative studies. International Journal of Behavioral Nutrition and Physical Activity, 3(1), 22. https://doi.org/10.1186/14795868-3-22

Rasmussen, W. D. (1989). Taking the University to the People: Seventy-Five Years of Cooperative Extension - Wayne D. Ramussen - Google Books (1st ed.). Iowa State University Press. Retrieved from https://books.google.com/books?hl=en\&lr=\&id=AijwWCIaqMkC\&oi=fnd\&pg=PR $7 \& d q=$ cooperative+extension+nutrition $\&$ ots $=$ n7RjU3GC8e \&sig=a0GVJvBKIzWy3 tin- $2 \mathrm{zzFoogs} 2 \mathrm{c} \# \mathrm{v}=$ onepage $\& \mathrm{q}=$ cooperative extension nutrition $\& \mathrm{f}=\mathrm{false}$

Rollins, B. Y., Savage, J. S., Fisher, J. O., \& Birch, L. L. (2016). Alternatives to restrictive feeding practices to promote self-regulation in childhood: a 
developmental perspective. Pediatric Obesity, 11(5), 326-332.

https://doi.org/10.1111/ijpo.12071

Sanders-Phillips, K., Settles-Reaves, B., Walker, D., \& Brownlow, J. (2009). Social Inequality and Racial Discrimination: Risk Factors for Health Disparities in Children of Color. Pediatrics. https://doi.org/10.1542/peds.2009-1100E

Sheehan, T. (2013). PINK AND DUDE CHEFS: A nutrition and culinary intervention for middle school students. Retrieved from

http://digitalcommons.calpoly.edu/cgi/viewcontent.cgi? article $=1983 \&$ context $=$ these s

Shonkoff, J. P., Boyce, W. T., \& McEwen, B. S. (2009). Neuroscience, Molecular Biology, and the Childhood Roots of Health Disparities. Jama, 301(21), 2252. https://doi.org/10.1001/jama.2009.754

Skinner, A. C., Perrin, E. M., \& Skelton, J. A. (2016). Prevalence of obesity and severe obesity in US children, 1999-2014. Obesity, 24(5), 1116-1123. https://doi.org/10.1002/oby.21497

Smathers, C., Lobb, J. (2017). Mobilizing Rural Communities to Prevent Childhood Obesity: A Tool Kit. Journal of Extension, 55(6).

Smith, K. B., \& Smith, M. S. (2016). Obesity Statistics. Primary Care - Clinics in Office Practice. https://doi.org/10.1016/j.pop.2015.10.001

Strauss, R. S., \& Pollack, H. A. (2003). Social Marginalization of Overweight Children. Archives of Pediatrics \& Adolescent Medicine, 157(8), 746. https://doi.org/10.1001/archpedi.157.8.746

Taveras, E. M., Gillman, M. W., Kleinman, K. P., Rich-Edwards, J. W., \& Rifas-Shiman, S. L. (2013). Reducing Racial/Ethnic Disparities in Childhood Obesity. JAMA Pediatrics, 167(8), 731. https://doi.org/10.1001/jamapediatrics.2013.85

Thomas, G. (2005). Obesity Fact Sheet in support of increasing support, coordination and funding for obesity prevention, (5). Retrieved from http://cfsloco.org/forms/GivingCN-ObesityFactSheet.pdf

Thomas, H. (2006). Obesity prevention programs for children and youth: why are their results so modest? Health Education Research, 21(6), 783-795. https://doi.org/10.1093/her/cyl143

Thompson, J. K., Heinberg, L. J., Altabe, M., \& Tantleff-Dunn, S. (1999). Exacting beauty: Theory, assessment, and treatment of body image disturbance. Washington: American Psychological Association. https://doi.org/10.1037/10312-000

Tiwari, A., Aggarwal, A., Tang, W., \& Drewnowski, A. (2017). Cooking at Home: A Strategy to Comply With U.S. Dietary Guidelines at No Extra Cost. American Journal of Preventive Medicine, 52(5), 616-624. https://doi.org/10.1016/j.amepre.2017.01.017

Tremmel, M., Gerdtham, U.-G., Nilsson, P. M., \& Saha, S. (2017). Economic Burden of Obesity: A Systematic Literature Review. International Journal of Environmental Research and Public Health, 14(4). https://doi.org/10.3390/ijerph14040435 
Utter, J., Larson, N., Laska, M. N., Winkler, M., \& Neumark-Sztainer, D. (2018). SelfPerceived Cooking Skills in Emerging Adulthood Predict Better Dietary Behaviors and Intake 10 Years Later: A Longitudinal Study. Journal of Nutrition Education and Behavior. https://doi.org/10.1016/J.JNEB.2018.01.021

Vaughan, K. B., Kaczynski, A. T., Wilhelm Stanis, S. A., Besenyi, G. M., Bergstrom, R., \& Heinrich, K. M. (2013). Exploring the Distribution of Park Availability, Features, and Quality Across Kansas City, Missouri by Income and Race/Ethnicity: an Environmental Justice Investigation. Annals of Behavioral Medicine, 45(S1), 28-38. https://doi.org/10.1007/s12160-012-9425-y

Vereecken, C., Pedersen, T. P., Ojala, K., Krolner, R., Dzielska, A., Ahluwalia, N., ... Kelly, C. (2015). Fruit and vegetable consumption trends among adolescents from 2002 to 2010 in 33 countries. The European Journal of Public Health, 25(suppl 2), 16-19. https://doi.org/10.1093/eurpub/ckv012

Wang, Y., \& Beydoun, M. A. (2007). The Obesity Epidemic in the United States Gender, Age, Socioeconomic, Racial/Ethnic, and Geographic Characteristics: A Systematic Review and Meta-Regression Analysis. Epidemiologic Reviews, 29(1), 6-28. https://doi.org/10.1093/epirev/mxm007

Wang, Y., \& Zhang, Q. (2006). Are American children and adolescents of low socioeconomic status at increased risk of obesity? Changes in association between overweight and family income between 1971 and 2002. Am J Clin Nutr, 84, 707-16. Retrieved from http://ajcn.nutrition.org/content/84/4/707.full.pdf

Wardle, J., \& Cooke, L. (2005). The impact of obesity on psychological well-being. Best Practice \& Research Clinical Endocrinology \& Metabolism, 19(3), 421-440. https://doi.org/10.1016/J.BEEM.2005.04.006

Wardle, J., Parmenter, K., \& Waller, J. (2000). Nutrition knowledge and food intake. Appetite, 34(3), 269-275. https://doi.org/10.1006/appe.1999.0311

Whitaker, R. C., Wright, J. A., Pepe, M. S., Seidel, K. D., \& Dietz, W. H. (1997). Predicting Obesity in Young Adulthood from Childhood and Parental Obesity. New England Journal of Medicine, 337(13), 869-873. https://doi.org/10.1056/NEJM199709253371301

WHO. (2017). Adolescent obesity and related behaviours : trends and inequalities in the WHO region 2002-2014. Who, 2002-2014. https://doi.org/10.4103/0972 5229.178178

WHO Increasing fruit and vegetable consumption to reduce the risk of noncommunicable diseases. (2017). WHO.

Wolstein, J., Babey, S. H., \& Diamant, A. L. (2015). Obesity in California. Retrieved from http://healthpolicy.ucla.edu/publications/Documents/PDF/2015/obesityreportjun2015.pdf

Worsley, A., Wang, W. C., Yeatman, H., Byrne, S., \& Wijayaratne, P. (2015). Does school health and home economics education influence adults' food knowledge?

Health Promotion International, 31(4), dav078. https://doi.org/10.1093/heapro/dav078 
Wright, C. M., Parker, L., Lamont, D., \& Craft, A. W. (2001). Implications of childhood obesity for adult health: findings from thousand families cohort study. BMJ (Clinical Research Ed.), 323(7324), 1280-4. https://doi.org/10.1136/BMJ.323.7324.1280

Zarnowiecki, D. M., Dollman, J., \& Parletta, N. (2014). Associations between predictors of children's dietary intake and socioeconomic position: A systematic review of the literature. Obesity Reviews, 15(5), 375-391. https://doi.org/10.1111/obr.12139 
APPENDICES 


\section{Appendix A: Instructor Survey}

\section{PINK AND DUDE CHEFS}

\section{INSTRUCTOR SURVEY}

Notes for interviewers:

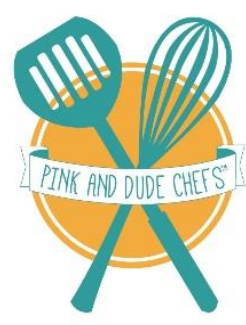

1. Questions must be asked as they are written.

2. If clarification is needed, do not deviate because questions should be asked in the same way to each participant.

3. Remind them that we don't expect them to know the answers, and to pick the answer they feel is best.

\section{Introduction:}

Hello , this is How are you today?

We greatly appreciate you taking the time to help us evaluate our online training. As we discussed in our previous phone call, this conversation will take about 15-20 minutes today.

I will be asking you a series of multiple choice questions. These questions will be used to help us understand who is participating in our online training. It will also be used to determine whether the online training is serving its best purposes for you.

Keep in mind, you most likely won't know all of the answers to these questions, and we don't expect you to know all of the answers. If you do not know the answer, make your best guess. There is no penalty for wrong answers.

Also, everything that you say is confidential. That means that I will not share what you say with other program staff.

If all of that sounds good to you, then let's begin with the survey. 
1. What is your sex?
a. Male
b. Female

2. What is your age group?
a. $\leq 20$ years
b. 21-25 years
c. 26-30 years
d. 31-35 years
e. $36-40$ years
f. $41-45$ years
g. 46-50 years
h. 51-55 years
i. 56-60 years
j. 61-65 years
k. > 65 years

3. What is your race/ethnicity?
a. White
b. Hispanic or Latino
c. Black or African American
d. Native American or American Indian
e. Asian/Pacific Islander
f. Mixed heritage/two or more

4. What is your education level?
a. Not a high school graduate
b. High school graduate
c. Associates or technical degree
d. Some college
e. College graduate or higher

5. Have you ever worked in a trained kitchen setting (i.e. restaurant, Starbucks, food truck, Meals on Wheels, etc.)
a. Yes
b. No

6. Which of the following should not be washed before you start cooking?
a. Vegetables
b. Fruits
c. Raw meats
d. Your hands
e. None of the above 
7. Which of the following must be cooked to the highest internal temperature?
a. Fish
b. Chicken and poultry
c. Beef
d. Veal

8. In order to be considered safe for consumption, which of the following may be cooked to the lowest internal temperature?
a. Fish
b. Chicken and poultry
c. Beef
d. Veal

9. To avoid cross contamination, which of the following should be stored on the lowest shelf in the fridge?
a. Raw chicken
b. Raw beef
c. Vegetables
d. Fruit
e. Bread

10. Which of the following is not considered a red meat:
a. Lamb
b. Veal
c. Beef
d. Pork

11. When is it not necessary to wash your hands to avoid contamination?
a. After touching raw meat
b. After scratching your face
c. After cracking eggs
d. After flipping through your workbook
e. It is always necessary to wash your hands

12. In order to be fully cooked, chicken needs to be cooked to an internal temperature of (Fahrenheit):
a. $165 \mathrm{~F}$
b. $160 \mathrm{~F}$
c. $145 \mathrm{~F}$
d. $140 \mathrm{~F}$ 
13. The temperature danger zone, which is conducive to the growth of bacteria and mold, is:
a. $60-160 \mathrm{~F}$
b. $20-120 \mathrm{~F}$
c. $30-130 \mathrm{~F}$
d. $40-140 \mathrm{~F}$

14. Which of the following is not a core objective of the Pink and Dude Chefs curriculum?

a. Educating students on proper food handling and kitchen safety

b. Fostering students' confidence in their cooking abilities

c. Exposing students to new ingredients they wouldn't have access to at home

d. Providing students with basic nutrition knowledge to make healthier food choices

15. When recruiting participants for the Pink and Dude Chefs program:

a. Target adolescents between the ages of 14 to 16 years

b. Focus on the healthy foods they will learn to make

c. Highlight that learning to cook will make them more independent

d. Emphasize that this is a nutrition education program

e. All of the above

16. Which of the following are important safety measures that reduce the chance of foodborne illness:

a. Washing aprons and chefs hats after each lesson

b. Washing hands after leaving the kitchen or using the restroom

c. Separating raw meat from cooked foods and fruits/vegetables

d. Strategic placement of raw meats in the refrigerator

e. All of the above

17. What should you do if there is a grease fire in your pan?

a. Douse the pan with a bucket of water

b. Smother the pan with a lid until it is completely cooled

c. Extinguish the fire with a towel

d. Utilize a fire extinguisher to stop the fire

18. The first step for cleaning a food processor or blender is:

a. Submerging it in water

b. Removing the blade

c. Disassembling it

d. Unplugging it 
19. A Pink and Dude Chefs program will be most successful if:
a. Multiple people help with running the program
b. Instructors revise recipes to save on food costs each week
c. A minimum of 15 students are enrolled in each session
d. Instructors arrive 15 minutes early to prepare for each lesson
e. All of the above

20. In order to follow the budget, instructors may not:
a. Substitute some of the recipe ingredients for cheaper and similar alternatives
b. Contact local food banks to ask for donations
c. Cook the recipes themselves without student involvement
d. Shop at multiple grocery stores to find the best deals

21. Which of the following is not a way to help keep control of the classroom?

a. Say "Pink Chefs" and have students respond with "Dude Chefs" to get their attention

b. Have students help set up appropriate classroom rules when the program begins

c. Assign disruptive students to specific tasks and give them positive feedback

d. Before each lesson, have the students help set up their work spaces

e. After each lesson, require the students to clean up their area

22. What do you do if a fight breaks out between students?

a. Get their attention by raising your voice

b. Send the students home without letting them complete the lesson

c. Lead them outside to resolve the issue so the lesson can continue

d. Reprimand the students in front of their peers to establish control

e. Separate the students and assign them to different tasks

23. Which is not an expected cost of running the Pink and Dude Chefs Program?
a. Transportation
b. Food
c. Personnel
d. None of the above 
24. At the end of each lesson, what should happen after kitchen clean-up is complete?

a. The students leave with their freshly made food, while the instructors take inventory of the kitchen

b. The students and instructor all sit down to enjoy the recipes they prepared that day

c. The instructor facilitates "closure"- a time for students to share what they learned that day with everyone

d. The instructor facilitates "reflection"- a time for students to write down what they learned in their workbooks

25. For each Pink and Dude Chefs lesson:

a. 1 volunteer is recommended for every 2 students

b. 1 volunteer is recommended for every 4 students

c. 1 volunteer is recommended for every 6 students

d. 1 volunteer is recommended no matter how many students there are

26. Which of the following is true regarding the Family Fiesta?

a. The Family Fiesta doesn't require any additional costs compared to a regular class

b. The Family Fiesta involves more preparation time and ingredients than a regular class

c. The Family Fiesta is a time for the students to showcase one recipe of their choice to their parents and guests

d. The Family Fiesta is a time for students to cook with minimal intervention from the instructor using the skills they've learned 


\section{Appendix B: Example Behavior Goal Sheet}

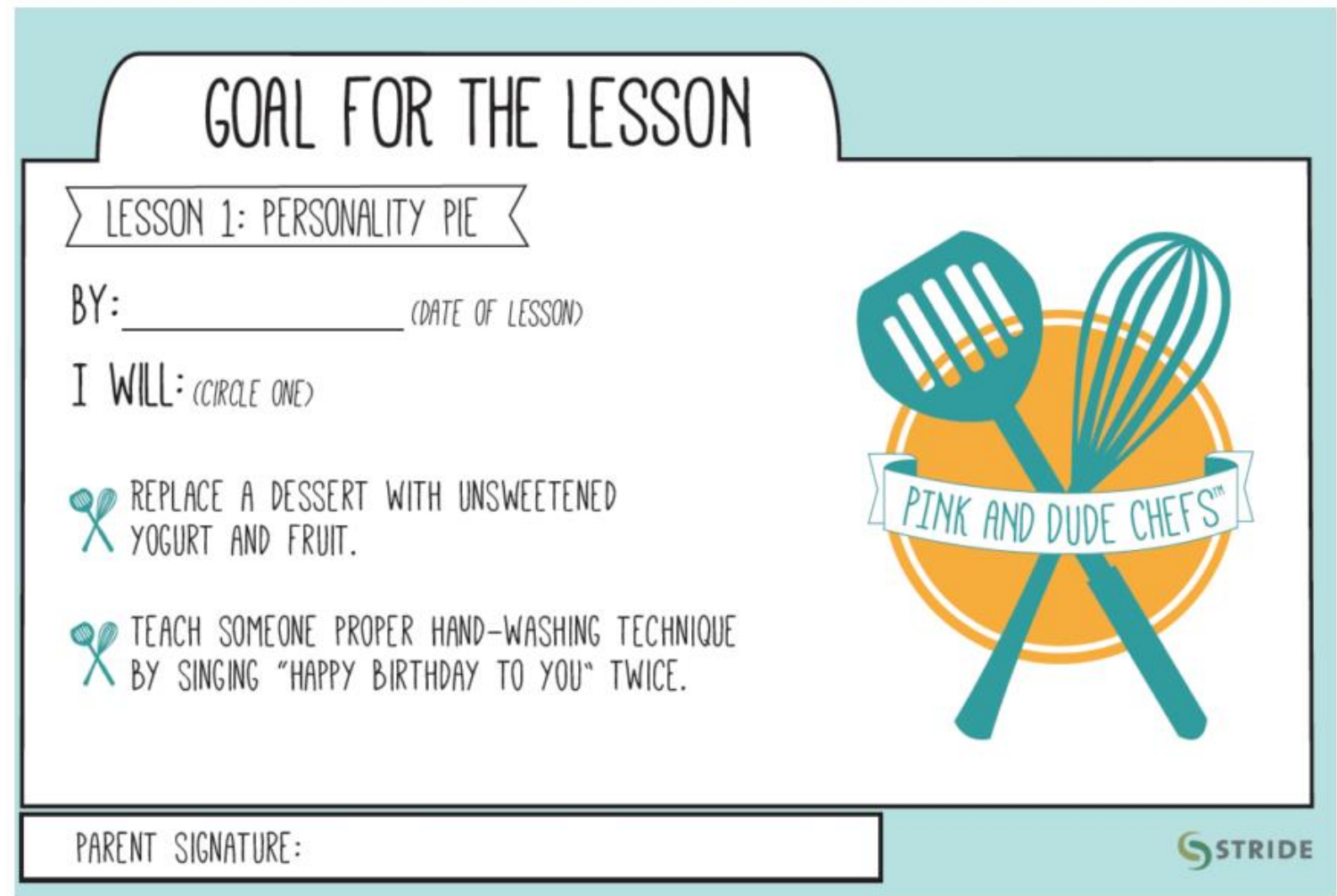




\section{Appendix C: Example Recipe}

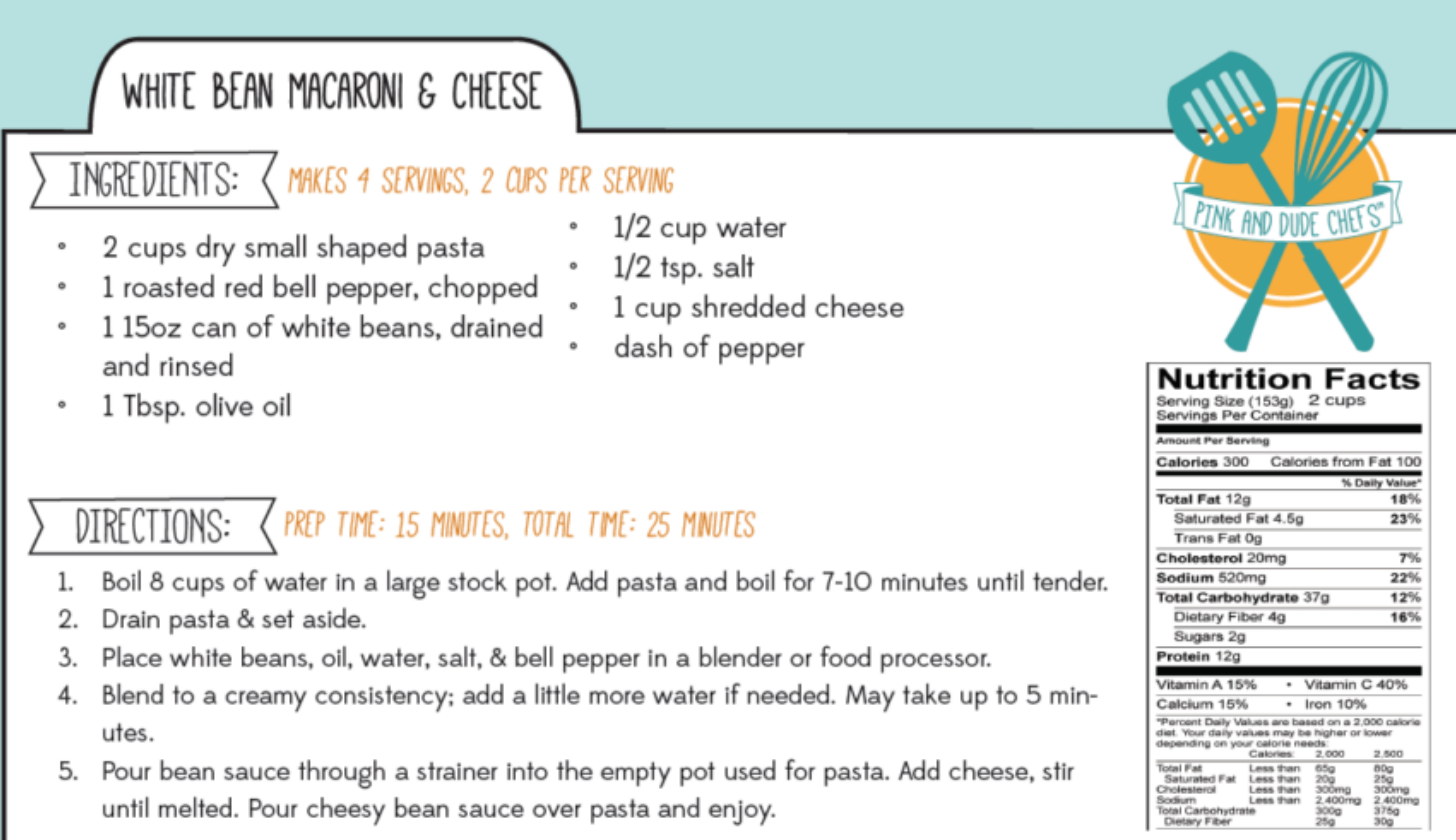

WHITE BEANS ARE A GOOD SOURCE OF FIBER TO SUPPORT YOUR DIGESTIVE SYSTEM. 


\section{Appendix D: Youth Survey}

\section{Instructions}

We would like you to complete this survey. You may skip questions you do not want to answer but we hope that you will answer all of them. Any information about who you are will be kept confidential.

\section{I: Nutrition Knowledge}

\section{Check the one best answer you can think of for the following questions.}

1. Fiber is found in which of the following?
$\square \quad$ Chicken
$\square \quad$ Olive oil
$\square \quad$ Butter
口 Oatmeal

2. $99 \%$ of the calcium in your body is found in your

$\begin{array}{llll}\square & \text { Skin } & \square & \text { Bones and teeth } \\ \square & \text { Hair } & \square & \text { Tongue }\end{array}$

3. Based on the USDA MyPlate guidelines, how much of the plate should be made up of fruits and vegetables?
$\square \quad 1 / 4$ of the plate
a $1 / 2$ of the plate
ㅁ $1 / 3$ of the plate
The whole plate

4. Which of the following is NOT found on the nutrition label?

\begin{tabular}{llll}
$\square$ & Calories & $\square$ & Ingredients \\
$\square$ & Expiration date & $\square$ & Sodium \\
\hline
\end{tabular}

5. Where can you find the most natural, healthy items in the grocery store?
The perimeter
The middle
$\square$ The check-out line
․ The frozen food aisle

6. The serving size of is equivalent to the size of a smartphone or a deck of cards.
$\square \quad$ Carbohydrates
Protein
Dairy
a Fat

7. Beans can be an excellent source of

Fat

$\begin{array}{ll}\square & \text { Sugar } \\ \square & \text { Dairy }\end{array}$

8. Which of the following is a different name for sugar?
$\square \quad$ Fructose
口 Soybean Oil
$\square \quad$ Rice Flour
口 Citric Acid 


\section{II: Kitchen Safety}

\section{Check the one best answer you can think of for the following questions.}

9. If a fire in the kitchen happens, you should do which of the following?

$\square \quad$ Use a fire extinguisher $\square$ Throw flour on the fire

$\square \quad$ Attempt to move a burning pan $\square$ Cover the stove with a towel

10. When using a knife in the kitchen you should only cut on

The stove

a A cutting board

$\square$ A paper towel

A frying pan

11. How much time should you spend washing your hands?

$\square \quad 5$ seconds $\square 15$ seconds

$\square \quad 10$ seconds $\square \quad 20$ seconds

12. How can you avoid cross-contamination?

$\square \quad$ Use the same knife for raw fish and fruit $\quad \square \quad$ Wash your hands after handling raw chicken

$\square \quad$ Mix cooked beef with raw beef

ㄱinse cutting boards under water

13. In order to avoid burns, you should

Be careful using your bare hands $\square \quad$ Leave an item in an open oven until it is cool

$\square \quad$ Use a pot holder or oven mitt

․ Never cook anything over 100 degrees

14. If a knife falls off a table, you should

Grab it quickly before it touches the floor

Ignore it

Let it fall and get out of the way

Pick it up and use it immediately 


\section{III: Cooking Skills}

\section{Check the one best answer you can think of for the following questions.}

15. Which of the following shows a diced carrot?
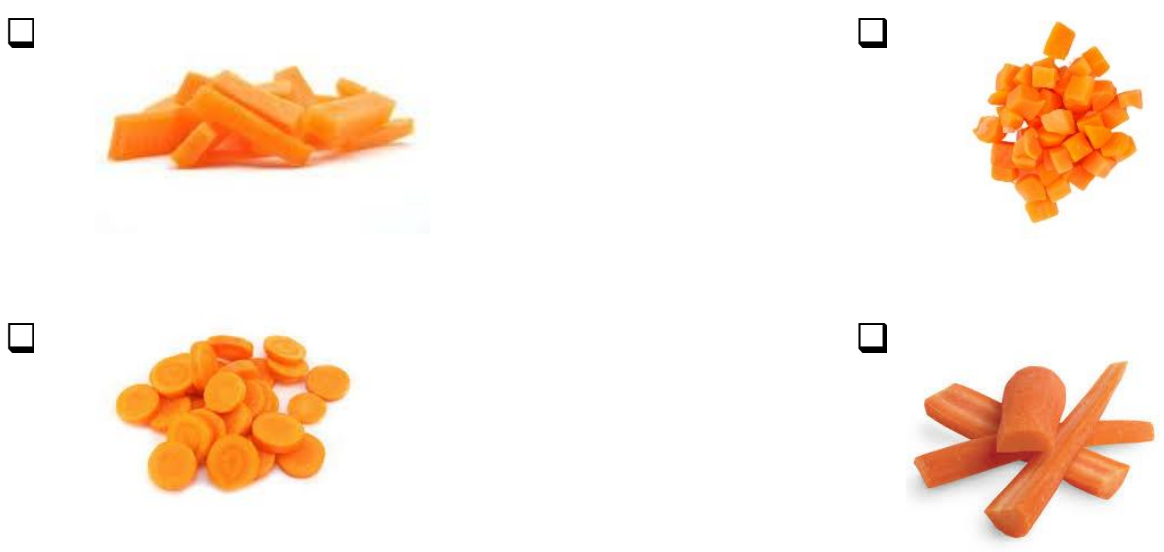

16. Which of the following should be used to measure liquids?
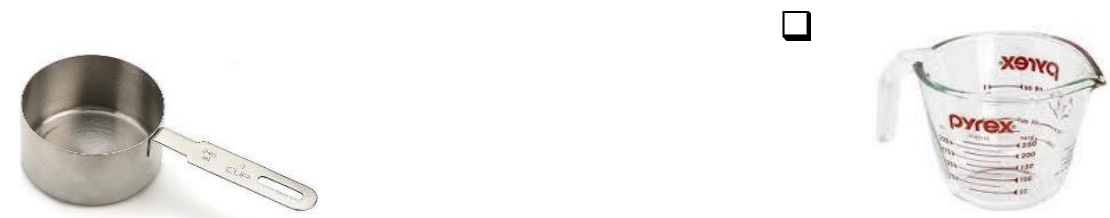

$\square$
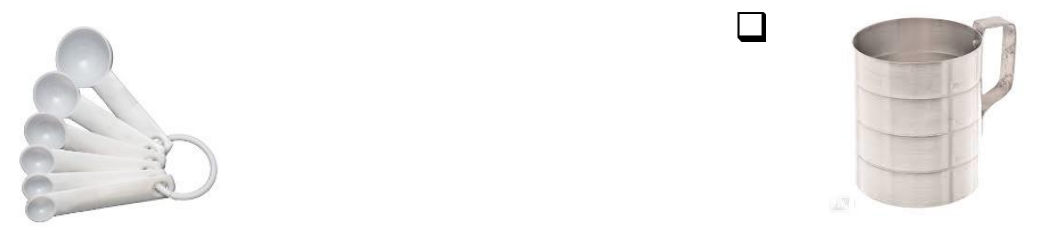

17. What cooking method is used to cook small pieces of vegetables in a small amount of oil?

$\begin{array}{llll}\square & \text { Stir-fry } & \square & \text { Poaching } \\ \square & \text { Simmering } & \square & \text { Steaming }\end{array}$

18. When baking, what is the first step of the recipe?
$\square \quad$ Preheat the oven
- Combine wet and dry ingredients
$\square \quad$ Mix dry ingredients
$\square \quad$ Turn on the stove

19. Chopped vegetables should be
$\square \quad$ Very tiny pieces
口 Bite-sized
$\square \quad$ Cut into strips
口 Shredded

20. In what order should you use the ingredients listed in a recipe?
$\square \quad$ It doesn't matter
口 In alphabetical order
$\square \quad$ Whatever the directions say
口 From top to bottom 


\section{IV: Confidence}

\begin{tabular}{|c|c|c|c|c|c|c|}
\hline \multicolumn{2}{|c|}{$\begin{array}{l}\text { Right now, how sure or confident are you } \\
\text { that you can ... }\end{array}$} & \multirow{2}{*}{$\begin{array}{c}\text { No } \\
\text { way I } \\
\text { can } \\
\text { do } \\
\text { this } \\
\square\end{array}$} & \multirow{2}{*}{$\begin{array}{c}\text { I can } \\
\text { barel } \\
\text { y do } \\
\text { this }\end{array}$} & \multirow{2}{*}{\begin{tabular}{|c|}
$\begin{array}{l}\text { I can sort } \\
\text { of do this }\end{array}$ \\
$\square$ \\
\end{tabular}} & \multirow{2}{*}{$\begin{array}{c}\text { I can } \\
\text { mostl } \\
\text { y do } \\
\text { this }\end{array}$} & \multirow{2}{*}{ 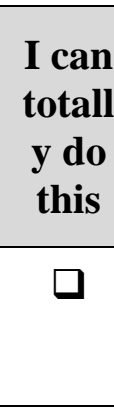 } \\
\hline 21. & $\begin{array}{l}\text { Help an adult family member prepare a } \\
\text { dish or a meal using fruits, vegetables or } \\
\text { other fresh ingredients }\end{array}$ & & & & & \\
\hline 22. & $\begin{array}{l}\text { Suggest a healthy item for the family's } \\
\text { grocery list }\end{array}$ & $\square$ & $\square$ & $\square$ & $\square$ & $\square$ \\
\hline 23. & Follow a simple recipe to make a dish & $\square$ & a & $\square$ & a & $\square$ \\
\hline 24. & Put out an oil or grease fire on the stove & $\square$ & $\square$ & $\square$ & $\square$ & $\square$ \\
\hline 25. & $\begin{array}{l}\text { Cook a dish or a meal using fresh fruits, } \\
\text { vegetables, meats or other raw ingredients } \\
\text { from scratch }\end{array}$ & 口 & a & $\square$ & a & $\square$ \\
\hline 26. & Identify key facts on a nutrition label & $\square$ & $\square$ & $\square$ & $\square$ & $\square$ \\
\hline 27. & $\begin{array}{l}\text { Use a kitchen knife to safely slice or dice } \\
\text { an ingredient }\end{array}$ & $\square$ & $\square$ & $\square$ & $\square$ & $\square$ \\
\hline 28. & $\begin{array}{l}\text { Accurately measure the right amount for a } \\
\text { recipe (teaspoon, tablespoon, 1/3 cup, } 16 \\
\text { ounces) }\end{array}$ & $\square$ & a & a & a & $\square$ \\
\hline 29. & Find healthy items in a grocery store & $\square$ & $\square$ & $\square$ & $\square$ & $\square$ \\
\hline
\end{tabular}


V: Would you try different food items?

\begin{tabular}{|c|c|c|c|c|c|c|c|}
\hline & $\begin{array}{l}\text { you willing to try these } \\
\text { ds? }\end{array}$ & $\begin{array}{l}\text { No } \\
\text { way! }\end{array}$ & $\begin{array}{l}\text { Yes, } \\
\text { may } \\
\text { be a } \\
\text { little }\end{array}$ & $\begin{array}{c}\text { Yes, } \\
\text { somew } \\
\text { hat }\end{array}$ & $\begin{array}{c}\text { Yes, } \\
\text { proba } \\
\text { bly } \\
\text { willin } \\
\text { g }\end{array}$ & $\begin{array}{c}\text { Yes, } \\
\text { for } \\
\text { sur } \\
\text { e! }\end{array}$ & $\begin{array}{l}\text { Don't } \\
\text { know } \\
\text { what } \\
\text { this is }\end{array}$ \\
\hline 30. & Almond Butter & $\square$ & a & a & $\square$ & a & a \\
\hline 31. & Vegetable stir-fry & a & a & a & a & a & a \\
\hline 32. & Whole Wheat Flour & $\square$ & ם & $\square$ & a & a & $\square$ \\
\hline 33. & Quinoa & 口 & ב & $\square$ & D & 口 & $\square$ \\
\hline 34. & Kale Chips & 口 & a & a & $\square$ & a & a \\
\hline 35. & Tofu & a & a & $\square$ & $\square$ & a & $\square$ \\
\hline
\end{tabular}




\section{VI: Your Food and Beverage Choices}

These questions are about the foods you eat. Think back over the past week, which is the past 7 days, and try to describe what you have eaten. Please provide your best guess.

\begin{tabular}{|c|c|c|c|c|c|c|c|}
\hline \multicolumn{2}{|r|}{$\begin{array}{l}\text { 36. In the past week, which is the past } 7 \text { days, } \\
\text { how many times do you eat these fruits? }\end{array}$} & \multirow{2}{*}{$\begin{array}{c}\begin{array}{c}\text { Not } \\
\text { at } \\
\text { all }\end{array} \\
\square\end{array}$} & \multirow{2}{*}{$\begin{array}{c}\text { Once } \\
\square\end{array}$} & \multirow{2}{*}{\begin{tabular}{|r} 
Twice \\
$\square$
\end{tabular}} & \multirow{2}{*}{\begin{tabular}{|r}
3 times \\
$\square$
\end{tabular}} & \multirow{2}{*}{$\begin{array}{r}4 \text { times } \\
\square\end{array}$} & \multirow{2}{*}{ 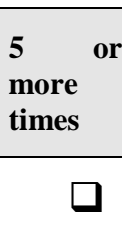 } \\
\hline a. & Apple & & & & & & \\
\hline b. & Banana & $\square$ & $\square$ & $\square$ & a & $\square$ & $\square$ \\
\hline c. & $\begin{array}{l}\text { Berries (blueberries, strawberries, } \\
\text { raspberries) }\end{array}$ & $\square$ & $\square$ & $\square$ & a & $\square$ & $\square$ \\
\hline d. & Cherries & $\square$ & $\square$ & $\square$ & a & $\square$ & $\square$ \\
\hline e. & Grapefruit & $\square$ & $\square$ & $\square$ & a & $\square$ & $\square$ \\
\hline f. & $\begin{array}{l}\text { Melons (honeydew, cantaloupe, } \\
\text { watermelon) }\end{array}$ & 口 & $\square$ & $\square$ & a & $\square$ & $\square$ \\
\hline g. & Orange & $\square$ & $\square$ & $\square$ & a & $\square$ & $\square$ \\
\hline \multicolumn{2}{|r|}{$\begin{array}{l}\text { 37. In the past week, which is the past } 7 \text { days, } \\
\text { how many times do you eat these } \\
\text { vegetables? }\end{array}$} & $\begin{array}{l}\text { Not } \\
\text { at } \\
\text { all }\end{array}$ & Once & Twice & $\begin{array}{l}3 \\
\text { times }\end{array}$ & $\begin{array}{l}4 \\
\text { times }\end{array}$ & $\begin{array}{l}5 \text { or } \\
\text { more } \\
\text { times }\end{array}$ \\
\hline a. & Asparagus & $\square$ & $\square$ & $\square$ & a & 口 & $\square$ \\
\hline b. & Avocados & $\square$ & $\square$ & $\square$ & a & $\square$ & $\square$ \\
\hline c. & Bell Peppers & $\square$ & $\square$ & $\square$ & $\square$ & $\square$ & $\square$ \\
\hline d. & Broccoli & $\square$ & $\square$ & $\square$ & 口 & $\square$ & $\square$ \\
\hline e. & Cabbage & $\square$ & $\square$ & $\square$ & a & $\square$ & $\square$ \\
\hline f. & Carrots & $\square$ & $\square$ & $\square$ & a & $\square$ & $\square$ \\
\hline g. & Cauliflower & $\square$ & $\square$ & $\square$ & 口 & $\square$ & $\square$ \\
\hline h. & Corn & $\square$ & $\square$ & $\square$ & $\square$ & a & $\square$ \\
\hline i. & Green Beans & D & ב & $\square$ & a & D & $\square$ \\
\hline j. & Greens (spinach, kale, lettuce) & $\square$ & $\square$ & $\square$ & a & $\square$ & $\square$ \\
\hline k. & Mushrooms & $\square$ & $\square$ & $\square$ & a & $\square$ & $\square$ \\
\hline 1. & Onion & $\square$ & $\square$ & $\square$ & a & $\square$ & $\square$ \\
\hline
\end{tabular}




\begin{tabular}{|l|l|r|r|r|r|r|r|}
\hline & $\begin{array}{l}\text { 37. In the past week, which is the past 7 } \\
\text { days, how many times do you eat these } \\
\text { vegetables? }\end{array}$ & $\begin{array}{l}\text { Not at } \\
\text { all }\end{array}$ & Once & Twice & $\begin{array}{l}\mathbf{3} \\
\text { times }\end{array}$ & $\begin{array}{l}\mathbf{4} \\
\text { times }\end{array}$ & $\begin{array}{l}\mathbf{5} \text { or } \\
\text { more } \\
\text { times }\end{array}$ \\
\hline m. & Peas & $\square$ & $\square$ & $\square$ & $\square$ & $\square$ & $\square$ \\
\hline n. & Potatoes (do NOT count fries or chips) & $\square$ & $\square$ & $\square$ & $\square$ & $\square$ & $\square$ \\
\hline o. & Sweet Potatoes (do NOT count fries) & $\square$ & $\square$ & $\square$ & $\square$ & $\square$ & $\square$ \\
\hline p. & Tomatoes & $\square$ & $\square$ & $\square$ & $\square$ & $\square$ & $\square$ \\
\hline q. & $\begin{array}{l}\text { Squash (examples: acorn, butternut, } \\
\text { zucchini, yellow squash) }\end{array}$ & $\square$ & $\square$ & $\square$ & $\square$ & $\square$ & $\square$ \\
\hline
\end{tabular}




\section{Appendix E: Semi-Structured Interview Script (Youth)}

\section{Notes for interviewers:}

The interview is designed to ask very broad questions that allow a wide range of responses from the participant. These questions should be asked as close to verbatim as possible.

- More specific probes help to illicit additional information and to clarify initial responses. These are more flexible and should align and flow with the conversation.

Your language should be adjusted as appropriate.

- Know who you are talking with before the interview. "Mother/father" should be replaced with the appropriate reference to the caregiver as appropriate depending on the relationship between caregiver and youth.

- Interviews are intended to be conducted in the last week of the program but before the Family Fiesta. The verb sense should be adjusted if interviews are conducted after the end of the program.

The questions are roughly grouped according to topics. Try to stay on the topic but don't be so rigid as to lose the opportunity to further explore or clarify a youth comment.

\section{Introduction:}

Hi____student's name]__. Thank you for agreeing to talk with me (us).

We are helping Cal Poly improve the Pink and Dude Chefs program.

I will be asking you several questions about the Pink and Dude Chefs program. There are no right or wrong answers. We really just want to know what you think and feel about the program.

Also, everything that you say is confidential. That means that I will not share what you say with the program staff so that they know who said what. We will give a summary of what all of the students say about the program.

Is it ok if I audio record our session? I do not want to miss anything you say. I will also take some notes to help me remember. 
I would like to begin by asking you a few general questions about the Pink and Dude Chefs Program.

1. What do you think of the Pink and Dude Chefs program?

2. What made you decide to participate?

3. Was there anything about the program that surprised you?

4. Did you look forward to coming each session?

5. Was it "cool" to be in the program?

6. Why do you think learning to cook or prepare food is important?

I am curious if you have talked to others about the Pink and Dude Chefs program...

6. Did you talk to your parents about Pink and Dude Chefs or what you learned?

a. if YES: What did you talk about?

b. If $N O$ : Why not?

7. Did you talk with your friends about Pink and Dude Chefs or what you learned?

a. If YES: What did you talk about?

i. Did your friends think that the program was cool?

ii. Do they think it is cool to learn to cook?

b. If $N O$ : Why not?

Now I am going to ask you a few questions about what you might have learned or what you might do differently because of the Pink and Dude Chefs program.

8. What has been the best thing about being in the Pink and Dude Chefs program?

a. Why? b. What else was great about being in the program?

9. Have you learned new things about healthy eating?

10. What new thing that you have learned has made you think the most? (For example, what has been the most interesting or surprising new thing you have learned?)

11. Because of this information, have you changed your eating habits?

If YES: Can you give me an example of how? 
12. Have you learned new cooking skills from the program?

a. If $N O$ : Why not?

b. If $Y E S$ :

i. Can you give me a few examples of something new that you learned to do in the kitchen?

ii. What is one thing that you feel really good or confident about doing?

iii. Are there any other cooking skills that you are good at?

iv. Is there anything you'd like to practice more?

13. Since the program started, are you helping more at home to prepare meals and snacks?

a. If $Y E S$ :

i. How often did you help in the kitchen before Pink and Dude Chefs?

ii. Can you give me a few examples of how you have been helping in the kitchen more recently?

iii. Why do you think you have been more involved in cooking at home?

b. If $N O$ :

i. Why do you think you have not been helping more at home to prepare means and snacks?

ii. How often do you help in the kitchen?

14. Since the program started, have your eating habits changed? That is, have you tried to change the foods that you eat?

a. If $Y E S$ :

i. Can you give me a few examples?

15. Have you tried to eat more fruits since the program started?

16. Have you tried to eat more vegetables since the program started?

17. Have you tried to eat or drink less of certain food or beverages?

a. If YES: Can you give me a few examples? 
18. Is it sometimes harder to choose healthier foods or beverages?

a. If $Y E S$ :

i. When do you think it is sometimes harder?

ii. Why do you think it is sometimes harder?

I have just a few more questions for you.

19. What can the PDC staff do to make the program better?

20. Are you interested in participating again, if there was another class offered at ?

21. Is there anything else you'd like to say about the program?

Thank you for your time and for talking with me (us) about the Pink and Dude Chefs Program! 


\section{Appendix F: Parent Interview}

Notes for Interviewers:

- Ensure written informed consent is obtained before the interview.

- The interview is designed to ask very broad questions that allow a wide range of responses from the participant. These questions should be asked as close to verbatim as possible.

- More specific probes help to illicit additional information and to clarify initial responses. These are more flexible and should align and flow with the conversation.

Your language should be adjusted as appropriate.

- Know who you are talking with before the interview. "Son/daughter" should be replaced with the appropriate term (e.g., grandson) as appropriate depending on the relationship between caregiver and youth.

- Interviews are intended to be conducted in the last week of the program but before the Family Fiesta. The verb sense should be adjusted if interviews are conducted after the end of the program.

The questions are roughly grouped according to topics. Try to stay on the topic but don't be so rigid as to lose the opportunity to further explore or clarify a parent comment.

\section{Introduction}

$\mathrm{Hi}$, is it ok that I (we) ask you some questions about the Pink and Dude Chefs program before we get started on the awards ceremony?

My name is I am from Cal Poly. We are helping Cal Poly improve the Pink and Dude Chefs program. Our conversation will take about 5-10 minutes.

- I will be asking you several questions about the Pink and Dude Chefs program.

$\circ$ Everything that you say is confidential. That means that I will not share what you personally say with the program staff. We will give a summary of what parents and caregivers say about the program.

- Also, do you mind if I record our conversation? I don't want to miss anything you say. I will also take some notes to help me remember. 


\section{I would like to begin by asking you what you think about the Pink and Dude Chefs Program ...}

1. What do you think of the program?

2. Was there anything about the program that surprised you?

3. Has your son/daughter talked with you about the program?
a.) How often?
b.) What kind of things has he/she said?

4. Did you encourage your son/daughter to participate?
a.) If $Y E S$ : Why?
b.) If $N O$ : Why not?

5. Has your son/daughter benefited from being in the PDC program?

If $Y E S$ :

a. How do you feel s/he has benefited from the PDC program?

b. In what ways? [Ask for examples if appropriate]

c. Why is that [a specific outcome] important?

6. Do you think your son/daughter has learned new things about healthy eating?

a. What do you think s/he has learned?

7. Has your son/daughter been more involved in food preparation or cooking at home?

a. If $Y E S$ :

i. In what ways? Can you give me a few examples? [listen for involvement AND specific skills and clarify as needed]

ii. Are there ways in which he/she wants to be involved that make cooking or preparing a meal more difficult (e.g. time-consuming)?

b. If $N O$, i. Why not?

8. Have you noticed any differences in your son's/daughter's eating habits since beginning the program?

a. If $Y E S$ :

i. In what ways?

ii. Can you give me a few examples? 
9. Do you wish that your son/daughter would eat healthier foods?

a. In what ways? Can you give me some examples of how you son/daughter could eat better?

b. What tends to get in the way of him/her eating better?

10. Did you learn anything new about food or cooking from your son/daughter after a PDC session?

a. If YES: Can you give me an example?

\section{Wrap-Up}

I have just a few more questions for you.

11. What suggestions do you have for making the Pink and Dude Chefs program better?

12. Is there anything else you'd like to share about your son's/daughter's participation in the program?

Thank you for your time and for talking with me (us) about the Pink and Dude Chefs Program. 


\title{
Appendix G: Informed Assent Form for Youth Participants
}

\author{
Informed Assent Form for Cal Poly Research \\ INFORMED ASSENT TO PARTICIPATE IN: \\ Pink and Dude Chefs, a program of Cal Poly
}

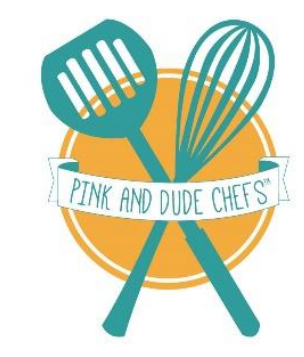

For the Participant

Pink and Dude Chefs is a research project that was created by professors and students at Cal Poly, San Luis Obispo. The people who are currently running the project are Dr. Aydin Nazmi in the Food Science and Nutrition Department, and Jacqueline Chen and Alyssa Vaziri, graduate students in the Food Science and Nutrition Department at Cal Poly, San Luis Obispo, California. The goal of Pink and Dude Chefs is to use cooking classes to make you more confident in your ability to cook meals at home. We hope to do this by teaching you the skills to prepare food, showing you how to buy food, and allowing you to create a menu.

Pink and Dude Chefs has a total of 12 educational cooking classes: _ classes per week on__. These classes will include a short talk regarding the daily topic; group activities and games; and cooking the recipe of the day. The classes are held at . Cal Poly STRIDE will not be able to provide you with rides to or from

As part of Pink and Dude Chefs, we will be asking you to take a survey at the beginning and end of the 12-week program. The questions in the survey will ask you about what you usually eat, how you feel about cooking, how you rate your cooking skills, and basic nutrition questions.

There will also be a post evaluation interview with each student following the end of the 12-week program. During this interview group, Jacqueline Chen and Alyssa Vaziri, the STRIDE Health Ambassador Coordinators, will lead the interview and ask you questions about your attitudes towards cooking, diet, and food preferences.

You are not required to take the survey or go to the interview and you can stop coming to the Pink and Dude Chefs classes at any time. You can also skip any questions you prefer not to answer.

There will always be adults present to prevent injuries during cooking and activities. You'll be required to wear closed-toed shoes with traction (slip-resistant shoes) for your protection. You will be taught safety rules for extinguishing a fire (a fire extinguisher is located in the kitchen), proper knife use and storage, consistent use of potholders to reduce the risk of burns, food safety and the proper handling of food to prevent food-borne illnesses.

There is a chance you may be injured as a result of participating in this program. The possible risks may include: burns from stovetop, oven, scalding water, cuts from knives, falls from spillage, choking from food consumption, or psychological stress from completing survey questions. If you get hurt while participating in Pink and 
Dude Chefs activities, notify an adult in the room immediately. Your parents have been told how to get medical attention if you require it. If you're uncomfortable with any of the questions or activities, please contact the Program Coordinators for Pink and Dude Chefs: Jacqueline Chen at (760) 519-7998 or Alyssa Vaziri at (619) 818-7215 for assistance.

The surveys that you take are all confidential. This means that we will write a code number on your survey instead of your name. Any information about you will be kept in a filing cabinet in a locked room. We will use a code number on any data sheets or other paperwork instead of your name. Only project coordinators will have access to any information about you. Your answers will remain private and only presented as anonymous or group results.

There are benefits that you might gain from participating in this program. These include: increased knowledge of nutrition and web-based cooking resources, building skills for healthful cooking, communication, time management and goal setting, and increased confidence for cooking family meals. You will be able to bring food home weekly. Other incentives you might receive include cooking tools and supplies, which are given for attendance and participation in activities and games.

We would like to take photographs and video of you as you participate in the program and use these images in presentations and publicity. Please indicate below if you don't want us to take photographs or video of you. You will not be identified by name.

No, I do not give permission for my photo and video to be taken for presentations and media use.

If you want to participate in this research project as described, please indicate this by signing below. Please keep one copy of this form for your parent/guardian.

\section{Thank you for your participation in this study!}

(PRINT) Name of Child Volunteer
(SIGNATURE) Date 


\title{
Appendix H: Informed Consent Form for Parents/Guardians (English)
}

\author{
Informed Consent Form for Cal Poly Research \\ Parental/Guardian Permission Form \\ INFORMED PERMISSION TO PARTICIPATE IN: \\ Pink and Dude Chefs, a program of Cal Poly
}

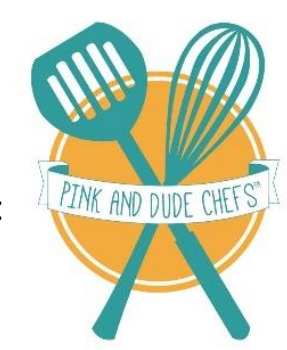

A research project using cooking classes to increase confidence for cooking meals prepared at home is being conducted by Dr. Aydin Nazmi in the Food Science and Nutrition Department, and Jacqueline Chen and Alyssa Vaziri, graduate students in the Food Science and Nutrition Department at Cal Poly, San Luis Obispo, California. The purpose of this study is to improve your child's confidence for cooking and to teach your child menu planning, food buying and food preparation skills.

Your child is being asked to take part in this study by attending a total of 12 educational cooking classes: _ 2-hour class per week held on These classes will include a short talk regarding the daily topic; group activities and games; and cooking the recipe of the day. The program will take place at

transportation to or from . No be provided by our program.

Your child will be asked to complete a survey before and a survey after the 12week program. These questions ask about your child's current diet, attitudes towards cooking, cooking skills, and general nutrition knowledge.

There will also be a post evaluation interview with each student following the end of the 12-week program. During this interview group, Jacqueline Chen and Alyssa Vaziri, the STRIDE Health Ambassador Coordinators, will lead the interview about their attitudes towards cooking, diet, and food preferences. In addition, there will be a parent component where the program coordinator will interview you about your perspective on the class and thoughts about how it influenced your child's food choices. You may choose to not attend this interview.

Please be aware that your child is not required to participate in this research and your child may discontinue his/her participation at any time. Your child may also omit any questions he/she prefers not to answer.

During food preparation, your child will be directly supervised to reduce the risk of injury. Your child will be required to wear closed-toed shoes with traction (slip-resistant shoes) for their protection. Your child will be taught safety rules for extinguishing a fire (a fire extinguisher is located in the kitchen), proper knife use and storage, consistent use of potholders to reduce the risk of burns, food safety and the proper handling of food to prevent food-borne illnesses. 
The possible risks associated with participation in this study are minor but may include burns from stovetop, oven, scalding water, cuts from knives, falls from spillage, choking from food consumption, or psychological stress from completing survey questions. If your child should experience any injuries due to possible cuts or burns, please be aware that you may contact your own physician/clinic or your nearest fire department. Insurance coverage is not offered for this program, should your child experience any injuries due to participation in the classes. If you should experience any discomfort with any part of the study, please be aware that you may contact the Program Coordinators for Pink and Dude Chefs: Jacqueline Chen at (760) 519-7998 or Alyssa Vaziri at (619) 818-7215 for assistance.

To protect your child's privacy all identifying information will be kept in a filing cabinet in a locked room. Participants will only be identified by code number on data sheets or other paperwork. Only project coordinators will have access to the information. Your child's responses will remain private and only presented as anonymous or group data.

Potential benefits associated with this program include: increased knowledge of nutrition and web-based cooking resources, building skills for healthful cooking, communication, time management and goal setting, and increased confidence for cooking family meals. All participants will bring food home weekly. Other incentives your child may receive include cooking tools and supplies, which are given for attendance and participation in activities and games.

We would like to take photographs and video of the children as they participate in the program and use these images in presentations and publicity. Please indicate below if you do not authorize this. Your child will not be identified by name.

\section{No, I do not give permission for my child's photo and video to be taken for} presentations and media use.

If you have questions regarding this study or would like to be informed of the results when the study is completed, please feel free to contact Dr. Aydin Nazmi (805) 756-6447 and/or the STRIDE office (805) 756-0673, STRIDE@ calpoly.edu. If you have concerns regarding the manner in which the study is conducted, you may contact Dr. Michael Black, Chair of the Cal Poly Human Subjects Committee, (805) 756-2894, mblack@ calpoly.edu or Dr. Dean Wendt, Dean of Research at (805) 756-2988 or dwendt@calpoly.edu. 
If you agree that your child may participate in this research project as described, please indicate your agreement by signing below. Please keep one copy of this form for your reference, and thank you for your participation in this study.

(PRINT) Name of Child Volunteer $\quad$ Date

(PRINT) Name of Parent or Guardian $\quad$ (SIGNATURE) Date

(PRINT) Email of Parent or Guardian Phone \#

(PRINT) Name of Emergency Contact Person (if different than Phone \# Parent/Guardian)

(PRINT) Relationship of Emergency Contact Person 


\title{
Appendix I: Informed Consent For Parents/Guardians (Spanish)
}

\author{
Consentimiento Informado para el estudio del equipo Cal Poly

\section{CONSENTIMIENTO INFORMADO PARA PARTICIPAR EN:}

Pink and Dude Chefs, un programa del equipo Cal Poly

Un proyecto de investigación con clases de cocina para aumentar la confianza para cocinar y preparar comida en el hogar se lleva a cabo por el Dr. Aydín Nazmi en el Departamento de Ciencia de los Alimentos y Nutrición, y Jacqueline Chen y Alyssa Vaziri, estudiantes de postgrado en la Ciencia de los Alimentos y Nutrición en Cal Poly, San Luis Obispo, California. El propósito de este estudio es mejorar la confianza de su hijo/a para cocinar y para enseñarle a su hijo/a la planificación del menú, la compra de alimentos y las habilidades de preparación de alimentos.

A su hijo/a se le invita a participar en este estudio, asistiendo a un total de 12 clases de educación para cocinar: clases de 2 horas por semana . Estas clases incluyen una breve plática sobre el tema del día, actividades de grupo y juegos, y cocinar la receta del día. El programa se llevará a cabo en

Nuestro programa no

ofrece transporte hacia o desde

Se le pide a su hijo/a que complete una encuesta sobre el programa antes de empezar el programa y después de las 12 semanas del programa. Estas preguntas son acerca de la dieta actual de su hijo, las actitudes hacia la cocina, habilidades en la cocina, y conocimiento general sobre la nutrición.

También habrá una entrevista después del final del programa de 12 semanas. En este entrevista de grupo, Jacqueline Chen y Alyssa Vaziri, las Coordinadoras de Embajadores Salud de STRIDE, dirigirá una discusión con los niños sobre sus actitudes hacia la cocina, la dieta y el ejercicio. Además habrá un componente en qual la Coordinadora de Embajadores Salud entrevistará usted sobre sus perspectivos del programa y sus pensamientos sobre como el mismo influenció la dieta de su hijo/a. Usted poderia decidir no hacer esta entrevista.

Tome en cuenta que a su hijo/a no se le obliga a participar en este estudio y que su hijo/a puede dejar de participar en cualquier momento. Su hijo/a también puede omitir preguntas que él/ella prefiere no contestar.

Durante la preparación de comida, su hijo/a estará bajo supervisión directa para reducir el riesgo de lesiones. Su hijo/a tendrá que usar zapatos cerrados con tracción (zapatos antideslizantes) para su protección. A su hijo/a se le enseñaran las reglas de seguridad para extinguir un incendio (un extintor de incendios se encuentra en la cocina), para usar y guardar el cuchillo, el uso consistente de las agarraderas para reducir el riesgo de quemaduras, la seguridad alimentaria y el manejo adecuado de los alimentos para evitar enfermedades transmitidas por los alimentos.

Los posibles riesgos asociados a la participación en este estudio son menores, pero pueden incluir quemaduras de estufa, horno, o agua hirviente, cortes de cuchillos, caídas 
de derrames, asfixia por el consumo de alimentos o el estrés psicológico de contestar las preguntas de la encuesta. Si su hijo/a presenta alguna lesión debido a los posibles recortes o quemaduras, por favor, sepa que puede comunicarse con su propio médico / clínica o al departamento de bomberos más cercana. La cobertura de aseguranza no se ofrece para este programa si su hijo/a presenta alguna lesión debido a la participación en las clases. Si se siente incómodo con cualquier parte del estudio, por favor, sepa que puede ponerse en contacto con las coordinadoras del programa Pink and Dude Chefs: Jacqueline Chen (760) 519-7998 o Alyssa Vaziri (619) 818-7215 para ayuda.

Para proteger la privacidad de su hijo/a, todos los datos de identificación se mantendrán en un armario en una habitación cerrada. Los participantes sólo serán identificados por número de código en las hojas de datos u otros documentos. Sólo los coordinadores del proyecto tendrán acceso a la información. Las respuestas de su hijo se mantendrán en privado y sólo se presentarán como datos anónimos o de grupo.

Los beneficios potenciales asociados con este programa son: un mayor conocimiento de la nutrición y recursos basados en Internet para cocinar, el desarrollo de habilidades para la cocina saludable, la comunicación, el manejo del tiempo y el establecimiento de metas, y una mayor confianza para cocinar las comidas en familia. Todos los participantes llevarán comida a casa cada semana. Otros incentivos que su hijo/a puede recibir incluyen utensilios de cocina y suministros que se dan por la asistencia y la participación en las actividades y los juegos.

Nos gustaría sacar fotografías y video de los niños mientras que participen en el programa y estas imágenes serán usadas en presentaciones y publicidad. Por favor, indique a continuación si usted no autoriza esto. Su hijo/a no será identificado por su nombre.

No, no doy permiso para que saquen foto o video de mi hijola para uso en presentaciones $u$ otros medios de comunicación

Si usted tiene preguntas sobre este estudio o si desea ser informado de los resultados cuando se complete el estudio, no dude en ponerse en contacto con el Dr. Aydin Nazmi al (805) 756-2660, y/o la oficina de STRIDE (805)756-0673, STRIDE@ calpoly.edu. Si usted tiene preocupaciones con respecto a la forma en que se lleva a cabo el estudio, puede comunicarse con el Dr. Michael Black, Chair of the Cal Poly Human Subjects Committee, (805) 756-2894, mblack@ calpoly.edu y/o Dr. Dean Wendt, Decano de la Investigación al (805) 756-2988, dwendt@ calpoly.edu. 
Si está de acuerdo que su hijo/a puede participar en este proyecto de estudio tal como se describe, por favor, indique su acuerdo firmando a continuación. Por favor, mantenga una copia de este formulario para su referencia, y gracias por su participación en este estudio.
Nombre del niño voluntario
Fecha

Nombre del padre/madre o tutor/a

(FIRMA)

Fecha
Email del padre/madre o tutor/a
Número de teléfono

$\begin{array}{ll}\text { Nombre de la Persona de Contacto de Emergencia } & \begin{array}{l}\text { Número de } \\ \text { teléfono }\end{array}\end{array}$

Relación de la persona de contacto de emergencia

Nombre del Investigador/a

(FIRMA)

Fecha 
